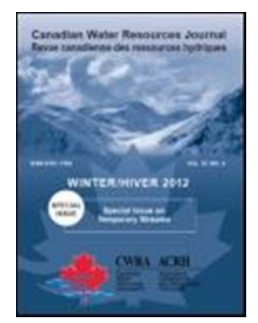

\title{
EQUIFINALITY AND AUTOMATIC CALIBRATION, WHAT IS THE IMPACT OF HYPOTHESIZING AN OPTIMAL PARAMETER SET ON MODELLED HYDROLOGICAL PROCESSES?
}

\begin{tabular}{|r|l|}
\hline Journal: & Canadian Water Resources Journal \\
\hline Manuscript ID & TCWR-2017-0065.R1 \\
\hline Manuscript Type: & Original Paper \\
\hline Date Submitted by the Author: & n/a \\
\hline Complete List of Authors: & $\begin{array}{l}\text { Foulon, Etienne; Institut national de la recherche scientifique, Eau Terre } \\
\text { Environnement } \\
\text { Rousseau, Alain; INRS, ETE }\end{array}$ \\
\hline Keywords: & $\begin{array}{l}\text { calibration, equifinality, HYDROTEL, objective function, parameter } \\
\text { uncertainty }\end{array}$ \\
\hline
\end{tabular}

SCHOLARONE"

Manuscripts 


\title{
EQUIFINALITY AND AUTOMATIC CALIBRATION, WHAT IS THE IMPACT OF
} HYPOTHESIZING AN OPTIMAL PARAMETER SET ON MODELLED HYDROLOGICAL PROCESSES?

\author{
Étienne Foulon ${ }^{1 *}$, Alain N. Rousseau ${ }^{1}$ \\ 1 INRS-ETE/Institut National de la Recherche Scientifique-Eau Terre Environnement, 490 \\ rue de la Couronne, Québec City, G1K 9A9, Québec, Canada \\ *Corresponding author: etiennefoulon59@gmail.com, 418-271-2687
}

Keywords :calibration, equifinality, hydrological model, HYDROTEL, objective function, parameter uncertainty 


\section{Abstract}

2 Accepting the concept of equifinality may result in larger uncertainty associated with model

3

4

predictions than that of the optimal parameter set paradigm. DepiteDespite the existence of uncertainty earacterisationcharacterization methods, the semi-_distributed hydrological model HYDROTEL has been used within the latter paradigm. What is the impact of hypothetizinghypothesizing an optimal parameter set? This paper focuses on the assesment of the impact of equifinality of calibration parameters with respect to modelled hydrological variables and indices, namely: (i) daily flows $\bar{j}_{2}$ (ii) seasonal seven- and thirty-day low flows ${ }_{;}$; and maximum flow $\bar{j}_{2}$ (iii) snow water equivalent (SWE), ; (iv) shallow ground water variations; and (v) actual evapotranspiration. This assessment is presented for ten southern Québec watersheds of the St. Lawrence River. The watershed models arewere calibrated and validated for 1982-1991 and 1991-2002, respectively. Automatic calibration iswas performed using the Dynamically Dimensioned Search (DDS) algorithm based on the maximization of two objective functions (OFs): (i) the Kling-Gupta efficiency; and (ii) the Nash-log. DDS was executed to calibrate 12 hydrological parameters for one optimization trial for each watershed and each OF with a budget of 5000 model runs. To analyse the parameter uncertainty and resulting equifinality, 250 sets of parameters were extracted from each trial run. Calibration performances for both OFs were between 0.75 and 0.95 , while the selected 250 best sets of parameters had OF values differing by less than $1 \%$. Results showshowed that the overall OF uncertainty was more importantlarger than the parameter uncertainty for all modelled processes except the SWE. Nevertheless, seasonal results suggestsuggested that parameter uncertainty eancould be greater than OF uncertainty for specific seasons or years, although it was not possible to make a general outcome stand out. In particular for impact studies where 
the variables of interest are not daily flows but rather hydrological indices or variables, parameter uncertainty will need to be accounted for.

\section{Résumé}

Accepter l'existence du concept d'équifinalité c'est reconnaître l'incertitude liée à l'existence d'une famille de solutions donnant des résultats de qualité similaire obtenus avec la même fonction objectif. Malgré l'existence de méthodes de caractérisations de cette incertitude, le modèle hydrologique HYDROTEL a été principalement utilisé jusqu'à maintenant selon le paradigme du calage optimal unique sans évaluer a posteriori les conséquences de ce choix. Cette étude propose d'évaluer l'impact du choix du jeu de paramètres optimisés sur certaines variables et indicateurs hydrologiques simulés, à savoir: (i) les débits journaliers; (ii) les débits d'étiage à 7 et 30 jours et les débits maximum; (iii) l'équivalent en eau de la neige (EEN), (iv) les variations du contenu en eau du sol peu profond; et (v) l'évapotranspiration réelle. Dans ce contexte, HYDROTEL est mis en place sur dix bassins versant du Québec méridional entre 1982 et 2002. Pour chacune des fonctions objectif (FO) (Kling Gupta efficiency et Nash-log) et chacun des bassins, l'algorithme Dynamically Dimensioned Search (DDS) dispose d'un budget de 5000 répétitions pour optimiser les 12 paramètres de calage d'HYDROTEL sur 1981-1991. Ainsi, 250 jeux de paramètres sont conservés pour évaluer

l'incertitude paramétrique et l'équifinalité résultante. Les résultats de calage indiquent des fonctions objectif comprises entre 0,75 et 0,95 , tandis que pour chaque modèle les 250 meilleures répétitions présentent des fonctions objectif égales à $1 \%$ près. Globalement, pour tous les processus simulés excepté pour l'EEN, l'incertitude relative aux FO était plus importante que celle relative aux jeux de paramètres. Cependant, les résultats saisonniers suggèrent que l'incertitude paramétrique peut dépasser celle due aux FO dans certaines conditions particulières. Elle devra donc être prise en compte, en particulier pour les études 
48 d'impacts et de risque hydrologique dont les variables d'intérêt sont principalement des indicateurs hydrologiques simulés et non pas les débits journaliers. 


\section{Introduction}

The equifinality concept refers to the existence of many parameter sets (and multiple model structures) associated with the same 'optimal' measure of efficiency (Beven 2006a; Beven and Freer 2001). Within a realistic parameter space, for a given mechanistic model of a complex environmental system, many local optima may exist. Despite the computational costs, equifinality has been revealed for many types of models and especially for rainfallrunoff models (Beven 1993; Beven and Binley 1992; Duan et al. 1992; Fu et al. 2015; Futter et al. 2015; Li et al. 2012; Linhoss et al. 2013; Prada et al. 2016; Romanowicz et al. 1994; Zeng et al. 2016; Zhang et al. 2012).

The main consequence of accepting the concept of equifinality is that the uncertainty associated with model predictions might be larger than that assessed within the optimal parameter set paradigm. Different types of approaches allow to deal with such an uncertainty (Vrugt et al. 2009a). Some approaches have their roots within a formal statistical (Bayesian) framework, but require in-depth understanding of mathematics and statistcs as well as experience in implementing (Fisher and Beven 1996; Freer et al. 1996) these methods on computers (Vrugt et al. 2009b). This probably explains the success of the generalized likelihood uncertainty estimation (GLUE) method of (Beven and Binley 1992). It operates within the context of Monte Carlo analysis coupled with Bayesian or fuzzy estimation and propagation of uncertainty. It is relativley easy to implement and requires no modifications to existing codes of simulation models. More recently, Tolson and Shoemaker (2007) presented how the dynamically dimensioned search (DDS) optimization algorithm coud replace random sampling in typical applications of GLUE. They also introduced a more efficent uncertainty analysis methodology called DDS-approximation of uncertainty (DDS-AU) that differs from the automatic calibration and uncertainty assessment using response surfaces (ACUARS) 
methods (Mugunthan and Shoemaker 2006). The former approach requires many optimisation trials while the latter approach uses only one trial coupled with a declustering technique.

The idea of an optimal parameter set remains strong in environmental sciences and even stronger in hydrological modelling. For a physcically-based, semi-distributed, model such as HYDROTEL (Bouda et al. 2014; Bouda et al. 2012; Fortin et al. 2001b; Turcotte et al. 2007a; Turcotte et al. 2003), this frame of mind is rooted in two perceptions: (i) multiple feasible descriptions of reality lead to ambiguity and are possibly viewed as a failure of the modelling exercice (Beven 2006a); and (ii) a manual search for an "optimum" is already computationally expensive (Turcotte et al. 2003) while an automatic search may provide only a slight increase in model efficiency in comparison with the latter manual calibration (Bouda et al. 2014). This is why in the last decade, at the risk of avoiding important issues of model acceptability and uncertainty (Beven 2006a), HYDROTEL has almost always been applied within the optimal parameter set paradigm.

For example, in several studies (Aissia et al. 2012; Fortin et al. 2001a; Fossey and Rousseau 2016a, 2016b; Fossey et al. 2015; Fossey et al. 2016; Khalili et al. 2011; Minville et al. 2009; Oreiller et al.; Quilbé et al. 2008; Rousseau et al. 2013), HYDROTEL has been manually calibrated following the four-step, trial-and-error, process-oriented, multiple-objective calibration strategy introduced by Turcotte et al. (2003). It has also been calibrated using the shuffled complex evolution algorithm (SCE-UA) designed by Duan et al. (1993) to find the optimal set of parameters while avoiding local optima (Bouda et al. 2014; Gaborit et al. 2015; Ludwig et al. 2009; Ricard et al. 2013; Trudel et al. 2016). But two exceptions emerge from the litterature, Bouda et al. (2012); Poulin et al. (2011) both used the SCE-UA algorithm to generate multiple parameter sets and assesed the uncertainty of hydrological modelling under the equifinality assumption. Poulin et al. (2011), based on one snow-dominated watershed, concluded that model uncertainty (conceptual models versus more physicaly-based models for 
example) can be more significant than parameter uncertainty. Meanwhile, Bouda et al. (2012), from their work on two watersheds, stressed the need for further research that may lead to the implementation of a systematic uncertainty analysis in an operational hydrological forecasting system. Nevertheless, they both highlighted the need for additonal validation of their results on additional watersheds.

It is important to mention that the technico-philosiphical debate started in 2006 (Beven 2006b, 2008) about the methods that should or should not be used to estimate the uncertainties associated with hydrological forecasting is beyond the scope of this paper. Indeed, the debate is still ongoing about the relative performances of formal (DREAM) and informal (GLUE) Bayesian approaches in estimating the consequences of equifinality (Beven 2009; Vrugt et al. 2009b, 2009c) and about the multiple sources of uncertainty and non-stationarity in the analysis and modelling of hydrological systems (Beven 2016; Nearing et al. 2016). In this paper, equifinality is simply explored through the implementation of the automatic calibration algorithm DDS(Dynamically Dimensioned Seareh) (Tolson and Shoemaker 2007), which has been reported as being superior to SCE-UA (Arsenault et al. 2014; Yen et al. 2016)._Our contribution builds on the work carried out on hydrological uncertainty to show in practical terms why equifinality does need to be taken into account by answering one simple question taken out of the technico-philosiphical debate: what are the consequences of not accounting for equifinality while calibrating HYDROTEL for an environmental impact study? Here, hydrological uncertainty (defined by the spread resulting from multiple calibrations) is assessed for five modelled hydrological variables and indices: (i) daily flows, (ii) seasonal hydrological indices such as the seven-day low flow (7d-Qmin), 30-day low flow (30dQmin), and the maximum flow (Qmax), (iii) snow water equivalent (SWE), (iv) shallow ground water content variations (GWC) and (v) actual evapotranspiration (AET). Innovation resides in three elements. A calibration strategy close to that of manual calibration was used 
in order to demonstrate the need to account for equifinality in impact assessment studies aside from the technico-philosophical debate started in 2006. Moreover, using 10 watersheds across Québec avoided limiting the significance of the results to a specific region. Last, the relative importance of OF uncertainty and parameter uncertainty were differentiated according to the variable being considered and its temporal scale (yearly or seasonal).

The next two sections of this paper introduce the modelled watersheds and the methods ${ }_{2} ;$ the third section introduces the results and ensuing discussions. Throughout the paper, the reader $\underline{s}$ should keep in mind that the results do not aim at assessing the formal statistical uncertainty associated with the hydrological processes, but rather at showing the concrete consequences of equifinality on modelled hydrological processes 


\section{Study area and data}

This study was carried out in southern Québec (Canada) on ten watersheds spread out in five hydrographic regions of the St. Lawrence River (Figure 1Figure 1). These ten watersheds, namely (i) Batiscan, (ii) Bécancour, (iii) Chamouchouane, (iv) Châteauguay, (v) Chaudière, (vi) Du Loup, (vii) Gatineau, (viii) Mistassini, (ix) Rouge, and (x) Yamaska have modelled drainage areas ranging from 855 up to $15,042 \mathrm{~km}^{2}$ and various land cover patterns. Table 1 shows-indicates that all the-watersheds, but Yamaska, have a forested (evergreen + deciduous trees) area that representscovering more than $90 \%$ of the modelled land cover. Yamaska is the only watershed with a significant portion of urban area. Batiscan has over $40 \%$ of evergreen while Gatineau, Chaudière, Rouge and Du Loup have 17, 21.5, 25.6 and 28.4\% of evergreen, respectively, and the remaining five watersheds have an evergreen area representing less than $10 \%$ of their total land cover. It is also noteworthy that Châteauguay, Bécancour and Chaudière have 17.0, 8.2 and $3.9 \%$ of cropland while the remaining seven watersheds have less than $1 \%$.

According to available meteorological data (1981-2002, 1995 and 1996 being unavailable) from National Resources Canada, the region surrounding the St. Lawrence River delineated in Figure 1Figure $1(78: 70 ; 45: 52)$ is characterized by a mean annual temperature of $1.8^{\circ} \mathrm{C}$ and mean annual total precipitation of $940 \mathrm{~mm}$. All watersheds are snow-dominated with peak flow occurring in spring. A summary of the hydroclimatic characteristics of the watersheds is provided in Table 2Table 2 and Table 3 Table 3 for two hydrological seasons, that is summer (June, 1 st to November, $30^{\text {th }}$ ) and winter (December, $1^{\text {st }}$ to May, $31^{\text {st }}$ ). While the mean summer rainfall is $545 \mathrm{~mm}$ and quite homogenous among the watersheds (standard deviation of $30 \mathrm{~mm}$ ), mean winter rainfall is more heterogeneous with a mean of $208 \mathrm{~mm}$ and a standard deviation of $64 \mathrm{~mm}$. Meanwhile, mean snowfall is $271 \mathrm{~mm}$ with a standard deviation of $52 \mathrm{~mm}$. Mean summer $\left(10.8^{\circ} \mathrm{C}\right)$ and winter $\left(-4.8^{\circ} \mathrm{C}\right)$ temperatures are also quite variable 
with respective standard deviations of 1.8 and $2.8^{\circ} \mathrm{C}$. This shows that in terms of climate characteristics, the studied watersheds are quite heterogeneous. In terms of hydrological characteristics, mean summer and winter daily flows are 1.2 and $1.9 \mathrm{~mm}$, respectively, with standard deviations of 0.44 and 0.23 . Winter flows are higher than summer flows on average because winter includes the snow melt and thus the spring peak flows. Higher variability in the summer flows is attributed to summer rainfall and convective storms that are more variable than snowfalls. The hydrological indices mean values indicate that the watersheds, despite being somewhat located along the St. Lawrence River, have heterogeneous characteristics with mean 7d-Qmin ranging from 2 up to $156 \mathrm{~m}^{3} \mathrm{~s}^{-1}$ and from 4 to $120 \mathrm{~m}^{3} \mathrm{~s}^{-1}$ for summer and winter, respectively. Heterogeneity is even higher for mean Qmax; that rangeranging from 29 up to $595 \mathrm{~m}^{3} \mathrm{~s}^{-1}$ and from 84 to $1350 \mathrm{~m}^{3} \mathrm{~s}^{-1}$ for summer and winter, respectively.

\section{$<$ Table 1: Land cover of the ten studied watersheds in southern Québec, CanadaTabłe 1: Land cover of the ten-studied-watersheds in-southern-Québec, Canada >}

Figure 1: Location of the study watersheds in Québec, Canada, and around the St.

\section{Lawrence River}

<Table 2: Summary (1982-2002) of the climate characteristics of the study watershedsTable 2: Summary (1982-2002) of the climate characteristics of the study watersheds>

<Table 3: Summary (1982-2002) of the hydrological characteristics of the study Formatted: Font: Bold watershedsTable 3: Summary (1982-2002) of the hydrologicalcharacteristics of the study watersheds> 
182

183

184

185

186

187

\section{Material and Methods}

\section{Hydrological model}

HYDROTEL is a process-based, continuous, semi-distributed hydrological model (Bouda et al. 2014; Bouda et al. 2012; Fortin et al. 2001b; Turcotte et al. 2007a; Turcotte et al. 2003) that is currently used for inflow forecasting by Hydro-Quebec, Quebec's major power utility, and the Quebec Hydrological Expertise Centre (CEHQ) which is in charge of the management and safety of publicly owned dams (Turcotte et al. 2004). It was designed to use available remote sensing and GIS data and use either a 3-hour or a daily time step. It is based on the spatial segmentation of a watershed into relatively homogeneous hydrological units (RHHUs, elementary subwatersheds or hillslopes as desired) and interconnected river segments (RSs) draining the aforementioned units. A semi-automatic, GIS-based framework called PHYSITEL (Noël et al. 2014; Rousseau et al. 2011; Turcotte et al. 2001) allows easy watershed segmentation and parameterization of the hydrological objects (RHHUs and RSs). The model is composed of seven computational modules, which run in successive steps. Each module simulates a specific hydrological-process (meteorological data interpolation, snowpack dynamics, soil temperature and freezing depth, potential evapotranspiration, vertical water budget, overland water routing, channel routing). and the reader $\underline{\text { Readers }}$ is - are referred to Fortin et al. (2001b) and Turcotte et al. (2007a) for more details on these aspects of HYDROTEL.

The main parameters of HYDROTEL can be subdivided into three groups presented in- (see Table 4Table 4). The first group includes the snow parameters and the second group includes the soil parameters. The last three individual parameters are related to the interpolations of temperature and precipitation according to the average of the three nearest meteorological stations weighed in by the square of the inverse distances between the RHHU and the three stations (a.k.a. the Reciprocal-Distance-Squared method). 
<Table 4: HYDROTEL key parametersTable 4: HYDROTEL key parameters>

\section{Data acquisition}

Observed climate data for $1981-2002$ were computed on a $0.75^{\circ} \times 0.75^{\circ}$ grid by isotropic kriging following the method described in Poirier et al. (2012) using the meteorological data provided by National Resources Canada. Each grid-point served as a meteorological station in HYDROTEL. Flow data were extracted from the CEHQ data base; which operates around 230 hydrometric stations $(\mathrm{CEHQ}, 2012)$. Stations were selected for their data availability and proximity to the outlets of the watersheds. For Batiscan (\#050304 [-72.4 $4^{\circ}$ long, 46.6 lat]),

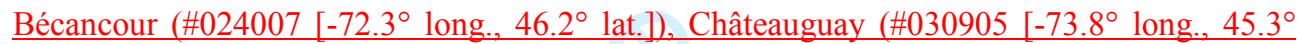
lat.]) and Rouge ( $\# 040204$ [-74. $7^{\circ}$ long., $45.7^{\circ}$ lat.]]), stations were located at the outlet of each watershed while for Chamouchouane (\#061901 $\left[-72.5^{\circ}\right.$ long., $48.7^{\circ}$ lat. $\left.]\right)$, Chaudière (\#023402 [-71.2 ${ }^{\circ}$ long., 46. $6^{\circ}$ lat.]), Du Loup (\#052805 [-73.2 ${ }^{\circ}$ long., $46.6^{\circ}$ lat.]), Gatineau

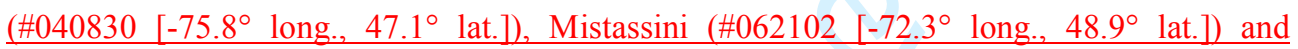
Yamaska (\#030304 $\left[-72.9^{\circ}\right.$ long., $45.5^{\circ}$ lat.]), the nearest stations were selected (see Figure 1Figure 1).

\section{Calibration/validation and parameter sets generation}

The calibration of HYDROTEL forModel calibration on each watershed was carried out using a global optimization algorithm, dynamically dimensioned search (DDS) presented in Tolson and Shoemaker (2007). It allows systematic and impartial calibration of HYDROTEL through all the watersheds using a fixed methodology. The shuffled complex evolution (SCE) algorithm (Duan et al. 1992; Duan et al. 1994; Duan et al. 1993) was also considered; viewed as the dominant optimization algorithm before 2007 with more than 300 different applications referring to the original set of SCE papers. However, it has since been proved that DDS is better suited for distributed watershed models requiring extensive computational time (Arsenault et al. 2014; Tolson and Shoemaker 2007; Yen et al. 2016). Indeed, DDS performs 

a low number of model evaluations before converging to a good calibration solution (Arsenault al. 2014; Tolson and Shoemaker 2007; Yen al. 2016). According to Yen et al. (2016), DDS outperforms other optimization techniques in both convergence speed and searching ability for parameter sets that satisfy statistical guidelines (Moriasi et al. 2007) while requiring only one algorithm parameter (perturbation factor, default value 0.2 ) in the optimization process. This default value was used in this paper.

Automatic calibration was performed based on the maximization of four objective functions (OFs) computed from observed flow data: (i) Kling-Gupta efficiency (KGE); (ii) Nash-log; that is the Nash-Sutcliffe efficiency (NSE) calculated on log transformed flows; (iii) NSE $\mathrm{Q}_{\mathrm{Q}}$ and (iv) $\mathrm{NSE}_{\mathbb{\mathrm { V }}}$ computed on root squared flows. DDS was executed for one optimization trial for each watershed and each OF with a budget of 5000 model runs - the trial was initiated from the same random set of parameter values for every watershed. To analyse the parameter uncertainty and resulting equifinality, the 250 sets of parameters resulting in the best OF values were extracted from each trial run. Then each model was run over a validation period using the corresponding 250 sets of parameters (10 models times 4 OFs). However, this paper solely focused on two of the four OFs studied namely KGE and Nash-log because including the two other OFs-functions would not help distinguishing the dominant type of uncertainty. Indeed, overall results for NSE are close to KGE results except around peak flows_(Gupta et al., 2009) while $\mathrm{NSE}_{\sqrt{\mathrm{QQ}}}$ represents a tradeoff between KGE and Nash-log. Plus, KGE is eurrently the most used OF in hydrological model calibration and $u$ Using the combination of KGE and Nash-log provides a contrasted calibration procedure that in turn favors high flows and low flows. 
simulated and observed standard deviations; and $\beta$ stands for the bias, that is the ratio between the mean simulated and mean observed flows.

$\underline{\text { Nash }-\log }=2 \cdot \alpha_{\log } \cdot r_{\log }-\alpha_{\log }^{2}-\beta_{\log n}^{2}$ $\mathrm{Eq} 2$ where $\alpha_{\log }$ and $r_{\log }$ are the linear correlation coefficient and measure of relative variability between the $\log$ transformed simulated and observed flows, respectively; and $\beta_{\log n}$ stands for the ratio between the bias of $\log$ transformed simulated and observed flows, normalized by the standard deviation of observed values.

The calibration period extended from December $1^{\text {st }}, 1982$ to November $30^{\text {th }}, 1991$; that is nine entire hydrological years. The validation period started on December $1^{\text {st }}, 1991$ and ended on November $30^{\text {th }}, 2002$ (remembering that the 1995-1996 meteorological data series were unavailable); that is eight complete hydrological years (hydrological years 1994 - December $1^{\text {st }}, 1994$ to November $30^{\text {th }}, 1995$, and 1995 -December $1^{\text {st }}, 1995$ to November $30^{\text {th }}, 1996$ were unavailable), corresponding to nine summers and eight winters (January to the end of May 1997 is used as a spin-up to make sure that the model is on the right track). In each case, a 1-year spin-up period was used to minimize initialization errors. During the 1995-1996 meteorological data gap, the model was fed with data from 1993-1994 to prevent the rivers from drying out. These simulation periods (calibration and validation) simply resulted from afollowed the split-sample strategy applied to the available meteorological and hydrological data. The length of the calibration period was not so long as to increase computational costs too much, but not so short as to have issues related to the interannual variability of climate data compared with the validation period. Figure 2 illustrates the appropriateness of this approach in terms of mean annual and seasonal temperatures and precipitations. As seen theFor the calibration and validation, the simulation periods are were relatively similar: precipitations and temperatures are within $\left[614 \dot{;}, 2_{2} 911 \mathrm{~mm}\right]$ and $\left[-1 ; \dot{;}_{2}+6^{\circ} \mathrm{C}\right]$, and $\left[646 ; \dot{;}_{2} 845\right.$ $\mathrm{mm}]$ and $\left[-0.2 \div ; \overline{\bar{y}}_{2} 6.4^{\circ} \mathrm{C}\right]$, for the calibration and validation periods, respectively. 
Out of the eighteen (18) key calibration parameters (Table 4Table 4), twelve (12) were actually adjusted in this study: six (6) snow parameters; five (5) soil parameters; and one (1) interpolation coefficient. Sensitivity analyses were not formally carried out for any of the watersheds beforehand, but these calibrated parameters are amongst the model most sensitive parameters (Turcotte et al. 2003). This selection of parameters was based on: (i) information provided by previous analyses (Ben Nasr 2014; Bouda et al. 2014), (ii) knowledge built through the operational use of HYDROTEL (Turcotte et al. 2004) and (iii) experience gained during the development of a hydroclimatic Hydroclimatic Atlas conveying the potential impact of climate change on water resources for the 2050 horizon over Southern Québec

291 (CEHQ 2013, 2015). The remaining parameters were fixed according to: (i) a regionalization study (Turcotte et al. 2007b), (ii) results from the application of a global calibration strategy (Ricard et al. 2013) used in CEHQ (2013, 2015), and (iii) from previous manual calibration exercises.

Figure 2: Relationship between mean annual and seasonal temperatures and 


\section{Results}

As previously mentioned model uncertainty related to parameters used for the calibration of HYDROTEL and to the choice of the OF was assessed through five modelled hydrological variables and indices: (i) modelled streamflows, (ii) hydrological indices computed from the latter, and three internal variables, namely (iii) snow water equivalent (SWE), (iv) actual evapotranspiration (AET) and (v) shallow ground water content variations (GWC). In this paper, parameter equifinality refers to the range that each calibration parameter covers within the predefined physical limits attributed to each parameter. Meanwhile parameter uncertainty refers to the consequences of parameter equifinality with respect to the model outputs. Finally, OF uncertainty refers to the effects of using two different functions on the model outputs. For each subsection, a different watershed is used as a showcase while the other nine and their related figures are referred to as alternate watersheds and available as supplemental information upon request to the corresponding author. This choice was made to focus on the global picture recounted-conveyed by this paper instead of focusing on the characteristics of a single watershed.

\section{Parameter equifinality}

Figure 3 shows the range covered by the 250 sets of parameters used in setting up the 20 models in HYDROTEL. The figure was computed by putting together for each model a radar plot of the calibration parameter values. For every set of parameters, a line iswas drawn to link every individual parameter. The computation of the 250 lines makesmade it possible to picture the range covered by the selected sets of parameters within a predefined physical interval that limits the automatic calibration algorithm. These limits were based on the information provided by previous sensitivity analyses, operational experience, and previous calibration exercises. 
For most watershed models, the parameter equifinality is limited. Indeed, parameter equifinality for the Batiscan watershed, for the KGE OF, covers a maximum of $9.2 \%$ of the physical range for the deciduous melting threshold parameter ( $\mathrm{C}$ in Figure 3), but about 5\% for the rain/snow limit (A in Figure 3) for example. The maximum parameter equifinality is obtained for the evergreen melting threshold on the Yamaska watershed for the KGE OF with an equifinality covering $45.6 \%$ of the physical range. Overall, the "most equifinal parameters" are the evergreen melting rate (B in Figure 3) and threshold (E in Figure 3).

\section{Figure 3: Radar plots of the twelve parameters used in the automatic calibration of} HYDROTEL for each study watershed. Parameter A is part of the interpolation coefficients, parameters $B$ through $G$ relate to the snow model, and parameters $F$ through $L$ relate to the soil group of parameters. The dark blue diagrams refer to the KGE objective function $\underline{O F}$ while the light blue diagrams refer to the Nash-log OF.

\section{Streamflows}

A tangible evidence of the equifinality of the 20 models is displayed by the narrow ranges of OF values resulting from the 250 calibrations and validations. This was expected despite the careful consideration given to the number of calibration parameters used to avoid over parametrization and limit the possibility of equifinality. Figure 4Figure 4 shows the KGE and Nash-log values obtained in calibration and validation for the Chamouchouane watershed. KGE as well as Nash-log calibration values belong to equally narrow ranges [0.9464 $\left.\dot{;}_{2} 0.9472\right]$ and $\left[0.9064 \dot{\xi}_{2} 0.9072\right]$. For the validation period, ranges are larger, but still quite narrow with $100 \%$ and $68 \%$ of KGE and Nash-log values fitting in the equally narrow ranges $\left[0.8225 \dot{\bar{y}}_{2}\right.$ $0.8305]$ and $\left[0.6340, \frac{\bar{y}_{2}}{0} 0.6420\right]$, respectively. Model performances are not as good in validation as in calibration. But as Table 6 Table 6 shows, differences in performances overpass a $15 \%$ difference only three times out of the 20 models. Moreover, the validation period performances either increase as wellor as decrease in comparison with calibration values, and 
that vouches for the split-sample strategy chosen. Indeed, Table 6 Table 6 introduces the median loss of performances computed from the individual losses of each of the 250 calibrations/validations which are different from what could be computed from Table 5Fable 5.

Table 5 Fable 5 shows that results of Figure 4Figure 4 are also valid for the alternate watersheds included in this paper. Indeed, for the calibration period, both KGE and Nash-log values can be constrained in a 0.01 interval while ${ }_{2}$ for the validation period ${ }_{2}$ values they are within a 0.15 interval. What is notable is that ranges seem larger for the Nash-log than for the KGE OFs. Also, the performances in calibration using the Nash-log OF are lower; whereby the mean of the KGE values is 0.916 , the mean of the Nash-log values is 0.840 . In-For validation $_{2}$ this gap widens with a mean KGE of 0.823 and a mean Nash-log of 0.679 . This important difference may be attributed to the relative inability of Nash-log to represent high flows. Indeed, high flows are less correctly assessed-reproduced by Nash-log than-when low flows are assessed using the KGE OF. This explains the observed difference in performances.

The simulated streamflow envelopes shown in Figure 5Figure 5 clearly illustrate parameter uncertainty with respect to the Rouge watershed. The hydrographs were computed according to the following steps: (i) for every 250 simulated flow series, mean values were generated for each day of the year, over the calibration ( 9 hydrological years) and validation periods ( 8 hydrological years); (ii) then for each model and simulation period, daily minimum and maximum values were taken from the entire set of mean series and plotted in order to obtain streamflow envelopes. As depicted in Figure 5Figure 5 which intraducing introduces the individual streamflow uncertainty envelopes for the alternate watersheds, the impact of parameter uncertainty is:

- small (most of the time under $0.1 \mathrm{~mm} /$ day) for both simulation periods and OFs, 

of $1 \mathrm{~mm} /$ day).

The OF uncertainty is shown by the global envelope that encompasses individual bands associated with the KGE and Nash-log series of modelled streamflows. Figure 5Figure 5 and alternate figures show that OF uncertainty is more important than parameter uncertainty most of the year (except during the recession of the spring peak flow where the envelopes overlap). Moreover, the spread of the global envelope for the ten watersheds reveals that OF uncertainty is generally more pronounced in the fall and the spring peak flows.

Figure 4: Distribution of the OF values for the Chamouchouane watershed: (a) KGE calibration period; (b) KGE validation period; (c) Nash-log calibration period; (d) Nashlog validation period calibration and validation periodsTable 5: Summary of the KGE and Nash-log values for the ten-watersheds over the calibration and validation periods>

<Table 6: Median of the KGE and Nash-log loss of performance (positive values)

Formatted: Font: Bold between the calibration and validation periodsTable 6: Median of the KGE and Nashlog loss of performance (positive values) between the calibration and validation periods $>$

Figure 5: Streamflow uncertainty envelopes for the Rouge watershed: (a) calibration (9year mean) and (b) validation periods (8-year mean). The black and green envelopes respectively stand for simulated flows under the KGE and Nash-log objective funetionsOFs, respectively, while the blue line depicts the observed values. 


\section{Hydrological indices}

Figure 6Figure 6 introduces ${ }_{2}$ for the Chamouchouane watershed the boxplots of the seasonal hydrological indices for each OF. The two boxplots per year represent the parameter uncertainty (250 sets of parameter) for the KGE and Nash-log OFs for each hydrological index. The reunion of the two boxplots represent the OF uncertainty. Results do not show the 30d-Qmin distributions as they are quite similar to the 7d-Qmin distributions, their median being just slightly greater and their interquartile range being similar.

Figure 6 Figure 6 shows that the impact of parameter uncertainty is rather small during both simulation periods (calibration and validation). Indeed for both OFs and both simulation periods, differences between the $1^{\text {st }}$ and $3^{\text {rd }}$ quartiles remain under $5 \%$ of the hydrological indices values. Parameter uncertainty is more important for winter Nash-log hydrological indices than for KGE values, whereas they are comparable for summer indices. The impact of OF uncertainty is for all hydrological indices, for almost every year, and for both simulation periods the impact is more important than that of the parameter uncertainty. It is especially the case for winter 7d-Qmin and 30d-Qmin where OF the uncertainty is at least five (5) times larger than the parameter uncertainty. This also applies to winter Qmax where it is at least twice as much important. The main findings that stand forcharacterizing almost all watersheds are the following:

- Parameter uncertainty is :

- quite stable across years and simulation periods, - smaller in summer than in winter especially for Qmax, o eemparable-similar for both OFs, both seasons and all hydrological indices (besides a few exceptions related to the performance of the calibration).

- OF uncertainty is:

- rather stable across years for every individual seasonal hydrological index, 
- more important than parameter uncertainty across the years, simulation periods, and seasons,

○ higherlarger in winter than in summer and more important for 7d-Qmin and 30d-Qmin.

Figure 6: Boxplots of the seasonal hydrological indices for the Chamouchaoune watershed for the calibration (1) and validation (2) periods: (as1) and (as2) display the distribution of the maximum summer peakflows; (aw1) and (aw2) the distribution of maximum winter peakflows; (bs1) and (bs2) the distribution of summer-7-day minimum

flows; and (bw1) and (bw2) the distribution of winter-7-day minimum flows. The black and green boxplots stand-illustrate for the distribution of simulated flows under the KGE and Nash-log OFs, respectively, while the blue dots depict the observed values. The superscripts $w$ and $d$ on the $x$-axis indicate the wettest and driest years of each simulation period, respectively.

Snow water equivalent

Figure 7Figure 7 shows the SWE uncertainty envelopes for the Yamaska watershed for the calibration and validation periods as well as the two OFs. The envelopes were computed using the same method as that used for the streamflows, except that since HYDROTEL is a semi-distributed model, mean areal values over the RHHUs were first computed to produce a single data series for each calibrated parameter set and each simulation period.

Figure 7Figure 7 shows that parameter uncertainty relative to SWE is less important at the beginning and the end of the snow season while being at a maximum at the peak where the envelopes are the widest. OF uncertainty for SWE, opposite-contrary to that for streamflows, is less important than parameter uncertainty as the individual envelopes overlap almost the

entire snow season. Parameter uncertainty is higher-more important for the Nash-log OF than for the KGE OF. However, these observations do not holdcannot be generalized when 
examining in details the results for the alternate watersheds. Nonetheless, the overall results can be separated into six groups:

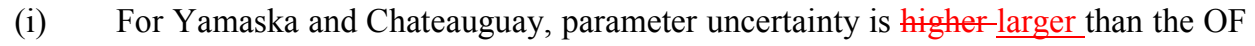
uncertainty for the whole year with individual envelopes being wider at the beginning of February and at the end of March. SWE is higher for the Nash-log OF than for the KGE OF.

(ii) For Chamouchouane and Mistassini, parameter uncertainty is higher larger than the OF uncertainty for the whole year with individual envelopes overlapping the entire year.

(iii) For Gatineau, parameter uncertainty is higher-larger than the OF uncertainty from November to the end of February. OF uncertainty then becomes higher larger than parameter uncertainty with individual envelopes not overlapping anymore. Individual envelopes are quite narrow throughout the year and KGE simulated SWE is slightly more important than the Nash-log simulated values.

(iv) For Batiscan, results are similar to those of group (iii); differing only with respect to the fact that individual envelopes become slightly wider indicating a more important parameter uncertainty

(v) For Du Loup and Rouge, results indicate a higher larger OF uncertainty for the whole year with narrow individual envelopes not overlapping. KGE simulated SWE values are more important than Nash-log values with a maximum difference of $50 \mathrm{~mm}$ at peak values.

(vi) For Bécancour and Chaudière, results are similar to those of group (v) differing only with respect to the fact that individual envelopes become wider, indicating that parameter uncertainty is higherlarger. 
467 Figure 7: Snow water equivalent (SWE) uncertainty envelopes for the Yamaska 468 watershed: (a) calibration (9-year mean) and (b) validation periods (8-year mean). The 469 black and green envelopes stand-illustrate the distribution offor simulated flows under the KGE and Nash-log objective functions $\underline{\mathrm{OFs}}$. The line indicates the period of overlapping between the uncertainty envelopes. 


\section{Actual evapotranspiration}

Figure 8 shows-depicts the seasonal AET for the Bécancour watershed obtained for both simulation periods and OFs. They were computed as the sum of AET over each hydrological year and season after applying the same methodology as that for the areal SWE in getting a single data series. Parameter uncertainty can be assessed through the amplitude of each boxplot while OF uncertainty is assessed through the combination of the KGE boxplots (black) and Nash-log boxplots (green).

Figure 8 shows that parameter uncertainty for the summer season covers around $5 \%$ of the AET values for both simulation periods and OFs; but for winter goes as far as $50 \%$. For summer, OF uncertainty is less significant than parameter uncertainty for many years where as illustrated by the overlapping of the individual boxplots overlap-(1981, 1983, 1985, 1986, 1987, 1988, 1992, 1994, 1998, 2000 and 2002). Nevertheless, OF uncertainty is more important than parameter uncertainty for all years but for winter 1990. Also, it is noteworthy that parameter uncertainty is less variable across years during summer than in-winter; indeed boxplots have the same width-across years. Last, Nash-log parameter uncertainty is comparable or higher larger than summer KGE parameter uncertainty in summer-whereas it is the opposite in for winter. However, these observations do not holdcannot be generalized when examining in details the results for of the other watersheds (alternate watersheds). Nonetheless, the overall results can be separated into six groups:

(i) For Batiscan, Châteauguay, Du Loup and Yamaska, both types of uncertainty are stable constant across simulation periods, years and seasons. OF uncertainty remains around $5 \%$ and does not go beyond $10 \%$ of the simulated AET values and is more important than parameter uncertainty, while parameter uncertainty is comparable similar for both OFs. 
(ii) For Rouge, results are similar to those of group (i) differing only with respect to OF uncertainty being larger, around $10 \%$, for both seasons of the simulation periods and all years.

(iii)For Gatineau and Mistassini, results are similar to those of group (ii) but present have values. This behavior is more pronounced in summer than in winter, and more so for Mistassini than for Gatineau.

(iv)For Chaudière, results are similar to those of group (ii) but present have an OF uncertainty that flirts with $20 \%$.

(v) For Chamouchouane, results are similar to those of group (i) because of the stable constant $\mathrm{OF}$ and parameter uncertainties. The difference is that OF uncertainty is nonexistent as individual boxplots overlap for all seasons, years and simulation periods. Parameter uncertainty related to the Nash-log OF is more important than that of KGE simulated values

(vi)For Bécancour, results were described in the previous paragraph and are different from the other groups as they present display variability across years and seasons that other watersheds do not show.

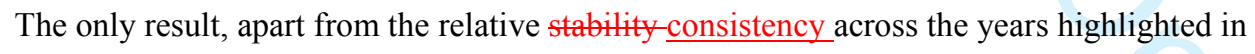
group (vi), that stands across all watersheds, but Bécancour in summer and Yamaska is that simulated AET values are higher for all years and all seasons under the Nash-log OF. This is not a surprising result as it pertains to the nature of the OF with respect to the water balance. That is, if a smaller percentage of precipitations gets discharged through rivers (Nash-log vs KGE), another way to balance the equation for HYDROTEL is to increase water output through evapotranspiration. 
Figure 8: Seasonal actual evapotranspiration for the Bécancour watershed: (a) summer calibration; (b) summer validation; (c) winter calibration and (d) winter validation. The black and green boxplots stand for simulated AET distributions under the KGE and Nash-log OF $\underline{s}$, respectively. The outliers are represented by red crosses. The superscripts $w$ and $d$ on the $x$-axis stand for the wettest and driest years of each simulation period, respectively.

\section{Shallow groundwater variations}

Figure 9 shows the envelopes of areal GWC variations for the calibration and validation periods as well as the two OFs for the Du Loup watershed. The envelopes were computed using the same method as that used for the areal SWE.

Figure 9 shows that parameter uncertainty is small and stable constant for both OFs throughout the whole year with a maximum uncertainty under $2 \mathrm{~mm}$. On the contrary, OF uncertainty is substantial for the whole year (20 to $40 \mathrm{~mm}$ for the calibration period, 10 to 20 $\mathrm{mm}$ for the validation period), but between January and March. For this latter period, the shallow ground water reserves are at their lowest point and individual envelopes overlap during the calibration period or are close to overlapping during the validation period. However, these observations do not hold when examining in details the results for the alternate watersheds. Nonetheless, the overall results can be separated into six groups:

(i) For Rouge and Mistassini, the GWC variation patterns are similar to those of Du Loup. Maximum reserves are attained-reached in early May after the snow has melted; they continuously decrease until early September where they reach their minimum to increase until the end of the fall season in early December. Finally, they decrease again to a near minimum value around early March when theat the onset of melt season-starts. OF and parameter uncertainties were described in the previous paragraph. 
(ii) For Batiscan, results show similar GWC variation patterns to those of group (i). than $20 \mathrm{~mm}$. The difference lies in the parameter uncertainty that covers most the OF uncertainty, but still remains under $10 \mathrm{~mm}$. Indeed, for the calibration period, OF uncertainty is less important than parameter uncertainty from November until the end of September. For the validation period, the overlapping is reduced from December until the end of May. Still, even in the remaining months, OF uncertainty is less important than that of group (i); incidentally not getting larger those of groups (i) and (ii), but behave almost at the opposite of group (i) with respect to OF and parameter uncertainties. OF uncertainty is non-existent for the whole year, but for a few days around peak value. Parameter uncertainty is small (less than $2 \mathrm{~mm}$ ) and individual envelopes overlap.

(iv) For Bécancour, results show similar GWC variation patterns to those of group (i) apart from the decrease during the snow season that is less pronounced. Parameter uncertainty is more important for both OFs as that of group (i); it represents a maximum of $10 \mathrm{~mm}$ for both OFs in the calibration period, but around $5 \underline{\mathrm{mm}}$ and close to $10 \mathrm{~mm}$ respectively for Nash-log and KGE simulated GWC. OF uncertainty as a result is still more significant than parameter uncertainty despite a lag between the OFs that make the individual envelopes overlap around peakflow values.

(v) For Chaudière, results show similar GWC variation patterns to those of Bécancour (group (iv)) but is clearly different from any other watershed with respect to the $\mathrm{OF}$ and parameter uncertainties. The Nash-log parameter uncertainty covers almost all KGE values and presents - has 40 and $20 \mathrm{~mm}$ wide intervals, 
respectively, for the calibration and validation periods. The KGE parameter uncertainty is less than $2 \mathrm{~mm}$ for the whole year which results in a non-existent $\mathrm{OF}$ uncertainty for the calibration period while still being significant between August and December for the validation period.

(vi) For Chateauguay and Yamaska, the GWC variation patterns differ from those of groups (i) to (v). The GWC is at a minimum around the end of August. The reserves are then replenished from September until the end of November, before decreasing only slightly, as opposed to groups (i) and (ii), during the snow season and attaining their maximum values after the snow has melted. Parameter uncertainty is small, under 2 and $5 \mathrm{~mm}$ respectively for KGE and Nash-log simulated GWC, respectively, and relatively stable-constant across the year. OF uncertainty is more important (maximum of 20 and $30 \mathrm{~mm}$ maximum respectively for calibration and validation, respectively) for the whole year, but just after peak value (May and June) for the calibration period and around peak value (April) for the validation period

It is noteworthy that the two variation patterns relative to $\mathrm{GWC}_{2}$ highlighted in the above groups $_{2}$ reflect the geographical location of the watersheds. Indeed, Bécancour, Châteauguay, Chaudière and Yamaska are located on the south shore of the St. Lawrence River, while Batiscan, Chamouchouane, Du Loup, Gatineau, Mistassini and Rouge are located on the north shore.

Figure 9: Shallow groundwater content uncertainty envelopes for the Du Loup watershed: (a) calibration (9-year mean) and (b) validation periods (8-year mean). The black and green envelopes stand forillustrate the distribution of simulated flows under the KGE and Nash-log ebjective functions $\underline{\mathrm{OFs}}$, respectively. 


\section{Discussion}

597

\section{Automatic calibration with DDS}

In the Material and Methods section- $\theta_{, 2}$ it is mentioned that DDS is better suited than SCEUA (Duan et al. 1992; Duan et al. 1994; Duan et al. 1993) for distributed watershed models that require-requiring extensive eomputing computational time and, thus, impose-leading to a low number of model evaluations before converging to a good solution (Arsenault et al. 2014; Tolson and Shoemaker 2007; Yen et al. 2016). This is mostly due to DDS dynamically adjusting the neighborhood of the best solution by changing the dimension of the search (Tolson and Shoemaker 2007). In other terms, DDS mimics manual calibrations of watershed models as follows: (i) early in the calibration exercise, a number of model parameters are modified to overcome relatively poor solutions, and (ii) later, to avoid losing the current gain in objective function values, parameters are modified one at a time. To avoid introducing a bias in the search algorithm, this paper used a random initial solution, but used the same random solution for every watershed in order to keep the experiments eomparableconsistent.

The stochastic nature of DDS means that multiple optimization trials initialized with different initial solutions can terminate at different final solutions (Tolson and Shoemaker 2008). To be consistent with the framework described in the introduction, that is a majority of the HYDROTEL application studies involved manual calibration, we decided to work with only one optimization trial and a budget of 5000 model runs to answer the research question with respect to equifinality in this constrained contextgiven this framework. Besides, the radar plots of parameter equifinality shown in Figure 3 do not seem to behave in a pattern related to the geographical situationlocation, the climate, or geological characteristics of each watershed. Indeed, the study watersheds are part of three different geological provinces (Ministère des Ressources naturelles Direction générale de Géologie Québec 2012): (i) the Greenville Province made of allochtonous material north of the St. Lawrence River; (ii) the 
St. Lawrence platform around the riverRiver; and (iii) the Appalachian province made of Humber material south of the River. They also belong to three climate classes defined by Litynski (1988) but mostly to class 14 that stands for moderate temperature, subhumid precipitations and long growing season. As a consequence, parameter regionalization is not obvious. This was pointed out as well by Ricard et al. (2013) who showed that a global calibration strategy over southern Québec was preferable although in some cases -the performances of watershed calibration using HYDROTEL was reduced when compared to local calibrations.

\section{OF uncertainty}

Overall, results for all the studied hydrological processes suggest that OF uncertainty is more important than the parameter uncertainty. In other words, OF uncertainty is seen when the largest of the individual envelopes or boxplots relative to each objective function (KGE and Nash-log) is smaller than the reunion of either envelopes or boxplots. The readerReaders should note that results obtained for the $\mathrm{NSE}_{\mathrm{Q}}$ and $\mathrm{NSE} \sqrt{\mathrm{Q}}$ OFs are in complete agreement with the previous statement. Figure 5Figure 5 and alternate figures do not clearly show the impact of OF uncertainty because individual envelopes often overlap. However, when considering the seasonal hydrological indices (Figure 6Figure 6 and alternate figures), the SWE (Figure 7Figure 7 and alternate figures), the actual evapotranspiration-AET (Figure 8 and alternate figures), and the GWC (Figure 9 and alternate figures), OF uncertainty is overall clearly illustratedhighlighted.

Some studies highlight the importance of model structure uncertainty over parameter equifinality (Futter et al. 2015; Mockler et al. 2016; Poulin et al. 2011; Shoaib et al. 2016). Poulin et al. (2011) used HYDROTEL and HSAMI to assess the effects of model structure and parameter equifinality on the uncertainty related to hydrological modelling. Their study revealed that the impact of hydrological model structure was more significant than the effect 
of parameter uncertainty (assessed through 68 sets of parameters). Yet, the uncertainty attributed to model structure with respect to streamflows and SWE were of the same order of magnitude than the OF uncertainty assessed in this paper. This would mandate the combination of both studies to clearly assess whether the impact of model structure and OF uncertainty are equivalent or complementary in assessing the consequences of considering the effects of equifinality on modelled hydrological processes.

Figure 6Figure 6 and alternate figures showed the boxplots of the seasonal hydrological indices for both OFs (section 0 ). Results section). They also indicated observed values as blue dots; less than $50 \%$ of the latter are not included within the interval of the simulated values for any of the hydrological indices (Qmax, 7d-Qmin, and 30d-Qmin). This could be seen as a calibration performance issue, but results suggest otherwise. Indeed, all observed values and all, but one, are included within the interval of the simulated values for the summer 7d-Qmin for the Châteauguay and Yamaska, respectively; which have the lowest performances for both OFs (refer to Table 5 Fable 5 of section 0 ).). This would rather suggest that KGE and Nash$\log$ OFs are not able to force the model to represent the hydrological indices properly. This may be related to the nature of both OFs that are computed over daily data versus hydrological indices computed over a period of time (seven and 30 days forfor_ $7 \mathrm{~d}-\mathrm{Qmin}$ as well as 30d-Qmin, respectively). However, for Qmax, this is simply related to the misrepresentation of maximum flows. This result is rather important as hydrological indices are often used in impact assessment studies. This would mandate the use of specific ebjective functions $\underline{\mathrm{OFs}}$ related to low or high flows or even the use of multi-objective functions.

\section{Parameter uncertainty}

Despite the fact that the OF uncertainty is overall more important than the consequences of parameter equifinality, parameter uncertainty relative to SWE ( more important than OF uncertainty. Indeed it is more important for the whole year for 
Châteauguay, Chamouchouane, Mistassini and Yamaska and, for a few months (November until the end of February), for Gatineau and Batiscan. Seasonal results also suggest that parameter uncertainty can be important or more significant even than OF uncertainty for specific seasons or years (Figure 6Figure 6, Figure 8 and alternate figures). To get a better understanding of the reasons why parameter uncertainty would prevail only for a few years, driest and wettest years were defined as the hydrological years with the least total amount of precipitation for the simulation periods (indicated on the $\mathrm{x}$-axis of seasonal hydrological indices and AET figures as $d$ and $w$ ). The effects of driest and wettest years were assessed in terms of prevalence of any of the two types of uncertainties and magnitudes of uncertainties on both the actual driest and wettesttypes of years, but also on the following year. Nothing particular stood out that could be construed as a general result that could have given insights about the evolution of the prevalence of the two types of uncertainties in the following years. To get this type of insight, we would probably need to perform calibrations under different sets of contrasting conditions (dry versus wet years). This refers to parameter identifiability as researched by Wilby (2005) on snowless watersheds, or to the application of testing schemes such as those performed by Seiller et al. (2012) and inspired by KlemeŠ (1986).

\section{Parameter equifinality}

Ben Nasr (2014) as well as Bouda et al. (2014) pointed out in sensitivity analyses carried out for two snow-dominated watersheds in southern Québec (Beaurivage and Montmorency modelled using HYDROTEL), that the depth of the lower boundary of the three soil layers $(\mathrm{z} 1, \mathrm{z} 2, \mathrm{z} 3)$, the potential evapotranspiration multiplying factor (PETF), and the recession coefficient (RC) were consistently amongst the most sensitive parameters (refer to Table 4Table 4 in section 0)... In both-case studiess, sensitivity was assessed from an initial optimal solution and parameter values were modified ( $\pm 25 \%$ ), but variations of $\pm 6.25 \%$ already gave substantial flow modifications. These results are within the same order of magnitude as the 
equifinality measured through the proposed methodology (section 0 )-and explain why some parameters in Figure 2 are more equifinal than others. Typically, parameters that were identified by Ben Nasr (2014) and Bouda et al. (2014) as the most sensitive parameters are less equifinal than others. This result is not surprising as it pertains to the following statement: the more sensitive a parameter, the least uncertain it can be around a global optimum for the OF to remain optimum.

The choice to work with 5000 model runs ensured that the OF values remained within a 0.01 interval (sectionrefer to $\theta$ Table 5Table 5) for 250 sets of parameters that captured parameter equifinality. Neither did working with 500 sets of parameters provide a larger parameter equifinality ${ }_{2}$ nor did working with 100 sets of parameters provide the complete parameter equifinality. This is important as Poulin et al. (2011) reported that parameter uncertainty increases with increasing numbers of calibration parameters and/or calibrations. This allows us to go beyond their research in making sure that our conclusions cannot be disputed with respect to the impact that parameter equifinality has on global or individual uncertainty envelopes.

To make sure that working with one optimization trial did not impair the possibility of capturing the equifinality of the parameters, the smallest watershed model in terms of modelled area (to minimize computational time) with the smallest parameter equifinality was calibrated for another 5000-simulation-optimization-_trial started at a different initial random solution. As shown in Figure 10Figure 10; this demonstrates that parameter equifinality can be increased if the calibration methodology is modified. Nonetheless, the covered part of the physical range does not come close to the maximum equifinality obtained for the Yamaska watershed in section 0 -Figure 3 . Thus, it can be assumed that the results introduced in this paper would not be drastically modified by a change in the calibration methodology. Plus it would contradict the choice made not to conduct a formal uncertainty analysis as this 
methodology of using two or more optimization trials would get closer to the DDS-AU methodology introduced by Tolson and Shoemaker (2008).

Figure 10: Radar plots of the twelve parameters used in the automatic calibration of HYDROTEL for each study watershed. Parameter A is part of the interpolation coefficients, parameters $B$ through $G$ relate to the snow model, and parameters $F$ through $L$ relate to the soil group of parameters. Figure (a) refers to the KGE objective ftnetion $\mathrm{OF}$; and (b) to the Nash-log ebjective funetion $\underline{\mathrm{OF}}$. The dark and light blue data refer to the first optimization trial of Figure 3, black data to the second optimization trial.

To summarize, it could be said that this paper shows the consequences of the existence of many good sets of parameters (parameter equifinality assessed in section 0 ) on modelled hydrological processes around a global optimum rather than properly evaluating their formal statistical uncertainty. If that were the aim, the methodology would have entailed working with one optimization trial per set of parameters which would have resulted in a total of 125000 simulations (250 sets of parameters * 500 simulations) since DDS typically needs 500 simulations to find a good global solution (compared to 10,000 for SCE-UA). Note that the computing time for a 10-year calibration period (with a prior 1-year spin-up), one optimization trial of 5000 simulations already took an average 45 hours (on a 64-bit computer with a quad-core $2.53 \mathrm{GHz}$ processor) for each watershed and every $\mathrm{OF}$, resulting in a total calibration time of 900 hours or 37.5 days ( 45 hours $* 10$ watersheds $* 2$ OFs) for the results presented in this paper (excluding the two OFs that were left out of this paper). 


\section{Conclusion}

In the last decade, HYDROTEL has almost always been applied within the optimal parameter set paradigm at the risk of avoiding important issues such as model acceptability and uncertainty (Beven 2006a). This paper builds on the work carried out on hydrological uncertainty by assesing the impact of equifinality and OF related uncertainty on five modelled hydrological variables and indices: (i) daily flows,; (ii) seasonal hydrological indices (7dQmin, 30d-Qmin, and Qmax),_; (iii) snow water equivalent (SWE),); (iv) shallow ground water content variations (GWC), 这 and (v) actual evapotranspiration (AET). This assessment was carried out for ten watersheds spread out in five hydrographic regions of the St. Lawrence River and spread across southern Québec (Canada).

Overall, as introduced in Table 7, the results for all the studied hydrological processes, but the SWE, suggest that OF uncertainty is more important than that arising from parameter equifinality. This would mean that within the context of a study with a limited budget, it would be advisable to prioritize using different objective functions to using many sets of optimal parameters. This result is rather important as it reinforces the choice made in the last decade with HYDROTEL. Nonetheless, parameter uncertainty with respect to SWE is more important than OF uncertainty for eight of the ten studied watersheds for four up to seven months of the year (snow season less than 7-month long). Plus, despite satisfactory performances for both simulation periods, parameter uncertainty with respect to streamflows is rather small during the whole year, except around spring peak flow; while OF uncertainty is generally more pronounced in the fall and during the spring peak flows. Overall, this shows that one type of uncertainty or the other is rather significant during half of the year. Seasonal results with respect to hydrological indices and AET also suggest that parameter uncertainty can be important, or more significant even, than OF uncertainty for specific seasons or years. These results are of the utmost importance for impact assessment studies where the variables 
of interest are not solely the daily flow data used for calibration, but rather hydrological indices or internal variables. This would mean that parameter uncertainty needsdoes need to be taken into account or at least needs to be further researched to better understand the mechanisms driving parameter uncertaintybehind the phenomena. This study demonstrates, using a substantial set of watersheds; that aside from the technico-philosiphical debate started in 2006, equifinality is not so technical to take into account and has tangible significant effect on the uncertainties associated with modeled hydrological processes. As such, we recommend that future work systematically include equifinality by using at least two sets of equifinal parameters without forgetting to assess OF uncertainty.

It is noteworthy that the methodology applied in this paper for the HYDROTEL model can be replicated for other hydrological models. Uncertainty associated with OFs and parameter equifinality still needs to be better understood and studied. To improve our understanding of HYDROTEL, and other physically based hydrological models, future work should focus on identifying or using OFs tailored for hydrological indices relevant to impact assessment studies. Finally, for a specific assessment, there is a need to consider as well the question of the uncertainty associated with model structure.

$<$ Table 7: Dominant type of uncertainty for each study watershed for the five modelled 


\section{Acknowledgements}

789 The authors would like to thank Marco Braun of Ouranos (Consortium on Regional

790 Climatology and Adaptation to Climate Change, Montreal, Qc, Canada), for his scientific

791 support as well as giving us access to the meteorological data, the Quebec Hydrological

792 Expertise Centre (CEHQ) for allowing us to use parts of their modelling platform, but

793 especially Simon Lachance Cloutier for his technical support, and Sébastien Tremblay of

794 INRS (Centre Eau Terre Environnement) for his computer support throughout the project.

795 Financial support for this project was provided by the Natural Sciences and Engineering

796 Research Council (NSERC) of Canada through the Discovery Grant Program (A.N.

797 Rousseau, principal investigator). 


\section{References}

Aissia, M. A. B., F. Chebana, T. B. M. J. Ouarda, L. Roy, G. Desrochers, I. Chartier, and É Robichaud. 2012. Multivariate analysis of flood characteristics in a climate change context of the watershed of the Baskatong reservoir, Province of Québec, Canada. Hydrological Processes 26 (1):130-142.

Arsenault, R., A. Poulin, P. Côté, and F. Brissette. 2014. Comparison of stochastic optimization algorithms in hydrological model calibration. Journal of Hydrologic Engineering 19 (7):1374-1384.

Ben Nasr, Imène. 2014. Incertitudes sur les débits simulés par le modèle HYDROTEL attribuables aux incertitudes sur les paramèetres. Application au bassin de la rivière Beaurivage, Québec, Canada, Institut National de la recherche scientifique, Centre Eau terre environnement, Québec, QC 94 pp.

Beven, K. 1993. Prophecy, reality and uncertainty in distributed hydrological modelling. Advances in Water Resources 16 (1):41-51.

Beven, K. 2006a. A manifesto for the equifinality thesis. Journal of Hydrology 320 (1-2):1836.

Beven, K. 2006b. On undermining the science? Hydrological Processes 20 (14):3141-3146.

Beven, K. 2008. On doing better hydrological science. Hydrological Processes 22 (17):35493553.

Beven, K. 2016. Facets of uncertainty: Epistemic uncertainty, non-stationarity, likelihood, hypothesis testing, and communication. Hydrological Sciences Journal 61 (9):16521665.

Beven, K., and A. Binley. 1992. The future of distributed models: Model calibration and uncertainty prediction. Hydrological Processes 6 (3):279-298.

Beven, K., and J. Freer. 2001. Equifinality, data assimilation, and uncertainty estimation in mechanistic modelling of complex environmental systems using the GLUE methodology. Journal of Hydrology 249 (1-4):11-29.

Beven, K. J. 2009. Comment on "Equifinality of formal (DREAM) and informal (GLUE) Bayesian approaches in hydrologic modeling?" by Jasper A. Vrugt, Cajo J. F. ter Braak, Hoshin V. Gupta and Bruce A. Robinson. Stochastic Environmental Research and Risk Assessment 23 (7):1059-1060.

Bouda, M., A. N. Rousseau, S. J. Gumiere, P. Gagnon, B. Konan, and R. Moussa. 2014. Implementation of an automatic calibration procedure for HYDROTEL based on prior OAT sensitivity and complementary identifiability analysis. Hydrological Processes 28 (12):3947-3961.

Bouda, M., A.N. Rousseau, B. Konan, P. Gagnon, and S.J. Gumiere. 2012. Case study: Bayesian uncertainty analysis of the distributed hydrological model HYDROTEL. Journal of Hydrologic Engineering 17 (9):1021-1032. 
CEHQ. 2012. Niveau d'eau et débit. http://www.cehq.gouv.qc.ca/hydrometrie/index.htm (accessed September 2017).

CEHQ. 2013. Atlas hydroclimatique du Québec méridional - Impact des changements climatiques sur les régimes de crue, d'étiage et d'hydraulicité à l'horizon 2050. Québec, $21 \mathrm{pp}$.

CEHQ. 2015. Hydroclimatic Atlas of Southern Québec. The Impact of Climate Change on High, Low and Mean Flow Regimes for the 2050 horizon. Québec, 81 pp.

Duan, Q., S. Sorooshian, and V. Gupta. 1992. Effective and efficient global optimization for conceptual rainfall-runoff models. Water Resources Research 28 (4):1015-1031.

Duan, Q., S. Sorooshian, and V. K. Gupta. 1994. Optimal use of the SCE-UA global optimization method for calibrating watershed models. Journal of Hydrology 158 (34):265-284.

Duan, Q. Y., V. K. Gupta, and S. Sorooshian. 1993. Shuffled complex evolution approach for effective and efficient global minimization. Journal of Optimization Theory and Applications 76 (3):501-521.

Fisher, J., and K. J. Beven. 1996. Modelling of stream flow at Slapton Wood using topmodel within an uncertainty estimation framework. Field Studies 8 (4):577-584.

Fortin, J.-P., R. Turcotte, S. Massicotte, R. Moussa, and J. Fitzback. 2001a. A distributed watershed model compatible with remote sensing and GIS data. Part 2: Application to the Chaudière watershed. Journal of Hydrologic Engineering 6 (2):100-108.

Fortin, J.-P., R. Turcotte, S. Massicotte, R. Moussa, J. Fitzback, and J.-P. Villeneuve. 2001b. A distributed watershed model compatible with remote sensing and GIS data. Part I: Description of the model. Journal of Hydrologic Engineering 6 (2):91-99.

Fossey, M., and A. N. Rousseau. 2016a. Assessing the long-term hydrological services provided by wetlands under changing climate conditions: A case study approach of a Canadian watershed. Journal of Hydrology 541, Part B:1287-1302.

Fossey, M., and A. N. Rousseau. 2016b. Can isolated and riparian wetlands mitigate the impact of climate change on watershed hydrology? A case study approach. Journal of Environmental Management 184, Part 2:327-339.

Fossey, M., A. N. Rousseau, F. Bensalma, S. Savary, and A. Royer. 2015. Integrating isolated and riparian wetland modules in the PHYSITEL/HYDROTEL modelling platform: Model performance and diagnosis. Hydrological Processes 29 (22):4683-4702.

Fossey, M., A. N. Rousseau, and S. Savary. 2016. Assessment of the impact of spatiotemporal attributes of wetlands on stream flows using a hydrological modelling framework: A theoretical case study of a watershed under temperate climatic conditions. Hydrological Processes 30 (11):1768-1781.

Freer, J., K. Beven, and B. Ambroise. 1996. Bayesian estimation of uncertainty in runoff prediction and the value of data: An application of the GLUE approach. Water Resources Research 32 (7):2161-2173. 
Fu, C., A. L. James, and H. Yao. 2015. Investigations of uncertainty in SWAT hydrologic simulations: A case study of a Canadian Shield catchment. Hydrological Processes 29 (18):4000-4017.

Futter, M. N., P. G. Whitehead, S. Sarkar, H. Rodda, and J. Crossman. 2015. Rainfall runoff modelling of the Upper Ganga and Brahmaputra basins using PERSiST. Environmental Sciences: Processes and Impacts 17 (6):1070-1081.

Gaborit, É, S. Ricard, S. Lachance-Cloutier, F. Anctil, and R. Turcotte. 2015. Comparing global and local calibration schemes from a differential split-sample test perspective. Canadian Journal of Earth Sciences 52 (11):990-999.

Gupta, H. V., H. Kling, K. K. Yilmaz, and G. F. Martinez (2009), Decomposition of the mean squared error and NSE performance criteria: Implications for improving hydrological modelling, Journal of Hydrology, 377(1-2), 80-91. doi: 10.1016/j.jhydrol.2009.08.003.

Khalili, M., F. Brissette, and R. Leconte. 2011. Effectiveness of Multi-Site Weather Generator for Hydrological Modeling. Journal of the American Water Resources Association 47 (2):303-314.

KlemeŠ, V. 1986. Operational testing of hydrological simulation models. Hydrological Sciences Journal 31 (1):13-24.

Li, C. Z., L. Zhang, H. Wang, Y. Q. Zhang, F. L. Yu, and D. H. Yan. 2012. The transferability of hydrological models under nonstationary climatic conditions. Hydrology and Earth System Sciences 16 (4):1239-1254.

Linhoss, A., R. Muñoz-Carpena, G. Kiker, and D. Hughes. 2013. Hydrologic modeling, uncertainty, and sensitivity in the okavango basin: Insights for scenario assessment. Journal of Hydrologic Engineering 18 (12):1767-1778.

Litynski, J. 1988. Climat du Québec d'après la classification numérique.

Ludwig, R., I. May, R. Turcotte, L. Vescovi, M. Braun, J. F. Cyr, L. G. Fortin, D. Chaumont, S. Biner, I. Chartier, D. Caya, and W. Mauser. 2009. The role of hydrological model complexity and uncertainty in climate change impact assessment. Advances in Geosciences 21:63-71.

Ministère des Ressources naturelles Direction générale de Géologie Québec. 2012. Map of the main Geological Subdivisions of Québec.

Minville, M., F. Brissette, S. Krau, and R. Leconte. 2009. Adaptation to climate change in the management of a Canadian water-resources system exploited for hydropower. Water Resources Management 23 (14):2965-2986.

Mockler, E. M., K. P. Chun, G. Sapriza-Azuri, M. Bruen, and H. S. Wheater. 2016. Assessing the relative importance of parameter and forcing uncertainty and their interactions in conceptual hydrological model simulations. Advances in Water Resources 97:299-313.

Moriasi, D.N., J.G. Arnold, M.W. VanLiew, R.L. Bingner, R.D. Harmel, and T.L. Veith. 2007. Model evaluation guidelines for systematic quantification of accuracy in watershed simulations. Transactions of the ASABE 50 (3):885-900. 
Mugunthan, P., and C. A. Shoemaker. 2006. Assessing the impacts of parameter uncertainty for computationally expensive groundwater models. Water Resources Research 42 (10).

Nearing, G. S., Y. Tian, H. V. Gupta, M. P. Clark, K. W. Harrison, and S. V. Weijs. 2016. A philosophical basis for hydrological uncertainty. Hydrological Sciences Journal 61 (9):1666-1678.

Noël, P., A. N. Rousseau, C. Paniconi, and D. F. Nadeau. 2014. An algorithm for delineating and extracting hillslopes and hillslope width functions from gridded elevation data. Journal of Hydrologic Engineering 19 (2):366-374.

Oreiller, M., D. F. Nadeau, M. Minville, and A. N. Rousseau. 2013. Modelling snow water equivalent and spring runoff in a boreal watershed, James Bay, Canada. Hydrological Processes.

Poirier, C., T. C. Fortier Filion, R. Turcotte, and P. Lacombe (2012), Apports verticaux journaliers estimés de 1900 à 2010, Rep., Centre d'expertise hydrique du Québec (CEHQ), Direction de l'expertise hydrique, Québec.

Poulin, A., F. Brissette, R. Leconte, R. Arsenault, and J. S. Malo. 2011. Uncertainty of hydrological modelling in climate change impact studies in a Canadian, snowdominated river basin. Journal of Hydrology 409 (3-4):626-636.

Prada, A. F., M. L. Chu, and J. A. Guzman. 2016. Probabilistic approach to modeling under changing scenarios. Paper read at 2016 American Society of Agricultural and Biological Engineers Annual International Meeting, ASABE 2016. pp.

Quilbé, R., A.N. Rousseau, J.S. Moquet, N.B. Trinh, Y. Dikibi, P. Gachon, and D. Chaumont. 2008. Assessing the effect of climate change on river flow using general circulation models and hydrological modeling - Application to the Chaudière River (Québec, Canada). Canadian Water Resources Journal 33 (1):73-94.

Ricard, S., R. Bourdillon, D. Roussel, and R. Turcotte. 2013. Global calibration of distributed hydrological models for large-scale applications. Journal of Hydrologic Engineering 18 (6):719-721.

Romanowicz, R. J., K. Beven, and J. A. Tawn. 1994. Evaluation of predictive uncertainty in nonlinear hydrological models using a Bayesian Approach. In Statistics for the Environment, Water Related Issues (Volume 2), ed. V. Barnett and F. Turkman, 297318. John Wiley \& Sons.

Rousseau, A. N., S. Savary, D. W. Hallema, S. J. Gumière, and E. Foulon. 2013. Modeling the effects of agricultural BMPs on sediments, nutrients and water quality of the Beaurivage River watershed (Quebec, Canada). Canadian Water Resources Journal 38 (2):99-120.

Rousseau, A.N., J.P. Fortin, R. Turcotte, A. Royer, S. Savary, F. Quévry, P. Noël, and C. Paniconi. 2011. PHYSITEL, a specialized GIS for supporting the implementation of distributed hydrological models. Water News, Official Magazine of CWRA - Canadian Water Resources Association 31 (1):18-20. 
Seiller, G., F. Anctil, and C. Perrin. 2012. Multimodel evaluation of twenty lumped hydrological models under contrasted climate conditions. Hydrology and Earth System Sciences 16 (4):1171-1189.

Shoaib, S. A., L. Marshall, and A. Sharma. 2016. A metric for attributing variability in modelled streamflows. Journal of Hydrology 541:1475-1487.

Tolson, B. A., and C. A. Shoemaker. 2007. Dynamically dimensioned search algorithm for computationally efficient watershed model calibration. Water Resources Research 43 (1).

Tolson, B. A., and C. A. Shoemaker. 2008. Efficient prediction uncertainty approximation in the calibration of environmental simulation models. Water Resources Research 44 (4).

Trudel, M., P. L. Doucet-Généreux, R. Leconte, and B. Côté. 2016. Vulnerability of water demand and aquatic habitat in the context of climate change and analysis of a noregrets adaptation strategy: Study of the Yamaska River Basin, Canada. Journal of Hydrologic Engineering 21 (2).

Turcotte, R., J.P. Fortin, A.N. Rousseau, S. Massicotte, and J.P. Villeneuve. 2001. Determination of the drainage structure of a watershed using a digital elevation model and a digital river and lake network. Journal of Hydrology 240 (3-4):225-242.

Turcotte, R., L. G. Fortin, V. Fortin, J. P. Fortin, and J. P. Villeneuve. 2007a. Operational analysis of the spatial distribution and the temporal evolution of the snowpack water equivalent in southern Québec, Canada. Nordic Hydrology 38 (3):211-234.

Turcotte, R., P. Lacombe, C. Dimnik, and J.P. Villeneuve. 2004. Distributed hydrological prediction for the management of Quebec's public dams. Canadian J. of Civil Engineering 31 (2):308-320.

Turcotte, R., A.N. Rousseau, J.-P. Fortin, and J.-P. Villeneuve. 2003. Development of a process-oriented, multiple-objective, hydrological calibration strategy accounting for model structure. In Advances in Calibration of Watershed Models, Water Science \& Application, no. 6, ed. Q. Duan, S. Sorooshian, H. Gupta, A. N. Rousseau and R. Turcotte, 153-163. Washinghton, USA: American Geophysical Union (AGU).

Turcotte, R., A.N. Rousseau, J.P. Fortin, V. Fortin, and J.P. Villeneuve. 2007b. Operational analysis of the spatial distribution and the temporal evolution of the snowpack water equivalent in southern Quebec, Canada. Nordic Hydrology 38 (3):211-234.

Vrugt, J. A., C. J. F. Ter Braak, C. G. H. Diks, B. A. Robinson, J. M. Hyman, and D. Higdon. 2009a. Accelerating Markov chain Monte Carlo simulation by differential evolution with self-adaptive randomized subspace sampling. International Journal of Nonlinear Sciences and Numerical Simulation 10 (3):273-290.

Vrugt, J. A., C. J. F. ter Braak, H. V. Gupta, and B. A. Robinson. 2009b. Equifinality of formal (DREAM) and informal (GLUE) Bayesian approaches in hydrologic modeling? Stochastic Environmental Research and Risk Assessment 23 (7):1011-1026.

Vrugt, J. A., C. J. F. ter Braak, H. V. Gupta, and B. A. Robinson. 2009c. Response to comment by Keith Beven on "Equifinality of formal (DREAM) and informal (GLUE) 
Bayesian approaches in hydrologic modeling?". Stochastic Environmental Research and Risk Assessment 23 (7):1061-1062.

Wilby, R. L. 2005. Uncertainty in water resource model parameters used for climate change impact assessment. Hydrological Processes 19 (16):3201-3219.

Yen, H., J. Jeong, and D. R. Smith. 2016. Evaluation of Dynamically Dimensioned Search Algorithm for Optimizing SWAT by Altering Sampling Distributions and Searching Range. Journal of the American Water Resources Association 52 (2):443-455.

Zeng, Q., H. Chen, C. Y. Xu, M. X. Jie, and Y. K. Hou. 2016. Feasibility and uncertainty of using conceptual rainfallrunoff models in design flood estimation. Hydrology Research 47 (4):701-717.

Zhang, X., G. Hörmann, N. Fohrer, and J. Gao. 2012. Parameter calibration and uncertainty estimation of a simple rainfall-runoff model in two case studies. Journal of Hydroinformatics 14 (4):1061-1074. 


\section{Tables}

1012 Table 1: Land cover of the ten studied watersheds in southern Québec, Canada

\begin{tabular}{|c|c|c|c|c|c|c|c|c|c|c|c|}
\hline & \multicolumn{2}{|c|}{ Evergreen } & \multicolumn{2}{|c|}{$\begin{array}{l}\text { Dedicuous } \\
\text { trees }\end{array}$} & \multicolumn{2}{|c|}{ Water } & \multicolumn{2}{|c|}{ Urban } & \multicolumn{2}{|c|}{ Farms } & \multirow[t]{2}{*}{ Total } \\
\hline & $\mathrm{km}^{2}$ & $\%$ & $\mathrm{~km}^{2}$ & $\%$ & $\mathrm{~km}^{2}$ & $\%$ & $\mathrm{~km}^{2}$ & $\%$ & $\mathrm{~km}^{2}$ & $\%$ & \\
\hline Batiscan & 1816 & 41.9 & 2264 & 52.3 & 187 & 4.3 & 0 & 0 & 67 & 1.6 & 4334 \\
\hline Bécancour & 255 & 9.7 & 2144 & 81.6 & 16 & 0.6 & 0 & 0 & 214 & 8.2 & 2629 \\
\hline Chamouchouane & 817 & 5.4 & 13156 & 87.5 & 1040 & 6.9 & 0 & 0 & 29 & 0.2 & 15042 \\
\hline Châteauguay & 112 & 5.0 & 1722 & 77.4 & 13 & 0.6 & 0 & 0 & 379 & 17.0 & 2227 \\
\hline Chaudière & 1229 & 21.5 & 4206 & 73.4 & 71 & 1.2 & 0 & 0 & 223 & 3.9 & 5728 \\
\hline Du Loup & 243 & 28.4 & 557 & 65.1 & 55 & 6.4 & 0 & 0 & 1 & 0.1 & 855 \\
\hline Gatineau & 1159 & 17.0 & 5298 & 77.8 & 353 & 5.2 & 0 & 0 & 0 & 0 & 6810 \\
\hline Mistassini & 569 & 6.1 & 8341 & 89.7 & 384 & 4.1 & 0 & 0 & 1 & 0 & 9295 \\
\hline Rouge & 1401 & 25.6 & 3791 & 69.2 & 285 & 5.2 & 0 & 0 & 2 & 0 & 5480 \\
\hline Yamaska & 23 & 1.7 & 2050 & 76.7 & 2 & 0.2 & 5 & 0.4 & 289 & 21.1 & 1389 \\
\hline
\end{tabular}


1013 Table 2: Summary (1982-2002) of the climate characteristics of the study watersheds

\begin{tabular}{|c|c|c|c|c|c|c|c|c|c|c|c|c|c|c|c|}
\hline & \multicolumn{6}{|c|}{ Rain (mm) } & \multicolumn{3}{|c|}{ Snow $(\mathbf{m m})$} & \multicolumn{6}{|c|}{ Tmoy Mean Temp. $\left({ }^{\circ} \mathbf{C}\right)$} \\
\hline & \multicolumn{3}{|c|}{ Summer } & \multicolumn{3}{|c|}{ Winter } & \multicolumn{3}{|c|}{ Annual } & \multicolumn{3}{|c|}{ Summer } & \multicolumn{3}{|c|}{ Winter } \\
\hline & Min & Mean & Max & Min & Mean & Max & i Min & Mean & Max & i Min & Mean & $\operatorname{Max}$ & Min & Mean & Max \\
\hline Batiscan & 337 & 558 & 645 & 97 & 180 & 403 & 286 & 356 & 416 & $i^{84}$ & 10,3 & 11,5 & $-7, ;$ & $-5, .4$ & $-3,1$ \\
\hline Bécancour & 392 & 585 & 809 & 129 & 260 & 490 & 169 & 260 & 372 & 10,3 & $11_{\overline{9}, 9}$ & 13,3 & $-5 ;, 0$ & $-2,9$ & $-1,-0$ \\
\hline Chamouchouane & 293 & 518 & 690 & 85 & 131 & 248 & 219 & 290 & 383 & 6,4 & 8,6 & $10_{\bar{y}=0}$ & $-11,4$ & $-8,7$ & $-5_{;=6}$ \\
\hline Chateauguay & 402 & 512 & 620 & 174 & 269 & $429 !$ & 137 & 193 & 252 & 12,4 & $13_{\overline{9}, 8} 8$ & $15 ; 2$ & $-3,8$ & $-1,1$ & $0 \overline{\bar{y}_{2}} 9$ \\
\hline Chaudière & 421 & 590 & 794 & 179 & 253 & $392 \vdots$ & 216 & 266 & 316 & 9,5 & 11,2 & 12,5 & $-5 ;, 4$ & $-3,3$ & $-1,5$ \\
\hline Du Loup & 423 & 547 & 643 & 154 & 233 & $480 \vdots$ & 178 & 224 & 247 & 8 & 10,2 & 11,5 & $-7,5$ & $-5, .3$ & $-3,0$ \\
\hline Gatineau & 324 & 519 & 671 & 86 & 145 & $242 !$ & : 224 & 290 & 350 & : 7,9 & 9.7 & 11,4 & $-8 ;=8$ & $-6,4$ & $-3,36$ \\
\hline Mistassini & 278 & 515 & 729 & 81 & 126 & $236 !$ & ; 224 & 300 & 384 & ; & $8, .2$ & $9 ; .7$ & $-12,0$ & $-9,2$ & $-6,1$ \\
\hline Rouge & 372 & 529 & 613 & 100 & 175 & 333 & 248 & 327 & 368 & 9 & $10 \bar{y} 8$ & $11 ; .9$ & $-6 ; .9$ & $-4, .4$ & $-2,-0$ \\
\hline Yamaska & 476 & 577 & 743 & 180 & 305 & $526 i$ & i 122 & 204 & 294 & $i 11 ; 6$ & $13_{,-1}$ & 14,55 & $-3 ; .9$ & $-1, .5$ & 0,6 \\
\hline
\end{tabular}

1014 
1015 Table 3: Summary (1982-2002) of the hydrological characteristics of the study watersheds

\begin{tabular}{|c|c|c|c|c|c|c|c|c|c|c|c|c|c|c|c|c|c|c|c|c|c|c|c|c|}
\hline & \multicolumn{6}{|c|}{$Q$ (mm/day) } & \multicolumn{6}{|c|}{ Qmax (m3/s) } & \multicolumn{6}{|c|}{$7 \mathrm{~d}-\mathrm{Qmin}(\mathrm{m} 3 / \mathrm{s})$} & \multicolumn{6}{|c|}{$30 \mathrm{~d}-Q \min (\mathrm{m} 3 / \mathrm{s})$} \\
\hline & \multicolumn{3}{|c|}{ Summer } & \multicolumn{3}{|c|}{ Winter } & \multicolumn{3}{|c|}{ Summer } & \multicolumn{3}{|c|}{ Winter } & \multicolumn{3}{|c|}{ Summer } & \multicolumn{2}{|c|}{ Winter } & \multicolumn{4}{|c|}{ Summer } & \multicolumn{3}{|c|}{\begin{tabular}{|l} 
Winter \\
\end{tabular}} \\
\hline & Min & Mean & Max & Min & Mean & $\operatorname{Max} i$ & I Min & Mean & Max & Min & Mean & Max & Min & Mean & Max & Min & Mean & $\operatorname{Max}$ & Min & Mean & Max & Min & Mean & $\operatorname{Max}$ \\
\hline Batiscan & 0.9 & 1.6 & 2.4 & 1,4 & 2,1 & 3,1 & 140 & 265 & 528 & 349 & 558 & 837 & 17 & 31 & 57 & 18 & 24 & 35 & 22 & 37 & 72 & 19 & 26 & 43 \\
\hline Bécancour & 0.6 & 1.1 & 1.9 & 1,5 & $2-1$ & 2,99 & 69 & 203 & 402 & 296 & 494 & 848 & 2 & 7 & 21 & 7 & 120 & 402 & 3 & 10 & 32 & 8 & 13 & 21 \\
\hline Chamouchouane & 1.1 & 1.8 & 2.6 & 1,2 & 1,5 & ${ }_{1,9} 9:$ & 404 & 781 & 1370 & 610 & 1350 & 2159 & 112 & 156 & 199 & 60 & 78 & 102 & '128 & 184 & 245 & 61 & 81 & 116 \\
\hline Chateauguay & 0.3 & 0.6 & 1.3 & 1,1 & 1,8 & $2,-6 \vdots$ & 27 & 168 & 623 & 193 & 460 & 1091 & 2 & 4 & 10 & 6 & 10 & 18 & 2 & 6 & 17 & 7 & 12 & 32 \\
\hline Chaudière & 0.5 & 1.1 & 2.1 & $1,-6$ & 2,2 & 3,0 & 236 & 646 & 1318 & 847 & 1339 & 2140 & 4 & 10 & 26 & 12 & 19 & 32 & 5 & 17 & 45 & 14 & 23 & 47 \\
\hline Du Loup & 0.3 & 0.8 & 1.3 & $1, ; 0$ & 1,6 & 2,33 & 12 & 29 & 79 & 55 & 84 & 130 & 1 & 2 & 6 & 3 & 4 & 5 & 1 & 3 & 7 & 3 & 4 & 6 \\
\hline Gatineau & 1.0 & 1.5 & 2.4 & $1_{\bar{y}, 1} 1$ & 1,7 & 2,5 & 202 & 425 & 1200 & 413 & 731 & 1500 & 19 & 38 & 56 & 20 & 32 & 46 & 21 & 50 & 92 & 22 & 34 & 48 \\
\hline Mistassini & 1.2 & 1.9 & 2.7 & 1,3 & $1, \ldots 7$ & $2,3 i$ & 314 & 595 & 959 & 604 & 1257 & 2050 & 58 & 92 & 129 & 27 & 39 & 67 & 70 & 119 & 159 & 28 & 41 & 76 \\
\hline Rouge & 0.8 & 1.2 & 1.7 & 1,3 & $2, \ldots$ & 2,9 & 118 & 243 & 376 & 381 & 588 & 914 & 11 & 27 & 45 & 24 & 36 & 50 & 6 & 32 & 61 & 25 & 39 & 59 \\
\hline Yamaska & 0.4 & 0.8 & 1.7 & $1, .2$ & 2,0 & $2,7 !$ & 44 & 142 & 239 & 182 & 320 & 559 & 11 & 1 & 3 & 2 & 4 & 7 & 11 & 2 & 6 & 2 & 6 & 13 \\
\hline
\end{tabular}


Table 4: HYDROTEL key parameters

\begin{tabular}{|c|c|c|}
\hline Type & Parameters & Units \\
\hline \multirow{8}{*}{$\begin{array}{l}\text { Snow } \\
\text { parameters }\end{array}$} & MFEF - Melt factor for evergreen forests* & $\mathrm{mm} / \mathrm{d} .{ }^{\circ} \mathrm{C}$ \\
\hline & MFDF - Melt factor for deciduous forests* & $\mathrm{mm} / \mathrm{d} .{ }^{\circ} \mathrm{C}$ \\
\hline & MFOA - Melt factor for open areas* & $\mathrm{mm} / \mathrm{d} .{ }^{\circ} \mathrm{C}$ \\
\hline & TEF - Threshold air temperature for melt in evergreen forests* & ${ }^{\circ} \mathrm{C}$ \\
\hline & TDF - Threshold air temperature for melt in deciduous forests* & ${ }^{\circ} \mathrm{C}$ \\
\hline & TOA - Threshold air temperature for melt in open areas* & ${ }^{\circ} \mathrm{C}$ \\
\hline & Melt rate at the snow-soil interface & $\mathrm{mm} / \mathrm{d}$ \\
\hline & Compaction coefficient & - \\
\hline \multirow{7}{*}{ Soil parameters } & PETF - Potential evapotranspiration multiplication factor* & - \\
\hline & z1- Depth of the lower boundary of soil layer \#1* & $\mathrm{m}$ \\
\hline & z2- Depth of the lower boundary of soil layer $\# 2 *$ & $\mathrm{~m}$ \\
\hline & z3- Depth of the lower boundary of soil layer \#3* & $\mathrm{m}$ \\
\hline & RC - Recession coefficient* & $\mathrm{m} / \mathrm{h}$ \\
\hline & Extinction coefficient & - \\
\hline & Maximum variation of soil moisture content & - \\
\hline \multirow{3}{*}{$\begin{array}{l}\text { Interpolation } \\
\text { coefficients }\end{array}$} & $\begin{array}{l}\text { TSL - Threshold air temperature for partitioning solid and liquid } \\
\text { precipitation* }\end{array}$ & ${ }^{\circ} \mathrm{C}$ \\
\hline & Precipitation vertical gradient & $\mathrm{mm} / 100 \mathrm{~m}$ \\
\hline & Temperature vertical gradient & ${ }^{\circ} \mathrm{C} / 100 \mathrm{~m}$ \\
\hline
\end{tabular}

1020 
1021 Table 5: Summary of the KGE and Nash-log values for the ten watersheds over the calibration and validation periods

\begin{tabular}{|c|c|c|c|c|c|c|c|c|c|c|c|c|}
\hline & \multicolumn{6}{|c|}{ Calibration } & \multicolumn{6}{|c|}{ Validation } \\
\hline & \multicolumn{3}{|c|}{ KGE } & \multicolumn{3}{|c|}{ Nash-log } & \multicolumn{3}{|c|}{ KGE } & \multicolumn{3}{|c|}{ Nash-log } \\
\hline & $\begin{array}{c}1 \text { st } \\
\text { decile }\end{array}$ & Median & $\begin{array}{c}\text { 9th } \\
\text { decile }\end{array}$ & $\begin{array}{c}1 \text { st } \\
\text { déeiledecile }\end{array}$ & Median & $\begin{array}{l}\text { 9th } \\
\text { decile }\end{array}$ & $\begin{array}{c}1 \text { st } \\
\text { déeiledecile }\end{array}$ & $e^{\text {Median }}$ & $\begin{array}{c}\text { 9th } \\
\text { decile }\end{array}$ & $\begin{array}{c}1 \text { st } \\
\text { déciledecile }\end{array}$ & $e^{\text {Median }}$ & $\begin{array}{c}\text { 9th } \\
\text { decile }\end{array}$ \\
\hline Batiscan & 0.946 & 0.946 & 0.947 & 0.894 & 0.896 & 0.897 & 0.799 & 0.805 & 0.810 & 0.670 & 0.674 & 0.694 \\
\hline Bécancour & 0.872 & 0.874 & 0.875 & 0.795 & 0.799 & 0.801 & 0.797 & 0.807 & 0.814 & 0.701 & 0.706 & 0.717 \\
\hline Chamouchouane & 0.947 & 0.947 & 0.947 & 0.907 & 0.907 & 0.907 & 0.823 & 0.826 & 0.829 & 0.632 & 0.637 & 0.641 \\
\hline Chateauguay & 0.859 & 0.860 & 0.860 & 0.767 & 0.768 & 0.768 & 0.763 & 0.767 & 0.775 & 0.692 & 0.695 & 0.699 \\
\hline Chaudière & 0.916 & 0.916 & 0.916 & 0.805 & 0.810 & 0.815 & 0.869 & 0.871 & 0.875 & 0.695 & 0.709 & 0.721 \\
\hline Du Loup & 0.944 & 0.945 & 0.945 & 0.842 & 0.842 & 0.842 & 0.792 & 0.796 & 0.802 & 0.700 & 0.703 & 0.704 \\
\hline Gatineau & 0.907 & 0.907 & 0.907 & 0.827 & 0.828 & 0.828 & 0.766 & 0.768 & 0.771 & 0.684 & 0.686 & 0.691 \\
\hline Mistassini & 0.955 & 0.955 & 0.956 & 0.904 & 0.905 & 0.905 & 0.873 & 0.875 & 0.876 & 0.646 & 0.652 & 0.660 \\
\hline Rouge & 0.947 & 0.947 & 0.947 & 0.887 & 0.887 & 0.887 & 0.876 & 0.878 & 0.880 & 0.700 & 0.702 & 0.704 \\
\hline Yamaska & 0.828 & 0.832 & 0.835 & 0.761 & 0.762 & 0.764 & 0.833 & 0.839 & 0.845 & 0.609 & 0.626 & 0.637 \\
\hline
\end{tabular}


1024 Table 6: Median of the KGE and Nash-log loss of performance (positive values) between the calibration and validation periods

\begin{tabular}{cc:c}
\hline & KGE & Nash-log \\
\hline Batiscan & $15 \%$ & $14 \%$ \\
Bécancour & $8 \%$ & $-8 \%$ \\
Chamouchouane & $13 \%$ & $20 \%$ \\
Chateauguay & $11 \%$ & $-14 \%$ \\
Chaudière & $5 \%$ & $-6 \%$ \\
Du Loup & $16 \%$ & $1 \%$ \\
Gatineau & $15 \%$ & $0 \%$ \\
Mistassini & $8 \%$ & $18 \%$ \\
Rouge & $7 \%$ & $9 \%$ \\
Yamaska & $-1 \%$ & $-6 \%$ \\
\hline
\end{tabular}


1027 Table 7: Dominant type of uncertainty for each study watershed for the five modelled hydrological variables

\begin{tabular}{|c|c|c|c|c|c|c|}
\hline & $\begin{array}{c}\text { Daily } \\
\text { Streamflows }\end{array}$ & $\begin{array}{l}\text { 7d-and 30d- } \\
\text { Qmin }\end{array}$ & Qmax & SWE & AET & GWC \\
\hline \multicolumn{7}{|l|}{ Batiscan } \\
\hline \multicolumn{7}{|c|}{ Bécancour } \\
\hline \multicolumn{7}{|c|}{ Chamouchouane } \\
\hline \multicolumn{7}{|c|}{ Châteauguay } \\
\hline \multicolumn{7}{|c|}{ Chaudière } \\
\hline \multicolumn{7}{|l|}{ Du Loup } \\
\hline \multicolumn{7}{|l|}{ Gatineau } \\
\hline \multicolumn{7}{|c|}{ Mistassini } \\
\hline \multicolumn{7}{|l|}{ Rouge } \\
\hline Yamaska & & 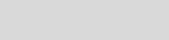 & & & & \\
\hline
\end{tabular}

OF uncertainty

Parameter uncertainty 


\section{Figures Captions}

1033

1034

1035

Figure 1: Location of the study watersheds in Québec, Canada, and around the St. Lawrence RiverFigure 1: Location of the study watersheds in Québec, Canada, and around the St. Lawrence River

Figure 2: Relationship between mean annual and seasonal temperatures and precipitations for the calibration and validation periods

Figure 3: Radar plots of the twelve parameters used in the automatic calibration of HYDROTEL for each study watershed. Parameter A is part of the interpolation coefficients, parameters B through $\mathrm{G}$ relate to the snow model, and parameters $\mathrm{F}$ through $\mathrm{L}$ relate to the soil group of parameters. The dark blue diagrams refer to the KGE OF while the light blue diagrams refer to the Nash-log OF.Figure 3: Radar plots of the twelve parameters used in the automatic calibration of HYDROTEL for each study watershed. Parameter $A$ is part of the interpolation coefficients, parameters $B$ through $G$ relate to the snow model, and parameters $F$ through $\mathrm{L}$ relate to the soil group of parameters. The dark blue diagrams refer to the KGE ebjective functionOF while the light blue diagrams refer to the Nash-log OF.

Figure 4: Distribution of the OF values for the Chamouchouane watershed: (a) KGE calibration period; (b) KGE validation period; (c) Nash-log calibration period; (d) Nash-log validation periodFigure 4: Distribution of the OF values for the Chamouchouane watershed: (a) KGE ealibration period; (b) KGE validation period; (c) Nash log ealibration period; (d) Nash-log validation period

Figure 5: Streamflow uncertainty envelopes for the Rouge watershed: (a) calibration (9-year mean) and (b) validation periods (8-year mean). The black and green envelopes stand for simulated flows under the KGE and Nash-log OFs, respectively, while the blue line depicts the observed values.Figure 5: Streamflow uncertainty envelopes for the Rouge watershed: (a) 
ealibration (9 year mean) and (b) validation periods (8 year mean). The black and green envelopes respectively stand for simulated flows under the KGE and Nash-log objective

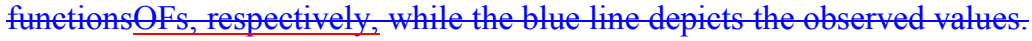

Figure 6: Boxplots of the seasonal hydrological indices for the Chamouchaoune watershed for the calibration (1) and validation (2) periods: (as1) and (as2) display the distribution of the maximum summer peakflows; (aw1) and (aw2) the distribution of maximum winter peakflows; (bs1) and (bs2) the distribution of summer-7-day minimum flows; and (bw1) and (bw2) the distribution of winter-7-day minimum flows. The black and green boxplots illustrate the distribution of simulated flows under the KGE and Nash-log OFs, respectively, while the blue dots depict the observed values. The superscripts $w$ and $d$ on the x-axis indicate the wettest and driest years of each simulation period, respectively.Figure 6: Boxplots of the seasonal hydrological indices for the Chamouchaoune watershed for the calibration (1) and validation (2) periods: (as1) and (asz) display the distribution of the maximum summer peakflows; (aw1) and (aw2) the distribution of maximum winter peakflows; (bs1) and (bs2) the distribution of summer-7-day minimum flows; and (bw1) and (bw2) the distribution of winter - day minimum flows. The black and green boxplots stand for illustrate the distribution of simulated flows under the KGE and Nash-log OFs, while the blue dots depict the observed values. The superscripts $w$ and $d$ on the $x$-axis indicate the wettest and driest years of each simulation period, respectively.

Figure 7: SWE uncertainty envelopes for the Yamaska watershed: (a) calibration (9-year mean) and (b) validation periods (8-year mean). The black and green envelopes illustrate the distribution of simulated flows under the KGE and Nash-log OFs.Figure 7: Snow water equivalent (SWE) uncertainty envelopes for the Yamaska watershed: (a) calibration (9-year mean) and (b) validation periods (8 year mean). The black and green envelopes stand 

forillustrate the distribution of simulated flows under the KGE and Nash-log objective functions $\mathrm{OFS}$. The line indicates the period of overlapping between the uncertainty envelopes.

Figure 8: Seasonal actual evapotranspiration for the Bécancour watershed: (a) summer calibration; (b) summer validation; (c) winter calibration and (d) winter validation. The black and green boxplots stand for simulated AET distributions under the KGE and Nash-log OFs, respectively. The outliers are represented by red crosses. The superscripts $w$ and $d$ on the xaxis stand for the wettest and driest years of each simulation period, respectively. Figure 8: Seasonal actual evapotranspiration for the Bécancour watershed: (a) summer calibration; (b) summer validation; (c) winter calibration and (d) winter validation. The black and green

Figure 9: Shallow groundwater content uncertainty envelopes for the Du Loup watershed: (a) calibration (9-year mean) and (b) validation periods (8-year mean). The black and green envelopes illustrate the distribution of simulated flows under the KGE and Nash-log OFs, respectively.Figure 9: Shallow groundwater content uncertainty envelopes for the Du Loup watershed: (a) calibration (9year mean) and (b) validation periods (8 year mean). The black and green envelopes stand forillustrate the distribution of simulated flows under the KGE and Nash-log objective functions $\underline{\underline{O F} \text {, }}$, respectively.

Figure 10: Radar plots of the twelve parameters used in the automatic calibration of HYDROTEL for each study watershed. Parameter A is part of the interpolation coefficients, parameters $\mathrm{B}$ through $\mathrm{G}$ relate to the snow model, and parameters $\mathrm{F}$ through $\mathrm{L}$ relate to the soil group of parameters. Figure (a) refers to the KGE OF; and (b) to the Nash-log OF. The dark and light blue data refer to the first optimization trial of Figure 3, black data to the second optimization trial.Figure 10: Radar plots of the twelve parameters used in the 
1105 automatic calibration of HYDROTEL for each study watershed. Parameter $A$ is part of the

1106 interpolation coefficients, parameters $B$ through $G$ relate to the snow model, and parameters $F$ through $\mathrm{L}$ relate to the soil group of parameters. Figure (a) refers to the KGE objective functionOF; and (b) to the Nash-log objective function@F. The dark and light blue data refer to the first optimization trial of Figure 3, black data to the second optimization trial.

1110

1111

1112 


\title{
EQUIFINALITY AND AUTOMATIC CALIBRATION, WHAT IS THE IMPACT OF HYPOTHESIZING AN OPTIMAL PARAMETER SET ON MODELLED HYDROLOGICAL PROCESSES?
}

\author{
Étienne Foulon $^{1 *}$, Alain N. Rousseau ${ }^{1}$ \\ 1 INRS-ETE/Institut National de la Recherche Scientifique-Eau Terre Environnement, 490 \\ rue de la Couronne, Québec City, G1K 9A9, Québec, Canada \\ *Corresponding author: etiennefoulon59@gmail.com, 418-271-2687
}

Keywords :calibration, equifinality, hydrological model, HYDROTEL, objective function, parameter uncertainty 


\section{Abstract}

2 Accepting the concept of equifinality may result in larger uncertainty associated with model

3 predictions than that of the optimal parameter set paradigm. Despite the existence of

4 uncertainty characterization methods, the semi-distributed hydrological model HYDROTEL

5 has been used within the latter paradigm. What is the impact of hypothesizing an optimal

6 parameter set? This paper focuses on the assesment of the impact of equifinality of calibration

7 parameters with respect to modelled hydrological variables and indices, namely: (i) daily

8 flows; (ii) seasonal seven- and thirty-day low flows; and maximum flow; (iii) snow water

9 equivalent (SWE); (iv) shallow ground water variations; and (v) actual evapotranspiration.

10 This assessment is presented for ten southern Québec watersheds of the St. Lawrence River.

11 The watershed models were calibrated and validated for 1982-1991 and 1991-2002,

12 respectively. Automatic calibration was performed using the Dynamically Dimensioned

13 Search (DDS) algorithm based on the maximization of two objective functions (OFs): (i) the

14 Kling-Gupta efficiency and (ii) the Nash-log. DDS was executed to calibrate 12 hydrological

15 parameters for one optimization trial for each watershed and each OF with a budget of 5000

16 model runs. To analyse parameter uncertainty and resulting equifinality, 250 sets of

17 parameters were extracted from each trial run. Calibration performances for both OFs were

18 between 0.75 and 0.95 , while the selected 250 best sets of parameters had OF values differing

19 by less than $1 \%$. Results showed that the overall OF uncertainty was larger than the parameter

20 uncertainty for all modelled processes except the SWE. Nevertheless, seasonal results

21 suggested parameter uncertainty could be greater than OF uncertainty for specific seasons or

22 years, although it was not possible to make a general outcome stand out. In particular for

23 impact studies where the variables of interest are not daily flows but rather hydrological

24 indices or variables, parameter uncertainty will need to be accounted for. 


\section{Résumé}

26

27

Accepter l'existence du concept d'équifinalité c'est reconnaître l'incertitude liée à l'existence d'une famille de solutions donnant des résultats de qualité similaire obtenus avec la même fonction objectif. Malgré l'existence de méthodes de caractérisations de cette incertitude, le modèle hydrologique HYDROTEL a été principalement utilisé jusqu'à maintenant selon le paradigme du calage optimal unique sans évaluer a posteriori les conséquences de ce choix. Cette étude propose d'évaluer l'impact du choix du jeu de paramètres optimisés sur certaines variables et indicateurs hydrologiques simulés, à savoir: (i) les débits journaliers; (ii) les débits d'étiage à 7 et 30 jours et les débits maximum; (iii) l'équivalent en eau de la neige (EEN), (iv) les variations du contenu en eau du sol peu profond et (v) l'évapotranspiration réelle. Dans ce contexte, HYDROTEL est mis en place sur dix bassins versant du Québec méridional entre 1982 et 2002. Pour chacune des fonctions objectif (FO) (Kling Gupta efficiency et Nash-log) et chacun des bassins, l'algorithme Dynamically Dimensioned Search (DDS) dispose d'un budget de 5000 répétitions pour optimiser les 12 paramètres de calage d'HYDROTEL sur 1981-1991. Ainsi, 250 jeux de paramètres sont conservés pour évaluer l'incertitude paramétrique et l'équifinalité résultante. Les résultats de calage indiquent des fonctions objectif comprises entre 0,75 et 0,95 , tandis que pour chaque modèle les 250 meilleures répétitions présentent des fonctions objectif égales à $1 \%$ près. Globalement, pour tous les processus simulés excepté pour l'EEN, l'incertitude relative aux FO était plus importante que celle relative aux jeux de paramètres. Cependant, les résultats saisonniers suggèrent que l'incertitude paramétrique peut dépasser celle due aux FO dans certaines conditions particulières. Elle devra donc être prise en compte, en particulier pour les études d'impacts et de risque hydrologique dont les variables d'intérêt sont principalement des indicateurs hydrologiques simulés et non pas les débits journaliers. 


\section{Introduction}

51 The equifinality concept refers to the existence of many parameter sets (and multiple model

52 structures) associated with the same 'optimal' measure of efficiency (Beven 2006a; Beven and Freer 2001). Within a realistic parameter space, for a given mechanistic model of a complex environmental system, many local optima may exist. Despite the computational costs, equifinality has been revealed for many types of models and especially for rainfallrunoff models (Beven 1993; Beven and Binley 1992; Duan et al. 1992; Fu et al. 2015; Futter et al. 2015; Li et al. 2012; Linhoss et al. 2013; Prada et al. 2016; Romanowicz et al. 1994; Zeng et al. 2016; Zhang et al. 2012).

The main consequence of accepting the concept of equifinality is that the uncertainty associated with model predictions might be larger than that assessed within the optimal parameter set paradigm. Different types of approaches allow to deal with such an uncertainty (Vrugt et al. 2009a). Some approaches have their roots within a formal statistical (Bayesian) framework, but require in-depth understanding of mathematics and statistcs as well as experience in implementing (Fisher and Beven 1996; Freer et al. 1996) these methods on computers (Vrugt et al. 2009b). This probably explains the success of the generalized likelihood uncertainty estimation (GLUE) method of (Beven and Binley 1992). It operates within the context of Monte Carlo analysis coupled with Bayesian or fuzzy estimation and propagation of uncertainty. It is relativley easy to implement and requires no modifications to existing codes of simulation models. More recently, Tolson and Shoemaker (2007) presented how the dynamically dimensioned search (DDS) optimization algorithm coud replace random sampling in typical applications of GLUE. They also introduced a more efficent uncertainty analysis methodology called DDS-approximation of uncertainty (DDS-AU) that differs from the automatic calibration and uncertainty assessment using response surfaces (ACUARS) 
methods (Mugunthan and Shoemaker 2006). The former approach requires many optimisation trials while the latter approach uses only one trial coupled with a declustering technique.

The idea of an optimal parameter set remains strong in environmental sciences and even stronger in hydrological modelling. For a physcically-based, semi-distributed, model such as HYDROTEL (Bouda et al. 2014; Bouda et al. 2012; Fortin et al. 2001b; Turcotte et al. 2007a; Turcotte et al. 2003), this frame of mind is rooted in two perceptions: (i) multiple feasible descriptions of reality lead to ambiguity and are possibly viewed as a failure of the modelling exercice (Beven 2006a); and (ii) a manual search for an "optimum" is already computationally expensive (Turcotte et al. 2003) while an automatic search may provide only a slight increase in model efficiency in comparison with the latter manual calibration (Bouda et al. 2014). This is why in the last decade, at the risk of avoiding important issues of model acceptability and uncertainty (Beven 2006a), HYDROTEL has almost always been applied within the optimal parameter set paradigm.

For example, in several studies (Aissia et al. 2012; Fortin et al. 2001a; Fossey and Rousseau 2016a, 2016b; Fossey et al. 2015; Fossey et al. 2016; Khalili et al. 2011; Minville et al. 2009; Oreiller et al.; Quilbé et al. 2008; Rousseau et al. 2013), HYDROTEL has been manually calibrated following the four-step, trial-and-error, process-oriented, multiple-objective calibration strategy introduced by Turcotte et al. (2003). It has also been calibrated using the shuffled complex evolution algorithm (SCE-UA) designed by Duan et al. (1993) to find the optimal set of parameters while avoiding local optima (Bouda et al. 2014; Gaborit et al. 2015; Ludwig et al. 2009; Ricard et al. 2013; Trudel et al. 2016). But two exceptions emerge from the litterature, Bouda et al. (2012); Poulin et al. (2011) both used the SCE-UA algorithm to generate multiple parameter sets and assesed the uncertainty of hydrological modelling under the equifinality assumption. Poulin et al. (2011), based on one snow-dominated watershed, concluded that model uncertainty (conceptual models versus more physicaly-based models for 
99

100

101

102

103

104

105

106

107

108

109

110

111

112

113

114

115

116

117

118

121

122

123

example) can be more significant than parameter uncertainty. Meanwhile, Bouda et al. (2012), from their work on two watersheds, stressed the need for further research that may lead to the implementation of a systematic uncertainty analysis in an operational hydrological forecasting system. Nevertheless, they both highlighted the need for additonal validation of their results on additional watersheds.

It is important to mention that the technico-philosiphical debate started in 2006 (Beven 2006b, 2008) about the methods that should or should not be used to estimate the uncertainties associated with hydrological forecasting is beyond the scope of this paper. Indeed, the debate is still ongoing about the relative performances of formal (DREAM) and informal (GLUE) Bayesian approaches in estimating the consequences of equifinality (Beven 2009; Vrugt et al. $2009 \mathrm{~b}, 2009 \mathrm{c})$ and about the multiple sources of uncertainty and non-stationarity in the analysis and modelling of hydrological systems (Beven 2016; Nearing et al. 2016). In this paper, equifinality is simply explored through the implementation of the automatic calibration algorithm DDS (Tolson and Shoemaker 2007), which has been reported as being superior to SCE-UA (Arsenault et al. 2014; Yen et al. 2016). Our contribution builds on the work carried out on hydrological uncertainty to show in practical terms why equifinality does need to be taken into account by answering one simple question taken out of the technico-philosiphical debate: what are the consequences of not accounting for equifinality while calibrating HYDROTEL for an environmental impact study? Here, hydrological uncertainty (defined by the spread resulting from multiple calibrations) is assessed for five modelled hydrological variables and indices: (i) daily flows, (ii) seasonal hydrological indices such as the seven-day low flow (7d-Qmin), 30-day low flow (30d-Qmin), and the maximum flow (Qmax), (iii) snow water equivalent (SWE), (iv) shallow ground water content variations (GWC) and (v) actual evapotranspiration (AET). Innovation resides in three elements. A calibration strategy close to that of manual calibration was used in order to demonstrate the need to account for 
124 equifinality in impact assessment studies aside from the technico-philosophical debate started 125 in 2006. Moreover, using 10 watersheds across Québec avoided limiting the significance of 126 the results to a specific region. Last, the relative importance of OF uncertainty and parameter 127 uncertainty were differentiated according to the variable being considered and its temporal 128 scale (yearly or seasonal).

129 The next two sections of this paper introduce the modelled watersheds and the methods, the 130 results and ensuing discussions. Throughout the paper, readers should keep in mind that the 131 results do not aim at assessing the formal statistical uncertainty associated with the 132 hydrological processes, but rather at showing the concrete consequences of equifinality on 133 modelled hydrological processes 


\section{Study area and data}

135 This study was carried out in southern Québec (Canada) on ten watersheds spread out in five

136 hydrographic regions of the St. Lawrence River (Figure 1). These ten watersheds, namely (i)

137 Batiscan, (ii) Bécancour, (iii) Chamouchouane, (iv) Châteauguay, (v) Chaudière, (vi) Du

138 Loup, (vii) Gatineau, (viii) Mistassini, (ix) Rouge, and (x) Yamaska have modelled drainage

139 areas ranging from 855 up to $15,042 \mathrm{~km}^{2}$ and various land cover patterns. Table 1 indicates all

140 watersheds, but Yamaska, have a forested (evergreen + deciduous trees) area covering more

141 than $90 \%$ of the modelled land cover. Yamaska is the only watershed with a significant

142 portion of urban area. Batiscan has over $40 \%$ of evergreen while Gatineau, Chaudière, Rouge

143 and Du Loup have 17, 21.5, 25.6 and 28.4\% of evergreen, respectively, and the remaining

144 five watersheds have an evergreen area representing less than $10 \%$ of their total land cover. It

145 is also noteworthy that Châteauguay, Bécancour and Chaudière have 17.0, 8.2 and 3.9\% of

146 cropland while the remaining seven watersheds have less than $1 \%$.

147 According to available meteorological data (1981-2002, 1995 and 1996 being unavailable)

148 from National Resources Canada, the region surrounding the St. Lawrence River delineated in

149 Figure 1 is characterized by a mean annual temperature of $1.8^{\circ} \mathrm{C}$ and mean annual total

150 precipitation of $940 \mathrm{~mm}$. All watersheds are snow-dominated with peak flow occurring in

151 spring. A summary of the hydroclimatic characteristics of the watersheds is provided in Table

1522 and Table 3 for two hydrological seasons, that is summer (June 1 st to November $30^{\text {th }}$ ) and

153 winter (December $1^{\text {st }}$ to May $31^{\text {st }}$ ). While the mean summer rainfall is $545 \mathrm{~mm}$ and quite

154 homogenous among the watersheds (standard deviation of $30 \mathrm{~mm}$ ), mean winter rainfall is

155 more heterogeneous with a mean of $208 \mathrm{~mm}$ and a standard deviation of $64 \mathrm{~mm}$. Meanwhile,

156 mean snowfall is $271 \mathrm{~mm}$ with a standard deviation of $52 \mathrm{~mm}$. Mean summer $\left(10.8^{\circ} \mathrm{C}\right)$ and

157 winter $\left(-4.8^{\circ} \mathrm{C}\right)$ temperatures are also quite variable with respective standard deviations of 1.8

158 and $2.8{ }^{\circ} \mathrm{C}$. This shows that in terms of climate characteristics, the studied watersheds are 
159 quite heterogeneous. In terms of hydrological characteristics, mean summer and winter daily

160 flows are 1.2 and $1.9 \mathrm{~mm}$, respectively, with standard deviations of 0.44 and 0.23 . Winter

161 flows are higher than summer flows on average because winter includes the snow melt and

162 thus the spring peak flows. Higher variability in the summer flows is attributed to summer

163 rainfall and convective storms that are more variable than snowfalls. The hydrological indices

164 mean values indicate that the watersheds, despite being somewhat located along the St.

165 Lawrence River, have heterogeneous characteristics with mean 7d-Qmin ranging from 2 up to

$166156 \mathrm{~m}^{3} \mathrm{~s}^{-1}$ and from 4 to $120 \mathrm{~m}^{3} \mathrm{~s}^{-1}$ for summer and winter, respectively. Heterogeneity is even

167 higher for mean Qmax; ranging from 29 up to $595 \mathrm{~m}^{3} \mathrm{~s}^{-1}$ and from 84 to $1350 \mathrm{~m}^{3} \mathrm{~s}^{-1}$ for

168 summer and winter, respectively.

169 < Table 1: Land cover of the ten studied watersheds in southern Québec, Canada >

170 Figure 1: Location of the study watersheds in Québec, Canada, and around the St.

171 Lawrence River

172 < Table 2: Summary (1982-2002) of the climate characteristics of the study watersheds>

173 < Table 3: Summary (1982-2002) of the hydrological characteristics of the study

174 watersheds> 


\section{Material and Methods}

176 Hydrological model

177 HYDROTEL is a process-based, continuous, semi-distributed hydrological model (Bouda $e t$ al. 2014; Bouda et al. 2012; Fortin et al. 2001b; Turcotte et al. 2007a; Turcotte et al. 2003) that is currently used for inflow forecasting by Hydro-Quebec, Quebec's major power utility, and the Quebec Hydrological Expertise Centre (CEHQ) which is in charge of the management and safety of publicly owned dams (Turcotte et al. 2004). It was designed to use available remote sensing and GIS data and use either a 3-hour or a daily time step. It is based on the spatial segmentation of a watershed into relatively homogeneous hydrological units (RHHUs, elementary subwatersheds or hillslopes as desired) and interconnected river segments (RSs) draining the aforementioned units. A semi-automatic, GIS-based framework called PHYSITEL (Noël et al. 2014; Rousseau et al. 2011; Turcotte et al. 2001) allows easy watershed segmentation and parameterization of the hydrological objects (RHHUs and RSs). The model is composed of seven computational modules, which run in successive steps. Each module simulates a specific process (meteorological data interpolation, snowpack dynamics,

190 soil temperature and freezing depth, potential evapotranspiration, vertical water budget,

191 overland water routing, channel routing). Readers are referred to Fortin et al. (2001b) and

192 Turcotte et al. (2007a) for more details on these aspects of HYDROTEL.

193 The main parameters of HYDROTEL can be subdivided into three groups (see Table 4). The

194 first group includes the snow parameters and the second group includes the soil parameters.

195 The last three individual parameters are related to the interpolations of temperature and 196 precipitation according to the average of the three nearest meteorological stations weighed in 197 by the square of the inverse distances between the RHHU and the three stations (a.k.a. the 198 Reciprocal-Distance-Squared method). 
<Table 4: HYDROTEL key parameters>

\section{Data acquisition}

201 Observed climate data for $1981-2002$ were computed on a $0.75^{\circ}$ x $0.75^{\circ}$ grid by isotropic

202 kriging following the method described in Poirier et al. (2012) using the meteorological data

203 provided by National Resources Canada. Each grid-point served as a meteorological station in

204 HYDROTEL. Flow data were extracted from the CEHQ data base; which operates around 205230 hydrometric stations (CEHQ, 2012). Stations were selected for their data availability and 206 proximity to the outlets of the watersheds. For Batiscan (\#050304 [-72.4 ${ }^{\circ}$ long, $46.6^{\circ}$ lat]), 207 Bécancour (\#024007 [-72.3 long., 46.2 ${ }^{\circ}$ lat.]), Châteauguay (\#030905 [-73.8 long., 45.3 208 lat.]) and Rouge (\#040204 [-74.7 long., $45.7^{\circ}$ lat.]), stations were located at the outlet of each 209 watershed while for Chamouchouane (\#061901 $\left[-72.5^{\circ}\right.$ long., $48.7^{\circ}$ lat.]), Chaudière 210 (\#023402 [-71.2 ${ }^{\circ}$ long., $46.6^{\circ}$ lat.]), Du Loup (\#052805 [-73.2 long., 46.6 ${ }^{\circ}$ lat.]), Gatineau

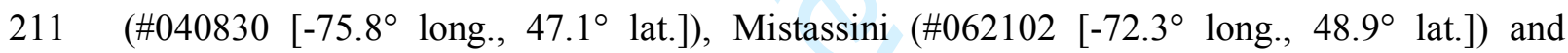

212 Yamaska (\#030304 [-72.9 long., 45.5 lat.]), the nearest stations were selected (see Figure 1).

\section{Calibration/validation and parameter sets generation}

214 Model calibration on each watershed was carried out using a global optimization algorithm,

215 DDS presented in Tolson and Shoemaker (2007). It allows systematic and impartial 216 calibration of HYDROTEL through all the watersheds using a fixed methodology. The 217 shuffled complex evolution (SCE) algorithm (Duan et al. 1992; Duan et al. 1994; Duan et al. 218 1993) was also considered; viewed as the dominant optimization algorithm before 2007 with 219 more than 300 different applications referring to the original set of SCE papers. However, it 220 has since been proved that DDS is better suited for distributed watershed models requiring 221 extensive computational time (Arsenault et al. 2014; Tolson and Shoemaker 2007; Yen et al. 222 2016). DDS performs a low number of model evaluations before converging to a good 223 calibration solution. According to Yen et al. (2016), DDS outperforms other optimization 
224 techniques in both convergence speed and searching ability for parameter sets that satisfy

225 statistical guidelines while requiring only one algorithm parameter (perturbation factor,

226 default value 0.2 ) in the optimization process. This default value was used in this paper.

227 Automatic calibration was performed based on the maximization of four objective functions

228 (OFs) computed from observed flow data: (i) Kling-Gupta efficiency (KGE); (ii) Nash-log;

229 that is the Nash-Sutcliffe efficiency (NSE) calculated on log transformed flows; (iii) $\mathrm{NSE}_{\mathrm{Q}}$

230 and (iv) $\mathrm{NSE}_{\sqrt{\mathrm{Q}}}$ computed on root squared flows. DDS was executed for one optimization trial

231 for each watershed and each OF with a budget of 5000 model runs - the trial was initiated

232 from the same random set of parameter values for every watershed. To analyse parameter

233 uncertainty and resulting equifinality, the 250 sets of parameters resulting in the best $\mathrm{OF}$

234 values were extracted from each trial run. Then each model was run over a validation period

235 using the corresponding 250 sets of parameters (10 models times 4 OFs). However, this paper

236 solely focused on two of the four OFs studied namely KGE and Nash-log because including

237 the two other functions would not help distinguishing the dominant type of uncertainty.

238 Indeed, overall results for NSE are close to KGE results except around peak flows (Gupta et

239 al., 2009) while $\mathrm{NSE}_{\sqrt{\mathrm{Q}}}$ represents a tradeoff between KGE and Nash-log. Using the

240 combination of KGE and Nash-log provides a contrasted calibration procedure that in turn

241 favors high flows and low flows.

$242 K G E=1-\sqrt{(r-1)^{2}+(\alpha-1)^{2}+(\beta-1)^{2}}$

\section{Eq 1}

243 where $r$ is the linear correlation coefficient between simulated and observed values; $\alpha$ is a

244 measure of relative variability in the simulated and observed values, that is the ratio between

245 simulated and observed standard deviations; and $\beta$ stands for the bias, that is the ratio between

246 the mean simulated and mean observed flows. 
248 where $\alpha_{\log }$ and $r_{\log }$ are the linear correlation coefficient and measure of relative variability

249 between the $\log$ transformed simulated and observed flows, respectively; and $\beta_{\log \mathrm{n}}$ stands for

250 the ratio between the bias of log transformed simulated and observed flows, normalized by

251 the standard deviation of observed values.

252 The calibration period extended from December $1^{\text {st }}, 1982$ to November $30^{\text {th }}, 1991$; that is nine 253 entire hydrological years. The validation period started on December $1^{\text {st }}, 1991$ and ended on 254 November $30^{\text {th }}, 2002$ (remembering that the $1995-1996$ meteorological data series were 255 unavailable); that is eight complete hydrological years (hydrological years 1994 - December $2561^{\text {st }}, 1994$ to November $30^{\text {th }}, 1995$, and 1995 -December $1^{\text {st }}, 1995$ to November $30^{\text {th }}, 1996$ 257 were unavailable), corresponding to nine summers and eight winters (January to the end of 258 May 1997 is used as a spin-up to make sure that the model is on the right track). In each case, 259 a 1-year spin-up period was used to minimize initialization errors. During the 1995-1996 260 meteorological data gap, the model was fed with data from 1993-1994 to prevent the rivers 261 from drying out. These simulation periods (calibration and validation) followed the split262 sample strategy applied to the available meteorological and hydrological data. The length of 263 the calibration period was not so long as to increase computational costs too much, but not so 264 short as to have issues related to the interannual variability of climate data compared with the 265 validation period. Figure 2 illustrates the appropriateness of this approach in terms of mean 266 annual and seasonal temperatures and precipitations. For the calibration and validation, the 267 simulation periods were relatively similar: precipitations and temperatures are within [614, $268911 \mathrm{~mm}]$ and $\left[-1,+6^{\circ} \mathrm{C}\right]$, and $[646,845 \mathrm{~mm}]$ and $\left[-0.2,6.4^{\circ} \mathrm{C}\right]$, respectively.

269 Out of the eighteen (18) key calibration parameters (Table 4), twelve (12) were actually 270 adjusted in this study: six (6) snow parameters; five (5) soil parameters; and one (1) 271 interpolation coefficient. Sensitivity analyses were not formally carried out for any of the 
272 watersheds beforehand, but these calibrated parameters are amongst the model most sensitive 273 parameters (Turcotte et al. 2003). This selection of parameters was based on: (i) information 274 provided by previous analyses (Ben Nasr 2014; Bouda et al. 2014), (ii) knowledge built 275 through the operational use of HYDROTEL (Turcotte et al. 2004) and (iii) experience gained 276 during the development of a Hydroclimatic Atlas conveying the potential impact of climate 277 change on water resources for the 2050 horizon over Southern Québec (CEHQ 2013, 2015). 278 The remaining parameters were fixed according to: (i) a regionalization study (Turcotte et al. 279 2007b), (ii) results from the application of a global calibration strategy (Ricard et al. 2013) 280 used in CEHQ (2013, 2015), and (iii) from previous manual calibration exercises.

281 Figure 2: Relationship between mean annual and seasonal temperatures and 282 precipitations for the calibration and validation periods 


\section{Results}

285 As previously mentioned model uncertainty related to parameters used for the calibration of 286 HYDROTEL and to the choice of the OF was assessed through five modelled hydrological 287 variables and indices: (i) modelled streamflows, (ii) hydrological indices computed from the 288 latter, and three internal variables, namely (iii) snow water equivalent (SWE), (iv) actual 289 evapotranspiration (AET) and (v) shallow ground water content variations (GWC). In this 290 paper, parameter equifinality refers to the range that each calibration parameter covers within 291 the predefined physical limits attributed to each parameter. Meanwhile parameter uncertainty 292 refers to the consequences of parameter equifinality with respect to the model outputs.

293 Finally, OF uncertainty refers to the effects of using two different functions on the model 294 outputs. For each subsection, a different watershed is used as a showcase while the other nine 295 and their related figures are referred to as alternate watersheds and available as supplemental 296 information upon request to the corresponding author. This choice was made to focus on the 297 global picture conveyed by this paper instead of focusing on the characteristics of a single 298 watershed.

\section{Parameter equifinality}

300 Figure 3 shows the range covered by the 250 sets of parameters used in setting up the 20 301 models in HYDROTEL. The figure was computed by putting together for each model a radar 302 plot of the calibration parameter values. For every set of parameters, a line was drawn to link 303 every individual parameter. The computation of the 250 lines made it possible to picture the 304 range covered by the selected sets of parameters within a predefined physical interval that 305 limits the automatic calibration algorithm. These limits were based on the information 306 provided by previous sensitivity analyses, operational experience, and previous calibration 307 exercises. 
308 For most watershed models, the parameter equifinality is limited. Indeed, parameter

309 equifinality for the Batiscan watershed, for the KGE OF, covers a maximum of $9.2 \%$ of the

310 physical range for the deciduous melting threshold parameter ( $\mathrm{C}$ in Figure 3), but about 5\%

311 for the rain/snow limit (A in Figure 3) for example. The maximum parameter equifinality is

312 obtained for the evergreen melting threshold on the Yamaska watershed for the KGE OF with

313 an equifinality covering $45.6 \%$ of the physical range. Overall, the "most equifinal parameters"

314 are the evergreen melting rate (B in Figure 3 ) and threshold (E in Figure 3).

315 Figure 3: Radar plots of the twelve parameters used in the automatic calibration of

316 HYDROTEL for each study watershed. Parameter $A$ is part of the interpolation

317 coefficients, parameters B through $G$ relate to the snow model, and parameters $F$

318 through $\mathbf{L}$ relate to the soil group of parameters. The dark blue diagrams refer to the

319 KGE OF while the light blue diagrams refer to the Nash-log OF.

320 Streamflows

321 A tangible evidence of the equifinality of the 20 models is displayed by the narrow ranges of

322 OF values resulting from the 250 calibrations and validations. This was expected despite the

323 careful consideration given to the number of calibration parameters used to avoid over

324 parametrization and limit the possibility of equifinality. Figure 4 shows the KGE and Nash-

$325 \log$ values obtained in calibration and validation for the Chamouchouane watershed. KGE as

326 well as Nash-log calibration values belong to equally narrow ranges [0.9464, 0.9472] and

$327[0.9064,0.9072]$. For the validation period, ranges are larger, but still quite narrow with $100 \%$

328 and $68 \%$ of KGE and Nash-log values fitting in the equally narrow ranges [0.8225, 0.8305$]$

329 and [0.6340, 0.6420], respectively. Model performances are not as good in validation as in

330 calibration. But as Table 6 shows, differences in performances overpass a $15 \%$ difference

331 only three times out of the 20 models. Moreover, the validation period performances either

332 increase or as decrease in comparison with calibration values, and that vouches for the split- 
333 sample strategy chosen. Indeed, Table 6 introduces the median loss of performances

334 computed from the individual losses of each of the 250 calibrations/validations which are 335 different from what could be computed from Table 5.

336 Table 5 shows that results of Figure 4 are also valid for the alternate watersheds included in 337 this paper. Indeed, for the calibration period, both KGE and Nash-log values can be 338 constrained in a 0.01 interval while, for the validation period, they are within a 0.15 interval. 339 What is notable is that ranges seem larger for the Nash-log than for the KGE OFs. Also, the 340 performances in calibration using the Nash-log OF are lower; whereby the mean of the KGE 341 values is 0.916 , the mean of the Nash-log values is 0.840 . For validation, this gap widens with 342 a mean KGE of 0.823 and a mean Nash-log of 0.679 . This important difference may be 343 attributed to the relative inability of Nash-log to represent high flows. Indeed, high flows are 344 less correctly reproduced by Nash-log when low flows are assessed using the KGE OF. This 345 explains the observed difference in performances.

346 The simulated streamflow envelopes shown in Figure 5 clearly illustrate parameter 347 uncertainty with respect to the Rouge watershed. The hydrographs were computed according 348 to the following steps: (i) for every 250 simulated flow series, mean values were generated for 349 each day of the year, over the calibration ( 9 hydrological years) and validation periods (8 350 hydrological years); (ii) then for each model and simulation period, daily minimum and 351 maximum values were taken from the entire set of mean series and plotted in order to obtain 352 streamflow envelopes. As depicted in Figure 5 which introduces the individual streamflow 353 uncertainty envelopes for the alternate watersheds, the impact of parameter uncertainty is:

354 - small (most of the time under $0.1 \mathrm{~mm} /$ day) for both simulation periods and OFs,

355 - concentrated around the spring peak flow for the Nash-log OF (reaching a maximum 356 of $1 \mathrm{~mm} /$ day). 
357 The OF uncertainty is shown by the global envelope that encompasses individual bands

358 associated with the KGE and Nash-log series of modelled streamflows. Figure 5 and alternate

359 figures show that OF uncertainty is more important than parameter uncertainty most of the

360 year (except during the recession of the spring peak flow where the envelopes overlap).

361 Moreover, the spread of the global envelope for the ten watersheds reveals that OF

362 uncertainty is generally more pronounced in the fall and the spring peak flows.

363 Figure 4: Distribution of the OF values for the Chamouchouane watershed: (a) KGE

364 calibration period; (b) KGE validation period; (c) Nash-log calibration period; (d) Nash-

$365 \log$ validation period

366 <Table 5: Summary of the KGE and Nash-log values for the ten watersheds over the

367 calibration and validation periods $>$

368 <Table 6: Median of the KGE and Nash-log loss of performance (positive values)

369 between the calibration and validation periods>

370 Figure 5: Streamflow uncertainty envelopes for the Rouge watershed: (a) calibration (9-

371 year mean) and (b) validation periods (8-year mean). The black and green envelopes

372 stand for simulated flows under the KGE and Nash-log OFs, respectively, while the blue

373 line depicts the observed values. 


\section{Hydrological indices}

376 Figure 6 introduces, for the Chamouchouane watershed the boxplots of the seasonal 377 hydrological indices for each OF. The two boxplots per year represent the parameter 378 uncertainty (250 sets of parameter) for the KGE and Nash-log OFs for each hydrological 379 index. The reunion of the two boxplots represent the OF uncertainty. Results do not show the 380 30d-Qmin distributions as they are quite similar to the 7d-Qmin distributions, their median 381 being just slightly greater and their interquartile range being similar.

382 Figure 6 shows that the impact of parameter uncertainty is rather small during both simulation 383 periods (calibration and validation). Indeed for both OFs and both simulation periods, 384 differences between the $1^{\text {st }}$ and $3^{\text {rd }}$ quartiles remain under $5 \%$ of the hydrological indices 385 values. Parameter uncertainty is more important for winter Nash-log hydrological indices than 386 for KGE values, whereas they are comparable for summer indices. The impact of OF 387 uncertainty is for all hydrological indices, for almost every year, and for both simulation 388 periods the impact is more important than that of the parameter uncertainty. It is especially the 389 case for winter 7d-Qmin and 30d-Qmin where the uncertainty is at least five (5) times larger 390 than the parameter uncertainty. This also applies to winter Qmax where it is at least twice as 391 much important. The main findings characterizing almost all watersheds are the following:

- quite stable across years and simulation periods,

- smaller in summer than in winter especially for Qmax,

- similar for both OFs, both seasons and all hydrological indices (besides a few exceptions related to the performance of the calibration).

397 - OF uncertainty is:

- rather stable across years for every individual seasonal hydrological index, 
- more important than parameter uncertainty across the years, simulation periods, and seasons,

o larger in winter than in summer and more important for 7d-Qmin and 30dQmin.

Figure 6: Boxplots of the seasonal hydrological indices for the Chamouchaoune watershed for the calibration (1) and validation (2) periods: (as1) and (as2) display the distribution of the maximum summer peakflows; (aw1) and (aw2) the distribution of maximum winter peakflows; (bs1) and (bs2) the distribution of summer-7-day minimum flows; and (bw1) and (bw2) the distribution of winter-7-day minimum flows. The black and green boxplots illustrate the distribution of simulated flows under the KGE and Nash-log OFs, respectively, while the blue dots depict the observed values. The superscripts $w$ and $d$ on the $x$-axis indicate the wettest and driest years of each simulation period, respectively.

\section{Snow water equivalent}

413 Figure 7 shows the SWE uncertainty envelopes for the Yamaska watershed for the calibration

414 and validation periods as well as the two OFs. The envelopes were computed using the same 415 method as that used for the streamflows, except that since HYDROTEL is a semi-distributed 416 model, mean areal values over the RHHUs were first computed to produce a single data series 417 for each calibrated parameter set and each simulation period.

418 Figure 7 shows that parameter uncertainty relative to SWE is less important at the beginning 419 and the end of the snow season while being at a maximum at the peak where the envelopes 420 are the widest. OF uncertainty for SWE, contrary to that for streamflows, is less important 421 than parameter uncertainty as the individual envelopes overlap almost the entire snow season.

422 Parameter uncertainty is more important for the Nash-log OF than for the KGE OF. However, 
423 these observations cannot be generalized when examining in details the results for the

424 alternate watersheds. Nonetheless, the overall results can be separated into six groups:

425 (i) For Yamaska and Chateauguay, parameter uncertainty is larger than the OF 426 uncertainty for the whole year with individual envelopes being wider at the beginning of February and at the end of March. SWE is higher for the Nash-log OF than for the KGE OF.

(ii) For Chamouchouane and Mistassini, parameter uncertainty is larger than the $\mathrm{OF}$ uncertainty for the whole year with individual envelopes overlapping the entire year.

(iii) For Gatineau, parameter uncertainty is larger than the OF uncertainty from November to the end of February. OF uncertainty then becomes larger than parameter uncertainty with individual envelopes not overlapping anymore. Individual envelopes are quite narrow throughout the year and KGE simulated SWE is slightly more important than the Nash-log simulated values.

(iv) For Batiscan, results are similar to those of group (iii); differing only with respect to the fact that individual envelopes become slightly wider indicating a more important parameter uncertainty

(v) For Du Loup and Rouge, results indicate a larger OF uncertainty for the whole year with narrow individual envelopes not overlapping. KGE simulated SWE values are more important than Nash-log values with a maximum difference of 50 $\mathrm{mm}$ at peak values.

(vi) For Bécancour and Chaudière, results are similar to those of group (v) differing only with respect to the fact that individual envelopes become wider, indicating that parameter uncertainty is larger. 
447 Figure 7: SWE uncertainty envelopes for the Yamaska watershed: (a) calibration (9448 year mean) and (b) validation periods (8-year mean). The black and green envelopes 449 illustrate the distribution of simulated flows under the KGE and Nash-log OFs. The line 450 indicates the period of overlapping between the uncertainty envelopes.

451 


\section{Actual evapotranspiration}

453 Figure 8 depicts the seasonal AET for the Bécancour watershed obtained for both simulation

454 periods and OFs. They were computed as the sum of AET over each hydrological year and 455 season after applying the same methodology as that for the areal SWE in getting a single data 456 series. Parameter uncertainty can be assessed through the amplitude of each boxplot while OF 457 uncertainty is assessed through the combination of the KGE boxplots (black) and Nash-log 458 boxplots (green).

Figure 8 shows that parameter uncertainty for the summer season covers around $5 \%$ of the AET values for both simulation periods and OFs; but for winter goes as far as $50 \%$. For summer, OF uncertainty is less significant than parameter uncertainty for many years as illustrated by the overlapping of the individual boxplots (1981, 1983, 1985, 1986, 1987, 1988, 1992, 1994, 1998, 2000 and 2002). Nevertheless, OF uncertainty is more important than parameter uncertainty for all years but for winter 1990. Also, it is noteworthy that parameter uncertainty is less variable across years during summer than winter; indeed boxplots have the same width. Last, Nash-log parameter uncertainty is comparable or larger than summer KGE

467 parameter uncertainty whereas it is the opposite for winter. However, these observations 468 cannot be generalized when examining in details the results of the other watersheds (alternate 469 watersheds). Nonetheless, the overall results can be separated into six groups:

(i) For Batiscan, Châteauguay, Du Loup and Yamaska, both types of uncertainty are constant across simulation periods, years and seasons. OF uncertainty remains around $5 \%$ and does not go beyond $10 \%$ of the simulated AET values and is more important than parameter uncertainty, while parameter uncertainty is similar for both OFs.

(ii) For Rouge, results are similar to those of group (i) differing only with respect to OF uncertainty being larger, around $10 \%$, for both seasons of the simulation periods and all years. 
477

478

479

480

481

482

483

484

485

486

487

488

489

490

491

492

493

494

495

496

497

(iii)For Gatineau and Mistassini, results are similar to those of group (ii) but have a larger parameter uncertainty for Nash-log simulated values than for KGE values. This behavior is more pronounced in summer than in winter, and more so for Mistassini than for Gatineau.

(iv)For Chaudière, results are similar to those of group (ii) but have an OF uncertainty that flirts with $20 \%$.

(v) For Chamouchouane, results are similar to those of group (i) because of the constant $\mathrm{OF}$ and parameter uncertainties. The difference is that $\mathrm{OF}$ uncertainty is nonexistent as individual boxplots overlap for all seasons, years and simulation periods. Parameter uncertainty related to the Nash-log OF is more important than that of KGE simulated values

(vi)For Bécancour, results were described in the previous paragraph and are different from the other groups as they display variability across years and seasons that other watersheds do not show.

The only result, apart from the relative consistency across the years highlighted in group (vi), that stands across all watersheds, but Bécancour in summer and Yamaska is that simulated AET values are higher for all years and all seasons under the Nash-log OF. This is not a surprising result as it pertains to the nature of the OF with respect to the water balance. That is, if a smaller percentage of precipitations gets discharged through rivers (Nash-log vs KGE), another way to balance the equation for HYDROTEL is to increase water output through evapotranspiration. 
Figure 8: Seasonal actual evapotranspiration for the Bécancour watershed: (a) summer calibration; (b) summer validation; (c) winter calibration and (d) winter validation. The black and green boxplots stand for simulated AET distributions under the KGE and Nash-log OFs, respectively. The outliers are represented by red crosses. The superscripts $w$ and $d$ on the $x$-axis stand for the wettest and driest years of each simulation period, respectively.

\section{Shallow groundwater variations}

Figure 9 shows the envelopes of areal GWC variations for the calibration and validation periods as well as the two OFs for the Du Loup watershed. The envelopes were computed using the same method as that used for the areal SWE.

Figure 9 shows that parameter uncertainty is small and constant for both OFs throughout the whole year with a maximum uncertainty under $2 \mathrm{~mm}$. On the contrary, OF uncertainty is

510 substantial for the whole year (20 to $40 \mathrm{~mm}$ for the calibration period, 10 to $20 \mathrm{~mm}$ for the 511 validation period), but between January and March. For this latter period, the shallow ground

512 water reserves are at their lowest point and individual envelopes overlap during the

513 calibration period or are close to overlapping during the validation period. However, these

514 observations do not hold when examining in details the results for the alternate watersheds.

515 Nonetheless, the overall results can be separated into six groups:

516 (i) For Rouge and Mistassini, the GWC variation patterns are similar to those of $\mathrm{Du}$

517 Loup. Maximum reserves are reached in early May after the snow has melted; they

518 continuously decrease until early September where they reach their minimum to 519 increase until the end of the fall season in early December. Finally, they decrease 520 again to a near minimum value around early March at the onset of melt season. OF and parameter uncertainties were described in the previous paragraph. 
(ii) For Batiscan, results show similar GWC variation patterns to those of group (i).

The difference lies in the parameter uncertainty that covers most the $\mathrm{OF}$ uncertainty, but still remains under $10 \mathrm{~mm}$. Indeed, for the calibration period, OF uncertainty is less important than parameter uncertainty from November until the end of September. For the validation period, the overlapping is reduced from December until the end of May. Still, even in the remaining months, OF uncertainty is less important than that of group (i); incidentally not getting larger than $20 \mathrm{~mm}$.

(iii) For Chamouchouane and Gatineau, results show similar GWC variation patterns to those of groups (i) and (ii), but behave almost at the opposite of group (i) with respect to $\mathrm{OF}$ and parameter uncertainties. OF uncertainty is non-existent for the whole year, but for a few days around peak value. Parameter uncertainty is small (less than $2 \mathrm{~mm}$ ) and individual envelopes overlap.

(iv) For Bécancour, results show similar GWC variation patterns to those of group (i) apart from the decrease during the snow season that is less pronounced. Parameter uncertainty is more important for both OFs as that of group (i); it represents a maximum of $10 \mathrm{~mm}$ for both OFs in the calibration period, but around $5 \mathrm{~mm}$ and close to $10 \mathrm{~mm}$ respectively for Nash-log and KGE simulated GWC. OF uncertainty as a result is still more significant than parameter uncertainty despite a lag between the OFs that make the individual envelopes overlap around peakflow values.

(v) For Chaudière, results show similar GWC variation patterns to those of Bécancour (group (iv)) but is clearly different from any other watershed with respect to the OF and parameter uncertainties. The Nash-log parameter uncertainty covers almost all KGE values and has 40 and $20 \mathrm{~mm}$ wide intervals, respectively, for the 
calibration and validation periods. The KGE parameter uncertainty is less than 2 $\mathrm{mm}$ for the whole year which results in a non-existent $\mathrm{OF}$ uncertainty for the calibration period while still being significant between August and December for the validation period.

(vi) For Chateauguay and Yamaska, the GWC variation patterns differ from those of groups (i) to (v). The GWC is at a minimum around the end of August. The and Nash-log OFs, respectively. decreasing only slightly, as opposed to groups (i) and (ii), during the snow season and attaining their maximum values after the snow has melted. Parameter uncertainty is small, under 2 and $5 \mathrm{~mm}$ for KGE and Nash-log simulated GWC, respectively, and relatively constant across the year. OF uncertainty is more important (maximum of 20 and $30 \mathrm{~mm}$ for calibration and validation, respectively) for the whole year, but just after peak value (May and June) for the calibration period and around peak value (April) for the validation period

It is noteworthy that the two variation patterns relative to GWC, highlighted in the above groups, reflect the geographical location of the watersheds. Indeed, Bécancour, Châteauguay, Chaudière and Yamaska are located on the south shore of the St. Lawrence River, while Batiscan, Chamouchouane, Du Loup, Gatineau, Mistassini and Rouge are located on the north shore.

Figure 9: Shallow groundwater content uncertainty envelopes for the Du Loup watershed: (a) calibration (9-year mean) and (b) validation periods (8-year mean). The black and green envelopes illustrate the distribution of simulated flows under the KGE 


\section{Discussion}

\section{Automatic calibration with DDS}

573 In the Material and Methods section, it is mentioned that DDS is better suited than SCE-UA 574 (Duan et al. 1992; Duan et al. 1994; Duan et al. 1993) for distributed watershed models 575 requiring extensive computational time and, thus, leading to a low number of model 576 evaluations before converging to a good solution (Arsenault et al. 2014; Tolson and 577 Shoemaker 2007; Yen et al. 2016). This is mostly due to DDS dynamically adjusting the 578 neighborhood of the best solution by changing the dimension of the search (Tolson and 579 Shoemaker 2007). In other terms, DDS mimics manual calibrations of watershed models as 580 follows: (i) early in the calibration exercise, a number of model parameters are modified to 581 overcome relatively poor solutions, and (ii) later, to avoid losing the current gain in objective 582 function values, parameters are modified one at a time. To avoid introducing a bias in the 583 search algorithm, this paper used a random initial solution, but used the same random solution

584 for every watershed in order to keep the experiments consistent.

585 The stochastic nature of DDS means that multiple optimization trials initialized with different 586 initial solutions can terminate at different final solutions (Tolson and Shoemaker 2008). To be 587 consistent with the framework described in the introduction, that is a majority of the 588 HYDROTEL application studies involved manual calibration, we decided to work with only 589 one optimization trial and a budget of 5000 model runs to answer the research question with 590 respect to equifinality given this framework. Besides, the radar plots of parameter equifinality

591 shown in Figure 3 do not seem to behave in a pattern related to the geographical location, the 592 climate, or geological characteristics of each watershed. Indeed, the study watersheds are part 593 of three different geological provinces (Ministère des Ressources naturelles Direction 594 générale de Géologie Québec 2012): (i) the Greenville Province made of allochtonous 595 material north of the St. Lawrence River; (ii) the St. Lawrence platform around the River; and 
596 (iii) the Appalachian province made of Humber material south of the River. They also belong

597 to three climate classes defined by Litynski (1988) but mostly to class 14 that stands for

598 moderate temperature, subhumid precipitations and long growing season. As a consequence,

599 parameter regionalization is not obvious. This was pointed out as well by Ricard et al. (2013)

600 who showed that a global calibration strategy over southern Québec was preferable although

601 in some cases the performances of watershed calibration using HYDROTEL was reduced

602 when compared to local calibrations.

\section{OF uncertainty}

604 Overall, results for all the studied hydrological processes suggest that OF uncertainty is more 605 important than parameter uncertainty. In other words, OF uncertainty is seen when the largest 606 of the individual envelopes or boxplots relative to each objective function (KGE and Nash$607 \log$ ) is smaller than the reunion of either envelopes or boxplots. Readers should note that 608 results obtained for the $\mathrm{NSE}_{\mathrm{Q}}$ and $\mathrm{NSE} \sqrt{\mathrm{Q}}$ OFs are in complete agreement with the previous 609 statement. Figure 5 and alternate figures do not clearly show the impact of OF uncertainty 610 because individual envelopes often overlap. However, when considering the seasonal 611 hydrological indices (Figure 6 and alternate figures), the SWE (Figure 7 and alternate 612 figures), the AET (Figure 8 and alternate figures), and the GWC (Figure 9 and alternate 613 figures), OF uncertainty is overall clearly highlighted.

614 Some studies highlight the importance of model structure uncertainty over parameter 615 equifinality (Futter et al. 2015; Mockler et al. 2016; Poulin et al. 2011; Shoaib et al. 2016). 616 Poulin et al. (2011) used HYDROTEL and HSAMI to assess the effects of model structure 617 and parameter equifinality on the uncertainty related to hydrological modelling. Their study 618 revealed that the impact of hydrological model structure was more significant than the effect 619 of parameter uncertainty (assessed through 68 sets of parameters). Yet, the uncertainty 620 attributed to model structure with respect to streamflows and SWE were of the same order of 
621 magnitude than the OF uncertainty assessed in this paper. This would mandate the 622 combination of both studies to clearly assess whether the impact of model structure and OF 623 uncertainty are equivalent or complementary in assessing the consequences of considering the 624 effects of equifinality on modelled hydrological processes.

625

626

Figure 6 and alternate figures showed the boxplots of the seasonal hydrological indices for both OFs (Results section). They also indicated observed values as blue dots; less than $50 \%$ of the latter are not included within the interval of the simulated values for any of the hydrological indices (Qmax, 7d-Qmin, and 30d-Qmin). This could be seen as a calibration performance issue, but results suggest otherwise. Indeed, all observed values and all, but one, are included within the interval of the simulated values for the summer $7 \mathrm{~d}-\mathrm{Qmin}$ for the Châteauguay and Yamaska, respectively; which have the lowest performances for both OFs (refer to Table 5). This would rather suggest that KGE and Nash-log OFs are not able to force the model to represent the hydrological indices properly. This may be related to the nature of both OFs that are computed over daily data versus hydrological indices computed over a period of time (seven and 30 days for 7d-Qmin as well as 30d-Qmin,respectively). However, for Qmax, this is simply related to the misrepresentation of maximum flows. This result is rather important as hydrological indices are often used in impact assessment studies. This would mandate the use of specific OFs related to low or high flows or even the use of multiobjective functions.

\section{Parameter uncertainty}

Despite the fact that the OF uncertainty is overall more important than the consequences of parameter equifinality, parameter uncertainty relative to SWE (Results section) is generally more important than OF uncertainty. Indeed it is more important for the whole year for Châteauguay, Chamouchouane, Mistassini and Yamaska and, for a few months (November until the end of February), for Gatineau and Batiscan. Seasonal results also suggest that 
646 parameter uncertainty can be important or more significant even than OF uncertainty for 647 specific seasons or years (Figure 6, Figure 8 and alternate figures). To get a better 648 understanding of the reasons why parameter uncertainty would prevail only for a few years, 649 driest and wettest years were defined as the hydrological years with the least total amount of 650 precipitation for the simulation periods (indicated on the x-axis of seasonal hydrological 651 indices and AET figures as $d$ and $w$ ). The effects of driest and wettest years were assessed in 652 terms of prevalence of any of the two types of uncertainties and magnitudes of uncertainties 653 on both types of years, but also on the following year. Nothing particular stood out that could 654 be construed as a general result that could have given insights about the evolution of the 655 prevalence of the two types of uncertainties in the following years. To get this type of insight, 656 we would probably need to perform calibrations under different sets of contrasting conditions 657 (dry versus wet years). This refers to parameter identifiability as researched by Wilby (2005) 658 on snowless watersheds, or to the application of testing schemes such as those performed by 659 Seiller et al. (2012) and inspired by Kleme ̌̌ (1986).

\section{Parameter equifinality}

661 Ben Nasr (2014) as well as Bouda et al. (2014) pointed out in sensitivity analyses carried out

662 for two snow-dominated watersheds in southern Québec (Beaurivage and Montmorency 663 modelled using HYDROTEL), that the depth of the lower boundary of the three soil layers 664 (z1, z2, z3), the potential evapotranspiration multiplying factor (PETF), and the recession 665 coefficient (RC) were consistently amongst the most sensitive parameters (refer to Table 4). In both studies, sensitivity was assessed from an initial optimal solution and parameter values

667 were modified ( $\pm 25 \%$ ), but variations of $\pm 6.25 \%$ already gave substantial flow modifications.

668 These results are within the same order of magnitude as the equifinality measured through the 669 proposed methodology and explain why some parameters in Figure 2 are more equifinal than 670 others. Typically, parameters that were identified by Ben Nasr (2014) and Bouda et al. (2014) 
671 as the most sensitive parameters are less equifinal than others. This result is not surprising as

672 it pertains to the following statement: the more sensitive a parameter, the least uncertain it can

673 be around a global optimum for the OF to remain optimum.

674 The choice to work with 5000 model runs ensured that the OF values remained within a 0.01

675 interval (refer to Table 5) for 250 sets of parameters that captured parameter equifinality.

676 Neither did working with 500 sets of parameters provide a larger parameter equifinality, nor

677 did working with 100 sets of parameters provide the complete parameter equifinality. This is

678 important as Poulin et al. (2011) reported that parameter uncertainty increases with increasing

679 numbers of calibration parameters and/or calibrations. This allows us to go beyond their

680 research in making sure that our conclusions cannot be disputed with respect to the impact

681 that parameter equifinality has on global or individual uncertainty envelopes.

682 To make sure that working with one optimization trial did not impair the possibility of

683 capturing the equifinality of the parameters, the smallest watershed model in terms of

684 modelled area (to minimize computational time) with the smallest parameter equifinality was

685 calibrated for another 5000-simulation-optimization trial started at a different initial random

686 solution. As shown in Figure 10, this demonstrates that parameter equifinality can be

687 increased if the calibration methodology is modified. Nonetheless, the covered part of the

688 physical range does not come close to the maximum equifinality obtained for the Yamaska

689 watershed in Figure 3. Thus, it can be assumed that the results introduced in this paper would

690 not be drastically modified by a change in the calibration methodology. Plus it would

691 contradict the choice made not to conduct a formal uncertainty analysis as this methodology

692 of using two or more optimization trials would get closer to the DDS-AU methodology

693 introduced by Tolson and Shoemaker (2008). 
694 Figure 10: Radar plots of the twelve parameters used in the automatic calibration of 695 HYDROTEL for each study watershed. Parameter A is part of the interpolation 696 coefficients, parameters $B$ through $G$ relate to the snow model, and parameters $F$ 697 through $\mathrm{L}$ relate to the soil group of parameters. Figure (a) refers to the KGE OF; and 698 (b) to the Nash-log OF. The dark and light blue data refer to the first optimization trial 699 of Figure 3, black data to the second optimization trial.

700 To summarize, it could be said that this paper shows the consequences of the existence of 701 many good sets of parameters on modelled hydrological processes around a global optimum 702 rather than properly evaluating their formal statistical uncertainty. If that were the aim, the 703 methodology would have entailed working with one optimization trial per set of parameters 704 which would have resulted in a total of 125000 simulations (250 sets of parameters * 500 705 simulations) since DDS typically needs 500 simulations to find a good global solution 706 (compared to 10,000 for SCE-UA). Note that the computing time for a 10 -year calibration 707 period (with a prior 1-year spin-up), one optimization trial of 5000 simulations already took 708 an average 45 hours (on a 64-bit computer with a quad-core $2.53 \mathrm{GHz}$ processor) for each 709 watershed and every OF, resulting in a total calibration time of 900 hours or 37.5 days (45 710 hours * 10 watersheds * 2 OFs) for the results presented in this paper (excluding the two OFs 711 that were left out of this paper). 


\section{Conclusion}

714 In the last decade, HYDROTEL has almost always been applied within the optimal parameter

715 set paradigm at the risk of avoiding important issues such as model acceptability and

716 uncertainty (Beven 2006a). This paper builds on the work carried out on hydrological

717 uncertainty by assesing the impact of equifinality and OF related uncertainty on five modelled

718 hydrological variables and indices: (i) daily flows; (ii) seasonal hydrological indices (7d-

719 Qmin, 30d-Qmin, and Qmax); (iii) snow water equivalent (SWE); (iv) shallow ground water

720 content variations (GWC); and (v) actual evapotranspiration (AET). This assessment was

721 carried out for ten watersheds spread out in five hydrographic regions of the St. Lawrence

722 River and spread across southern Québec (Canada).

723 Overall, as introduced in Table 7, the results for all the studied hydrological processes, but the

724 SWE, suggest that OF uncertainty is more important than that arising from parameter

725 equifinality. This would mean that within the context of a study with a limited budget, it

726 would be advisable to prioritize using different objective functions to using many sets of

727 optimal parameters. This result is rather important as it reinforces the choice made in the last

728 decade with HYDROTEL. Nonetheless, parameter uncertainty with respect to SWE is more

729 important than OF uncertainty for eight of the ten studied watersheds for four up to seven

730 months of the year (snow season less than 7-month long). Plus, despite satisfactory

731 performances for both simulation periods, parameter uncertainty with respect to streamflows

732 is rather small during the whole year, except around spring peak flow; while OF uncertainty is

733 generally more pronounced in the fall and during the spring peak flows. Overall, this shows

734 that one type of uncertainty or the other is rather significant during half of the year. Seasonal

735 results with respect to hydrological indices and AET also suggest that parameter uncertainty

736 can be important, or more significant even, than OF uncertainty for specific seasons or years.

737 These results are of the utmost importance for impact assessment studies where the variables 
738 of interest are not solely the daily flow data used for calibration, but rather hydrological

739 indices or internal variables. This would mean that parameter uncertainty does need to be

740 taken into account or at least needs to be further researched to better understand the

741 mechanisms behind the phenomena. This study demonstrates, using a substantial set of

742 watersheds; that aside from the technico-philosiphical debate started in 2006, equifinality is

743 not so technical to take into account and has tangible significant effect on the uncertainties

744 associated with modeled hydrological processes. As such, we recommend that future work

745 systematically include equifinality by using at least two sets of equifinal parameters without

746 forgetting to assess OF uncertainty.

747 It is noteworthy that the methodology applied in this paper for the HYDROTEL model can be 748 replicated for other hydrological models. Uncertainty associated with OFs and parameter

749 equifinality still needs to be better understood and studied. To improve our understanding of

750 HYDROTEL, and other physically based hydrological models, future work should focus on

751 identifying or using OFs tailored for hydrological indices relevant to impact assessment

752 studies. Finally, for a specific assessment, there is a need to consider as well the question of

753 the uncertainty associated with model structure.

754 < Table 7: Dominant type of uncertainty for each study watershed for the five modelled 755 hydrological variables> 


\section{Acknowledgements}

758 The authors would like to thank Marco Braun of Ouranos (Consortium on Regional

759 Climatology and Adaptation to Climate Change, Montreal, Qc, Canada), for his scientific

760 support as well as giving us access to the meteorological data, the Quebec Hydrological

761 Expertise Centre (CEHQ) for allowing us to use parts of their modelling platform, but

762 especially Simon Lachance Cloutier for his technical support, and Sébastien Tremblay of

763 INRS (Centre Eau Terre Environnement) for his computer support throughout the project.

764 Financial support for this project was provided by the Natural Sciences and Engineering

765 Research Council (NSERC) of Canada through the Discovery Grant Program (A.N.

766 Rousseau, principal investigator). 


\section{References}

769

770

771

772

773

774

775

776

777

778

779

780

781

782

783

784

785

786

787

788

789

790

791

792

793

794

795

796

797

798

799

800

801

802

803

804

805

Aissia, M. A. B., F. Chebana, T. B. M. J. Ouarda, L. Roy, G. Desrochers, I. Chartier, and É Robichaud. 2012. Multivariate analysis of flood characteristics in a climate change context of the watershed of the Baskatong reservoir, Province of Québec, Canada. Hydrological Processes 26 (1):130-142.

Arsenault, R., A. Poulin, P. Côté, and F. Brissette. 2014. Comparison of stochastic optimization algorithms in hydrological model calibration. Journal of Hydrologic Engineering 19 (7):1374-1384.

Ben Nasr, Imène. 2014. Incertitudes sur les débits simulés par le modèle HYDROTEL attribuables aux incertitudes sur les paramèetres. Application au bassin de la rivière Beaurivage, Québec, Canada, Institut National de la recherche scientifique, Centre Eau terre environnement, Québec, QC 94 pp.

Beven, K. 1993. Prophecy, reality and uncertainty in distributed hydrological modelling. Advances in Water Resources 16 (1):41-51.

Beven, K. 2006a. A manifesto for the equifinality thesis. Journal of Hydrology 320 (1-2):1836.

Beven, K. 2006b. On undermining the science? Hydrological Processes 20 (14):3141-3146.

Beven, K. 2008. On doing better hydrological science. Hydrological Processes 22 (17):35493553.

Beven, K. 2016. Facets of uncertainty: Epistemic uncertainty, non-stationarity, likelihood, hypothesis testing, and communication. Hydrological Sciences Journal 61 (9):16521665.

Beven, K., and A. Binley. 1992. The future of distributed models: Model calibration and uncertainty prediction. Hydrological Processes 6 (3):279-298.

Beven, K., and J. Freer. 2001. Equifinality, data assimilation, and uncertainty estimation in mechanistic modelling of complex environmental systems using the GLUE methodology. Journal of Hydrology 249 (1-4):11-29.

Beven, K. J. 2009. Comment on "Equifinality of formal (DREAM) and informal (GLUE) Bayesian approaches in hydrologic modeling?" by Jasper A. Vrugt, Cajo J. F. ter Braak, Hoshin V. Gupta and Bruce A. Robinson. Stochastic Environmental Research and Risk Assessment 23 (7):1059-1060.

Bouda, M., A. N. Rousseau, S. J. Gumiere, P. Gagnon, B. Konan, and R. Moussa. 2014. Implementation of an automatic calibration procedure for HYDROTEL based on prior OAT sensitivity and complementary identifiability analysis. Hydrological Processes 28 (12):3947-3961.

Bouda, M., A.N. Rousseau, B. Konan, P. Gagnon, and S.J. Gumiere. 2012. Case study: Bayesian uncertainty analysis of the distributed hydrological model HYDROTEL. Journal of Hydrologic Engineering 17 (9):1021-1032. 
806 CEHQ. 2012. Niveau d'eau et débit. http://www.cehq.gouv.qc.ca/hydrometrie/index.htm 807 (accessed September 2017).

808 CEHQ. 2013. Atlas hydroclimatique du Québec méridional - Impact des changements

809

810

811

812

813

814

815

816

817

818

819

820

821

822

823

824

825

826

827

828

829

830

831

832

833

834

835

836

837

838

839

840

841

842

843

844 climatiques sur les régimes de crue, d'étiage et d'hydraulicité à l'horizon 2050. Québec, $21 \mathrm{pp}$.

CEHQ. 2015. Hydroclimatic Atlas of Southern Québec. The Impact of Climate Change on High, Low and Mean Flow Regimes for the 2050 horizon. Québec, 81 pp.

Duan, Q., S. Sorooshian, and V. Gupta. 1992. Effective and efficient global optimization for conceptual rainfall-runoff models. Water Resources Research 28 (4):1015-1031.

Duan, Q., S. Sorooshian, and V. K. Gupta. 1994. Optimal use of the SCE-UA global optimization method for calibrating watershed models. Journal of Hydrology 158 (34):265-284.

Duan, Q. Y., V. K. Gupta, and S. Sorooshian. 1993. Shuffled complex evolution approach for effective and efficient global minimization. Journal of Optimization Theory and Applications 76 (3):501-521.

Fisher, J., and K. J. Beven. 1996. Modelling of stream flow at Slapton Wood using topmodel within an uncertainty estimation framework. Field Studies 8 (4):577-584.

Fortin, J.-P., R. Turcotte, S. Massicotte, R. Moussa, and J. Fitzback. 2001a. A distributed watershed model compatible with remote sensing and GIS data. Part 2: Application to the Chaudière watershed. Journal of Hydrologic Engineering 6 (2):100-108.

Fortin, J.-P., R. Turcotte, S. Massicotte, R. Moussa, J. Fitzback, and J.-P. Villeneuve. 2001b. A distributed watershed model compatible with remote sensing and GIS data. Part I: Description of the model. Journal of Hydrologic Engineering 6 (2):91-99.

Fossey, M., and A. N. Rousseau. 2016a. Assessing the long-term hydrological services provided by wetlands under changing climate conditions: A case study approach of a Canadian watershed. Journal of Hydrology 541, Part B:1287-1302.

Fossey, M., and A. N. Rousseau. 2016b. Can isolated and riparian wetlands mitigate the impact of climate change on watershed hydrology? A case study approach. Journal of Environmental Management 184, Part 2:327-339.

Fossey, M., A. N. Rousseau, F. Bensalma, S. Savary, and A. Royer. 2015. Integrating isolated and riparian wetland modules in the PHYSITEL/HYDROTEL modelling platform: Model performance and diagnosis. Hydrological Processes 29 (22):4683-4702.

Fossey, M., A. N. Rousseau, and S. Savary. 2016. Assessment of the impact of spatiotemporal attributes of wetlands on stream flows using a hydrological modelling framework: A theoretical case study of a watershed under temperate climatic conditions. Hydrological Processes 30 (11):1768-1781.

Freer, J., K. Beven, and B. Ambroise. 1996. Bayesian estimation of uncertainty in runoff prediction and the value of data: An application of the GLUE approach. Water Resources Research 32 (7):2161-2173. 
845

846

847

848

849

850

851

852

853

854

855

856

857

858

859

860

861

862

863

864

865

866

867

868

869

870

871

872

873

874

875

876

877

878

879

880

881

882

883

Fu, C., A. L. James, and H. Yao. 2015. Investigations of uncertainty in SWAT hydrologic simulations: A case study of a Canadian Shield catchment. Hydrological Processes 29 (18):4000-4017.

Futter, M. N., P. G. Whitehead, S. Sarkar, H. Rodda, and J. Crossman. 2015. Rainfall runoff modelling of the Upper Ganga and Brahmaputra basins using PERSiST. Environmental Sciences: Processes and Impacts 17 (6):1070-1081.

Gaborit, É, S. Ricard, S. Lachance-Cloutier, F. Anctil, and R. Turcotte. 2015. Comparing global and local calibration schemes from a differential split-sample test perspective. Canadian Journal of Earth Sciences 52 (11):990-999.

Gupta, H. V., H. Kling, K. K. Yilmaz, and G. F. Martinez (2009), Decomposition of the mean squared error and NSE performance criteria: Implications for improving hydrological modelling, Journal of Hydrology, 377(1-2), 80-91. doi: 10.1016/j.jhydrol.2009.08.003.

Khalili, M., F. Brissette, and R. Leconte. 2011. Effectiveness of Multi-Site Weather Generator for Hydrological Modeling. Journal of the American Water Resources Association 47 (2):303-314.

Kleme ̌́, V. 1986. Operational testing of hydrological simulation models. Hydrological Sciences Journal 31 (1):13-24.

Li, C. Z., L. Zhang, H. Wang, Y. Q. Zhang, F. L. Yu, and D. H. Yan. 2012. The transferability of hydrological models under nonstationary climatic conditions. Hydrology and Earth System Sciences 16 (4):1239-1254.

Linhoss, A., R. Muñoz-Carpena, G. Kiker, and D. Hughes. 2013. Hydrologic modeling, uncertainty, and sensitivity in the okavango basin: Insights for scenario assessment. Journal of Hydrologic Engineering 18 (12):1767-1778.

Litynski, J. 1988. Climat du Québec d'après la classification numérique.

Ludwig, R., I. May, R. Turcotte, L. Vescovi, M. Braun, J. F. Cyr, L. G. Fortin, D. Chaumont, S. Biner, I. Chartier, D. Caya, and W. Mauser. 2009. The role of hydrological model complexity and uncertainty in climate change impact assessment. Advances in Geosciences 21:63-71.

Ministère des Ressources naturelles Direction générale de Géologie Québec. 2012. Map of the main Geological Subdivisions of Québec.

Minville, M., F. Brissette, S. Krau, and R. Leconte. 2009. Adaptation to climate change in the management of a Canadian water-resources system exploited for hydropower. Water Resources Management 23 (14):2965-2986.

Mockler, E. M., K. P. Chun, G. Sapriza-Azuri, M. Bruen, and H. S. Wheater. 2016. Assessing the relative importance of parameter and forcing uncertainty and their interactions in conceptual hydrological model simulations. Advances in Water Resources 97:299-313.

Moriasi, D.N., J.G. Arnold, M.W. VanLiew, R.L. Bingner, R.D. Harmel, and T.L. Veith. 2007. Model evaluation guidelines for systematic quantification of accuracy in watershed simulations. Transactions of the ASABE 50 (3):885-900. 
884

885

886

887

888

889

890

891

892

893

894

895

896

897

898

899

900

901

902

903

904

905

906

907

908

909

910

911

912

913

914

915

916

917

918

919

920

921

922

923

Mugunthan, P., and C. A. Shoemaker. 2006. Assessing the impacts of parameter uncertainty for computationally expensive groundwater models. Water Resources Research 42 (10).

Nearing, G. S., Y. Tian, H. V. Gupta, M. P. Clark, K. W. Harrison, and S. V. Weijs. 2016. A philosophical basis for hydrological uncertainty. Hydrological Sciences Journal 61 (9):1666-1678.

Noël, P., A. N. Rousseau, C. Paniconi, and D. F. Nadeau. 2014. An algorithm for delineating and extracting hillslopes and hillslope width functions from gridded elevation data. Journal of Hydrologic Engineering 19 (2):366-374.

Oreiller, M., D. F. Nadeau, M. Minville, and A. N. Rousseau. 2013. Modelling snow water equivalent and spring runoff in a boreal watershed, James Bay, Canada. Hydrological Processes.

Poirier, C., T. C. Fortier Filion, R. Turcotte, and P. Lacombe (2012), Apports verticaux journaliers estimés de 1900 à 2010, Rep., Centre d'expertise hydrique du Québec (CEHQ), Direction de l'expertise hydrique, Québec.

Poulin, A., F. Brissette, R. Leconte, R. Arsenault, and J. S. Malo. 2011. Uncertainty of hydrological modelling in climate change impact studies in a Canadian, snowdominated river basin. Journal of Hydrology 409 (3-4):626-636.

Prada, A. F., M. L. Chu, and J. A. Guzman. 2016. Probabilistic approach to modeling under changing scenarios. Paper read at 2016 American Society of Agricultural and Biological Engineers Annual International Meeting, ASABE 2016. pp.

Quilbé, R., A.N. Rousseau, J.S. Moquet, N.B. Trinh, Y. Dikibi, P. Gachon, and D. Chaumont. 2008. Assessing the effect of climate change on river flow using general circulation models and hydrological modeling - Application to the Chaudière River (Québec, Canada). Canadian Water Resources Journal 33 (1):73-94.

Ricard, S., R. Bourdillon, D. Roussel, and R. Turcotte. 2013. Global calibration of distributed hydrological models for large-scale applications. Journal of Hydrologic Engineering 18 (6):719-721.

Romanowicz, R. J., K. Beven, and J. A. Tawn. 1994. Evaluation of predictive uncertainty in nonlinear hydrological models using a Bayesian Approach. In Statistics for the Environment, Water Related Issues (Volume 2), ed. V. Barnett and F. Turkman, 297318. John Wiley \& Sons.

Rousseau, A. N., S. Savary, D. W. Hallema, S. J. Gumière, and E. Foulon. 2013. Modeling the effects of agricultural BMPs on sediments, nutrients and water quality of the Beaurivage River watershed (Quebec, Canada). Canadian Water Resources Journal 38 (2):99-120.

Rousseau, A.N., J.P. Fortin, R. Turcotte, A. Royer, S. Savary, F. Quévry, P. Noël, and C. Paniconi. 2011. PHYSITEL, a specialized GIS for supporting the implementation of distributed hydrological models. Water News, Official Magazine of CWRA - Canadian Water Resources Association 31 (1):18-20. 
924

925

926

927

928

929

930

931

932

933

934

935

936

937

938

939

940

941

942

943

944

945

946

947

948

949

950

951

952

953

954

955

956

957

958

959

960

961

962

963

Seiller, G., F. Anctil, and C. Perrin. 2012. Multimodel evaluation of twenty lumped hydrological models under contrasted climate conditions. Hydrology and Earth System Sciences 16 (4):1171-1189.

Shoaib, S. A., L. Marshall, and A. Sharma. 2016. A metric for attributing variability in modelled streamflows. Journal of Hydrology 541:1475-1487.

Tolson, B. A., and C. A. Shoemaker. 2007. Dynamically dimensioned search algorithm for computationally efficient watershed model calibration. Water Resources Research 43 (1).

Tolson, B. A., and C. A. Shoemaker. 2008. Efficient prediction uncertainty approximation in the calibration of environmental simulation models. Water Resources Research 44 (4).

Trudel, M., P. L. Doucet-Généreux, R. Leconte, and B. Côté. 2016. Vulnerability of water demand and aquatic habitat in the context of climate change and analysis of a noregrets adaptation strategy: Study of the Yamaska River Basin, Canada. Journal of Hydrologic Engineering 21 (2).

Turcotte, R., J.P. Fortin, A.N. Rousseau, S. Massicotte, and J.P. Villeneuve. 2001. Determination of the drainage structure of a watershed using a digital elevation model and a digital river and lake network. Journal of Hydrology 240 (3-4):225-242.

Turcotte, R., L. G. Fortin, V. Fortin, J. P. Fortin, and J. P. Villeneuve. 2007a. Operational analysis of the spatial distribution and the temporal evolution of the snowpack water equivalent in southern Québec, Canada. Nordic Hydrology 38 (3):211-234.

Turcotte, R., P. Lacombe, C. Dimnik, and J.P. Villeneuve. 2004. Distributed hydrological prediction for the management of Quebec's public dams. Canadian J. of Civil Engineering 31 (2):308-320.

Turcotte, R., A.N. Rousseau, J.-P. Fortin, and J.-P. Villeneuve. 2003. Development of a process-oriented, multiple-objective, hydrological calibration strategy accounting for model structure. In Advances in Calibration of Watershed Models, Water Science \& Application, no. 6, ed. Q. Duan, S. Sorooshian, H. Gupta, A. N. Rousseau and R. Turcotte, 153-163. Washinghton, USA: American Geophysical Union (AGU).

Turcotte, R., A.N. Rousseau, J.P. Fortin, V. Fortin, and J.P. Villeneuve. 2007b. Operational analysis of the spatial distribution and the temporal evolution of the snowpack water equivalent in southern Quebec, Canada. Nordic Hydrology 38 (3):211-234.

Vrugt, J. A., C. J. F. Ter Braak, C. G. H. Diks, B. A. Robinson, J. M. Hyman, and D. Higdon. 2009a. Accelerating Markov chain Monte Carlo simulation by differential evolution with self-adaptive randomized subspace sampling. International Journal of Nonlinear Sciences and Numerical Simulation 10 (3):273-290.

Vrugt, J. A., C. J. F. ter Braak, H. V. Gupta, and B. A. Robinson. 2009b. Equifinality of formal (DREAM) and informal (GLUE) Bayesian approaches in hydrologic modeling? Stochastic Environmental Research and Risk Assessment 23 (7):1011-1026.

Vrugt, J. A., C. J. F. ter Braak, H. V. Gupta, and B. A. Robinson. 2009c. Response to comment by Keith Beven on "Equifinality of formal (DREAM) and informal (GLUE) 
Bayesian approaches in hydrologic modeling?". Stochastic Environmental Research and Risk Assessment 23 (7):1061-1062.

966 Wilby, R. L. 2005. Uncertainty in water resource model parameters used for climate change impact assessment. Hydrological Processes 19 (16):3201-3219.

968

969

970

971

972

973

974

975

976

977

978

979
Yen, H., J. Jeong, and D. R. Smith. 2016. Evaluation of Dynamically Dimensioned Search Algorithm for Optimizing SWAT by Altering Sampling Distributions and Searching Range. Journal of the American Water Resources Association 52 (2):443-455.

Zeng, Q., H. Chen, C. Y. Xu, M. X. Jie, and Y. K. Hou. 2016. Feasibility and uncertainty of using conceptual rainfallrunoff models in design flood estimation. Hydrology Research 47 (4):701-717.

Zhang, X., G. Hörmann, N. Fohrer, and J. Gao. 2012. Parameter calibration and uncertainty estimation of a simple rainfall-runoff model in two case studies. Journal of Hydroinformatics 14 (4):1061-1074. 


\section{Tables}

981 Table 1: Land cover of the ten studied watersheds in southern Québec, Canada

\begin{tabular}{lccccccccccc}
\hline & \multicolumn{2}{c}{ Evergreen } & \multicolumn{2}{c}{$\begin{array}{c}\text { Dedicuous } \\
\text { trees }\end{array}$} & \multicolumn{3}{c}{ Water } & \multicolumn{3}{c}{ Urban } & \multicolumn{2}{c}{ Farms } & \multirow{2}{*}{ Total } \\
& $\mathrm{km}^{2}$ & $\%$ & $\mathrm{~km}^{2}$ & $\%$ & $\mathrm{~km}^{2}$ & $\%$ & $\mathrm{~km}^{2}$ & $\%$ & $\mathrm{~km}^{2}$ & $\%$ & \\
\hline Batiscan & 1816 & 41.9 & 2264 & 52.3 & 187 & 4.3 & 0 & 0 & 67 & 1.6 & 4334 \\
Bécancour & 255 & 9.7 & 2144 & 81.6 & 16 & 0.6 & 0 & 0 & 214 & 8.2 & 2629 \\
Chamouchouane & 817 & 5.4 & 13156 & 87.5 & 1040 & 6.9 & 0 & 0 & 29 & 0.2 & 15042 \\
Châteauguay & 112 & 5.0 & 1722 & 77.4 & 13 & 0.6 & 0 & 0 & 379 & 17.0 & 2227 \\
Chaudière & 1229 & 21.5 & 4206 & 73.4 & 71 & 1.2 & 0 & 0 & 223 & 3.9 & 5728 \\
Du Loup & 243 & 28.4 & 557 & 65.1 & 55 & 6.4 & 0 & 0 & 1 & 0.1 & 855 \\
Gatineau & 1159 & 17.0 & 5298 & 77.8 & 353 & 5.2 & 0 & 0 & 0 & 0 & 6810 \\
Mistassini & 569 & 6.1 & 8341 & 89.7 & 384 & 4.1 & 0 & 0 & 1 & 0 & 9295 \\
Rouge & 1401 & 25.6 & 3791 & 69.2 & 285 & 5.2 & 0 & 0 & 2 & 0 & 5480 \\
Yamaska & 23 & 1.7 & 2050 & 76.7 & 2 & 0.2 & 5 & 0.4 & 289 & 21.1 & 1389 \\
\hline
\end{tabular}


982 Table 2: Summary (1982-2002) of the climate characteristics of the study watersheds

\begin{tabular}{|c|c|c|c|c|c|c|c|c|c|c|c|c|c|c|c|}
\hline & \multicolumn{5}{|c|}{ Rain (mm) } & \multicolumn{4}{|c|}{ Snow (mm) } & \multicolumn{6}{|c|}{ Mean Temp. $\left({ }^{\circ} \mathrm{C}\right)$} \\
\hline & \multicolumn{3}{|c|}{ Summer } & \multicolumn{3}{|c|}{ Winter } & \multicolumn{3}{|c|}{ Annual } & \multicolumn{3}{|c|}{ Summer } & \multicolumn{3}{|c|}{ Winter } \\
\hline & Min & Mean & Max & Min & Mean & $\operatorname{Max}$ & Min & Mean & $\operatorname{Max}$ & Min & Mean & Max & Min & Mean & Max \\
\hline Batiscan & 337 & 558 & 645 & 97 & 180 & 403 & 286 & 356 & 416 & 8.4 & 10.3 & 11.5 & -7.7 & -5.4 & -3.1 \\
\hline Bécancour & 392 & 585 & 809 & 129 & 260 & 490 & 169 & 260 & 372 & 10.3 & 11.9 & 13.3 & -5.0 & -2.9 & -1.0 \\
\hline Chamouchouane & 293 & 518 & 690 & 85 & 131 & 248 & 219 & 290 & 383 & \begin{tabular}{l}
6.4 \\
\hdashline
\end{tabular} & 8.6 & 10.0 & -11.4 & -8.7 & -5.6 \\
\hline Chateauguay & 402 & 512 & 620 & 174 & 269 & 429 & 137 & 193 & 252 & 12.4 & 13.8 & 15.2 & -3.8 & -1.1 & 0.9 \\
\hline Chaudière & 421 & 590 & 794 & 179 & 253 & 392 & : 216 & 266 & 316 & $\begin{array}{l}9.5 \\
\mid\end{array}$ & 11.2 & 12.5 & -5.4 & -3.3 & -1.5 \\
\hline Du Loup & 423 & 547 & 643 & 154 & 233 & 480 & 178 & 224 & 247 & 8.5 & 10.2 & 11.5 & -7.5 & -5.3 & -3.0 \\
\hline Gatineau & 324 & 519 & 671 & 86 & 145 & 242 & 224 & 290 & 350 & $\begin{array}{l}7.9 \\
7\end{array}$ & 9.7 & 11.4 & -8.8 & -6.4 & -3.6 \\
\hline Mistassini & 278 & 515 & 729 & 81 & 126 & 236 & 224 & 300 & 384 & 5.9 & 8.2 & 9.7 & -12.0 & -9.2 & -6.1 \\
\hline Rouge & 372 & 529 & 613 & 100 & 175 & 333 & 248 & 327 & 368 & 9.2 & 10.8 & 11.9 & -6.9 & -4.4 & -2.0 \\
\hline Yamaska & 476 & 577 & 743 & 180 & 305 & 526 & 122 & 204 & 294 & $\begin{array}{l}11.6 \\
1\end{array}$ & 13.1 & 14.5 & -3.9 & -1.5 & 0.6 \\
\hline
\end{tabular}


984 Table 3: Summary (1982-2002) of the hydrological characteristics of the study watersheds

\begin{tabular}{|c|c|c|c|c|c|c|c|c|c|c|c|c|c|c|c|c|c|c|c|c|c|c|c|c|}
\hline & \multicolumn{6}{|c|}{$Q$ (mm/day) } & \multicolumn{6}{|c|}{$Q \max (\mathbf{m} 3 / \mathbf{s})$} & \multicolumn{5}{|c|}{ 7d-Qmin $(\mathrm{m} 3 / \mathrm{s})$} & \multicolumn{7}{|c|}{ 30d-Qmin (m3/s) } \\
\hline & \multicolumn{3}{|c|}{ Summer } & \multicolumn{3}{|c|}{ Winter } & \multicolumn{3}{|c|}{ Summer } & \multicolumn{3}{|c|}{ Winter } & \multicolumn{3}{|c|}{ I Summer } & \multicolumn{2}{|r|}{ Winter } & \multicolumn{4}{|c|}{ i Summer } & \multicolumn{3}{|c|}{ Winter } \\
\hline & Min & Mean & Max & Min & Mean & Max & I Min & Mean & Max & Min & Mean & Max & I Min & Mean & $\operatorname{Max}$ & Min & Mean & $\operatorname{Max}$ & Min & Mean & $\operatorname{Max}$ & Min & Mean & Max \\
\hline Batiscan & 0.9 & 1.6 & 2.4 & 1.4 & 2.1 & 3.1 & 140 & 265 & 528 & 349 & 558 & 837 & 17 & 31 & 57 & 18 & 24 & 35 & 22 & 37 & 72 & 19 & 26 & 43 \\
\hline Bécancour & 0.6 & 1.1 & 1.9 & 1.5 & 2.1 & 2.9 & 69 & 203 & 402 & 296 & 494 & 848 & 2 & 7 & 21 & 7 & 120 & 402 & 3 & 10 & 32 & 8 & 13 & 21 \\
\hline Chamouchouane & 1.1 & 1.8 & 2.6 & 1.2 & 1.5 & 1.9 & 404 & 781 & 1370 & 610 & 1350 & 2159 & 112 & 156 & 199 & 60 & 78 & 102 & 128 & 184 & 245 & 61 & 81 & 116 \\
\hline Chateauguay & 0.3 & 0.6 & 1.3 & 1.1 & 1.8 & 2.6 & 27 & 168 & 623 & 193 & 460 & 1091 & 12 & 4 & 10 & 6 & 10 & 18 & 2 & 6 & 17 & 7 & 12 & 32 \\
\hline Chaudière & 0.5 & 1.1 & 2.1 & 1.6 & 2.2 & 3.0 & 236 & 646 & 1318 & 847 & 1339 & 2140 & 4 & 10 & 26 & 12 & 19 & 32 & 5 & 17 & 45 & 14 & 23 & 47 \\
\hline Du Loup & 0.3 & 0.8 & 1.3 & 1.0 & 1.6 & 2.3 & 12 & 29 & 79 & 55 & 84 & 130 & 1 & 2 & 6 & 3 & 4 & 5 & 1 & 3 & 7 & 3 & 4 & 6 \\
\hline Gatineau & 1.0 & 1.5 & 2.4 & 1.1 & 1.7 & 2.5 & 202 & 425 & 1200 & 413 & 731 & 1500 & 19 & 38 & 56 & 20 & 32 & 46 & 21 & 50 & 92 & 22 & 34 & 48 \\
\hline Mistassini & 1.2 & 1.9 & 2.7 & 1.3 & 1.7 & 2.3 & 314 & 595 & 959 & 604 & 1257 & 2050 & 58 & 92 & 129 & 27 & 39 & 67 & 70 & 119 & 159 & 28 & 41 & 76 \\
\hline Rouge & 0.8 & 1.2 & 1.7 & 1.3 & 2.0 & 2.9 & 118 & 243 & 376 & 381 & 588 & 914 & 11 & 27 & 45 & 24 & 36 & 50 & I 6 & 32 & 61 & 25 & 39 & 59 \\
\hline Yamaska & 0.4 & 0.8 & 1.7 & 1.2 & 2.0 & 2.7 & 44 & 142 & 239 & 182 & 320 & 559 & 1 & 1 & 3 & 2 & 4 & 7 & 1 & 2 & 6 & 2 & 6 & 13 \\
\hline
\end{tabular}




\section{Table 4: HYDROTEL key parameters}

\begin{tabular}{|c|c|c|}
\hline Type & Parameters & Units \\
\hline \multirow{8}{*}{$\begin{array}{c}\text { Snow } \\
\text { parameters }\end{array}$} & MFEF - Melt factor for evergreen forests* & $\mathrm{mm} / \mathrm{d} .{ }^{\circ} \mathrm{C}$ \\
\hline & MFDF - Melt factor for deciduous forests* & $\mathrm{mm} / \mathrm{d} .{ }^{\circ} \mathrm{C}$ \\
\hline & MFOA - Melt factor for open areas* & $\mathrm{mm} / \mathrm{d} .{ }^{\circ} \mathrm{C}$ \\
\hline & TEF - Threshold air temperature for melt in evergreen forests* & ${ }^{\circ} \mathrm{C}$ \\
\hline & TDF - Threshold air temperature for melt in deciduous forests* & ${ }^{\circ} \mathrm{C}$ \\
\hline & TOA - Threshold air temperature for melt in open areas* & ${ }^{\circ} \mathrm{C}$ \\
\hline & Melt rate at the snow-soil interface & $\mathrm{mm} / \mathrm{d}$ \\
\hline & Compaction coefficient & - \\
\hline \multirow{7}{*}{ Soil parameters } & PETF - Potential evapotranspiration multiplication factor* & - \\
\hline & z1- Depth of the lower boundary of soil layer $\# 1^{*}$ & $\mathrm{~m}$ \\
\hline & z2- Depth of the lower boundary of soil layer $\# 2 *$ & $\mathrm{~m}$ \\
\hline & z3- Depth of the lower boundary of soil layer \#3* & $\mathrm{m}$ \\
\hline & RC - Recession coefficient* & $\mathrm{m} / \mathrm{h}$ \\
\hline & Extinction coefficient & - \\
\hline & Maximum variation of soil moisture content & - \\
\hline \multirow{3}{*}{$\begin{array}{c}\text { Interpolation } \\
\text { coefficients }\end{array}$} & $\begin{array}{l}\text { TSL - Threshold air temperature for partitioning solid and liquid } \\
\text { precipitation* }\end{array}$ & ${ }^{\circ} \bar{C}$ \\
\hline & Precipitation vertical gradient & $\mathrm{mm} / 100 \mathrm{~m}$ \\
\hline & Temperature vertical gradient & ${ }^{\circ} \mathrm{C} / 100 \mathrm{~m}$ \\
\hline
\end{tabular}


990 Table 5: Summary of the KGE and Nash-log values for the ten watersheds over the 991 calibration and validation periods

\begin{tabular}{|c|c|c|c|c|c|c|c|c|c|c|c|c|}
\hline & \multicolumn{6}{|c|}{ Calibration } & \multicolumn{6}{|c|}{ Validation } \\
\hline & \multicolumn{3}{|c|}{ KGE } & \multicolumn{3}{|c|}{ Nash-log } & \multicolumn{3}{|c|}{ KGE } & \multicolumn{3}{|c|}{ Nash-log } \\
\hline & $\begin{array}{c}1 \text { st } \\
\text { decile }\end{array}$ & Median & $\begin{array}{c}\text { 9th } \\
\text { decile }\end{array}$ & $\begin{array}{c}\text { 1st } \\
\text { decile }\end{array}$ & Median & $\begin{array}{c}\text { 9th } \\
\text { decile }\end{array}$ & $\begin{array}{c}1 \mathrm{st} \\
\text { decile }\end{array}$ & Median & $\begin{array}{c}\text { 9th } \\
\text { decile }\end{array}$ & $\begin{array}{c}\text { 1st } \\
\text { decile }\end{array}$ & Median & $\begin{array}{c}\text { 9th } \\
\text { decile }\end{array}$ \\
\hline Batiscan & 0.946 & 0.946 & 0.947 & 0.894 & 0.896 & 0.897 & 0.799 & 0.805 & 0.810 & 0.670 & 0.674 & 0.694 \\
\hline Bécancour & 0.872 & 0.874 & 0.875 & 0.795 & 0.799 & 0.801 & 0.797 & 0.807 & 0.814 & 0.701 & 0.706 & 0.717 \\
\hline Chamouchouane & 0.947 & 0.947 & 0.947 & 0.907 & 0.907 & 0.907 & 0.823 & 0.826 & 0.829 & 0.632 & 0.637 & 0.641 \\
\hline Chateauguay & 0.859 & 0.860 & 0.860 & 0.767 & 0.768 & 0.768 & 0.763 & 0.767 & 0.775 & 0.692 & 0.695 & 0.699 \\
\hline Chaudière & 0.916 & 0.916 & 0.916 & 0.805 & 0.810 & 0.815 & 0.869 & 0.871 & 0.875 & 0.695 & 0.709 & 0.721 \\
\hline Du Loup & 0.944 & 0.945 & 0.945 & 0.842 & 0.842 & 0.842 & 0.792 & 0.796 & 0.802 & 0.700 & 0.703 & 0.704 \\
\hline Gatineau & 0.907 & 0.907 & 0.907 & 0.827 & 0.828 & 0.828 & 0.766 & 0.768 & 0.771 & 0.684 & 0.686 & 0.691 \\
\hline Mistassini & 0.955 & 0.955 & 0.956 & 0.904 & 0.905 & 0.905 & 0.873 & 0.875 & 0.876 & 0.646 & 0.652 & 0.660 \\
\hline Rouge & 0.947 & 0.947 & 0.947 & 0.887 & 0.887 & 0.887 & 0.876 & 0.878 & 0.880 & 0.700 & 0.702 & 0.704 \\
\hline Yamaska & 0.828 & 0.832 & 0.835 & 0.761 & 0.762 & 0.764 & 0.833 & 0.839 & 0.845 & 0.609 & 0.626 & 0.637 \\
\hline
\end{tabular}

992 
993 Table 6: Median of the KGE and Nash-log loss of performance (positive values) between 994 the calibration and validation periods

\begin{tabular}{cc:c}
\hline & KGE & Nash-log \\
\hline Batiscan & $15 \%$ & $14 \%$ \\
Bécancour & $8 \%$ & $-8 \%$ \\
Chamouchouane & $13 \%$ & $20 \%$ \\
Chateauguay & $11 \%$ & $-14 \%$ \\
Chaudière & $5 \%$ & $-6 \%$ \\
Du Loup & $16 \%$ & $1 \%$ \\
Gatineau & $15 \%$ & $0 \%$ \\
Mistassini & $8 \%$ & $18 \%$ \\
Rouge & $7 \%$ & $9 \%$ \\
Yamaska & $-1 \%$ & $-6 \%$ \\
\hline
\end{tabular}

995 
996 Table 7: Dominant type of uncertainty for each study watershed for the five modelled 997 hydrological variables

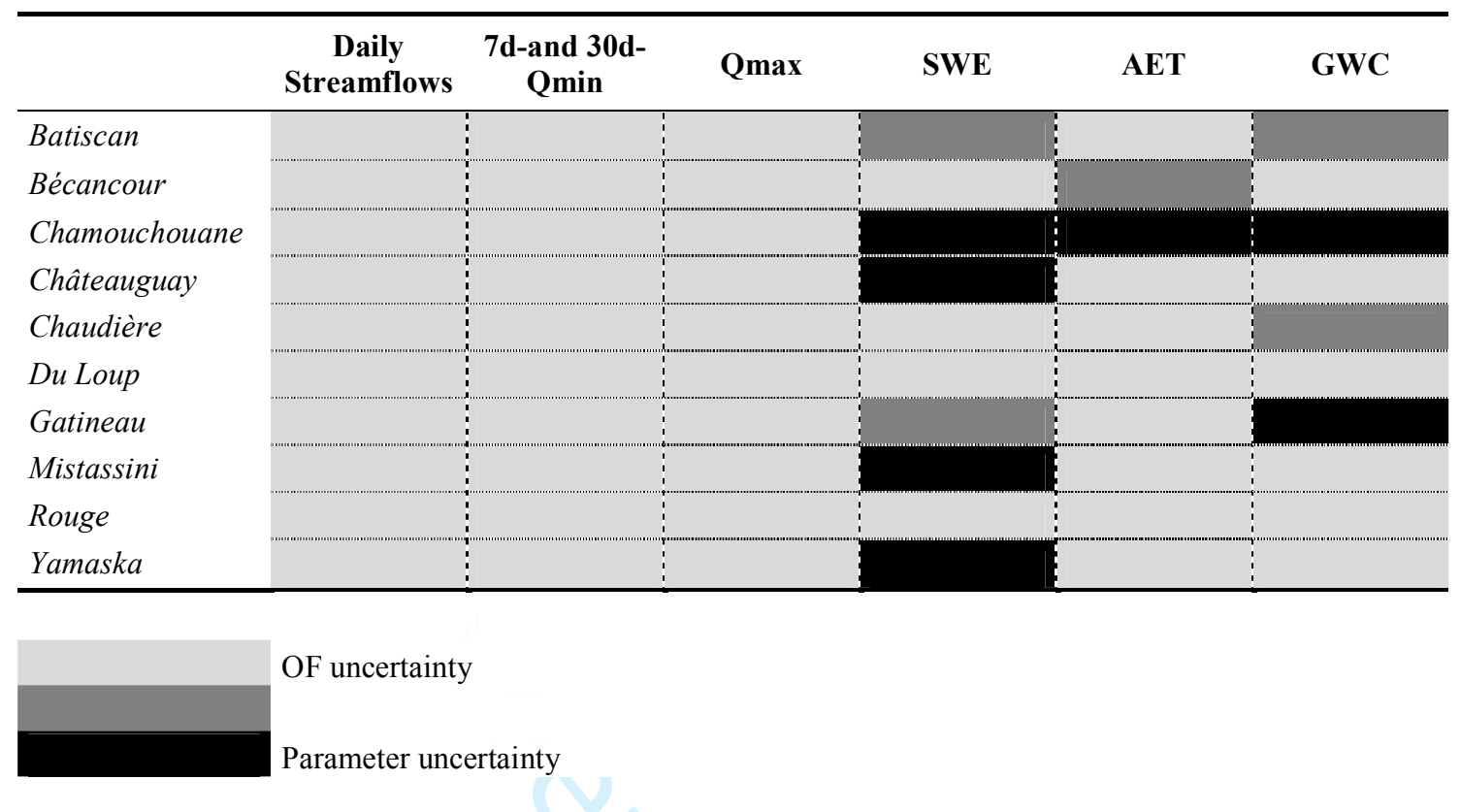

999

1000 


\section{Figure Captions}

1002 Figure 1: Location of the study watersheds in Québec, Canada, and around the St. Lawrence 1003 River

1004 Figure 2: Relationship between mean annual and seasonal temperatures and precipitations for 1005 the calibration and validation periods

1006 Figure 3: Radar plots of the twelve parameters used in the automatic calibration of 1007 HYDROTEL for each study watershed. Parameter A is part of the interpolation coefficients, 1008 parameters $B$ through $G$ relate to the snow model, and parameters $F$ through $L$ relate to the 1009 soil group of parameters. The dark blue diagrams refer to the KGE OF while the light blue 1010 diagrams refer to the Nash-log OF.

1011 Figure 4: Distribution of the OF values for the Chamouchouane watershed: (a) KGE

1012 calibration period; (b) KGE validation period; (c) Nash-log calibration period; (d) Nash-log 1013 validation period

1014 Figure 5: Streamflow uncertainty envelopes for the Rouge watershed: (a) calibration (9-year 1015 mean) and (b) validation periods (8-year mean). The black and green envelopes stand for 1016 simulated flows under the KGE and Nash-log OFs, respectively, while the blue line depicts 1017 the observed values.

1018 Figure 6: Boxplots of the seasonal hydrological indices for the Chamouchaoune watershed for 1019 the calibration (1) and validation (2) periods: (as1) and (as2) display the distribution of the 1020 maximum summer peakflows; (aw1) and (aw2) the distribution of maximum winter 1021 peakflows; (bs1) and (bs2) the distribution of summer-7-day minimum flows; and (bw1) and 1022 (bw2) the distribution of winter-7-day minimum flows. The black and green boxplots 1023 illustrate the distribution of simulated flows under the KGE and Nash-log OFs, respectively, 
1024 while the blue dots depict the observed values. The superscripts $w$ and $d$ on the x-axis indicate

1025 the wettest and driest years of each simulation period, respectively.

1026 Figure 7: SWE uncertainty envelopes for the Yamaska watershed: (a) calibration (9-year

1027 mean) and (b) validation periods (8-year mean). The black and green envelopes illustrate the 1028 distribution of simulated flows under the KGE and Nash-log OFs.

1029 Figure 8: Seasonal actual evapotranspiration for the Bécancour watershed: (a) summer 1030 calibration; (b) summer validation; (c) winter calibration and (d) winter validation. The black 1031 and green boxplots stand for simulated AET distributions under the KGE and Nash-log OFs, 1032 respectively. The outliers are represented by red crosses. The superscripts $w$ and $d$ on the $\mathrm{x}-$ 1033 axis stand for the wettest and driest years of each simulation period, respectively.

1034 Figure 9: Shallow groundwater content uncertainty envelopes for the Du Loup watershed: (a) 1035 calibration (9-year mean) and (b) validation periods (8-year mean). The black and green 1036 envelopes illustrate the distribution of simulated flows under the KGE and Nash-log OFs, 1037 respectively.

1038 Figure 10: Radar plots of the twelve parameters used in the automatic calibration of 1039 HYDROTEL for each study watershed. Parameter A is part of the interpolation coefficients, 1040 parameters $B$ through $G$ relate to the snow model, and parameters $F$ through $L$ relate to the 1041 soil group of parameters. Figure (a) refers to the KGE OF; and (b) to the Nash-log OF. The 1042 dark and light blue data refer to the first optimization trial of Figure 3, black data to the 1043 second optimization trial. 

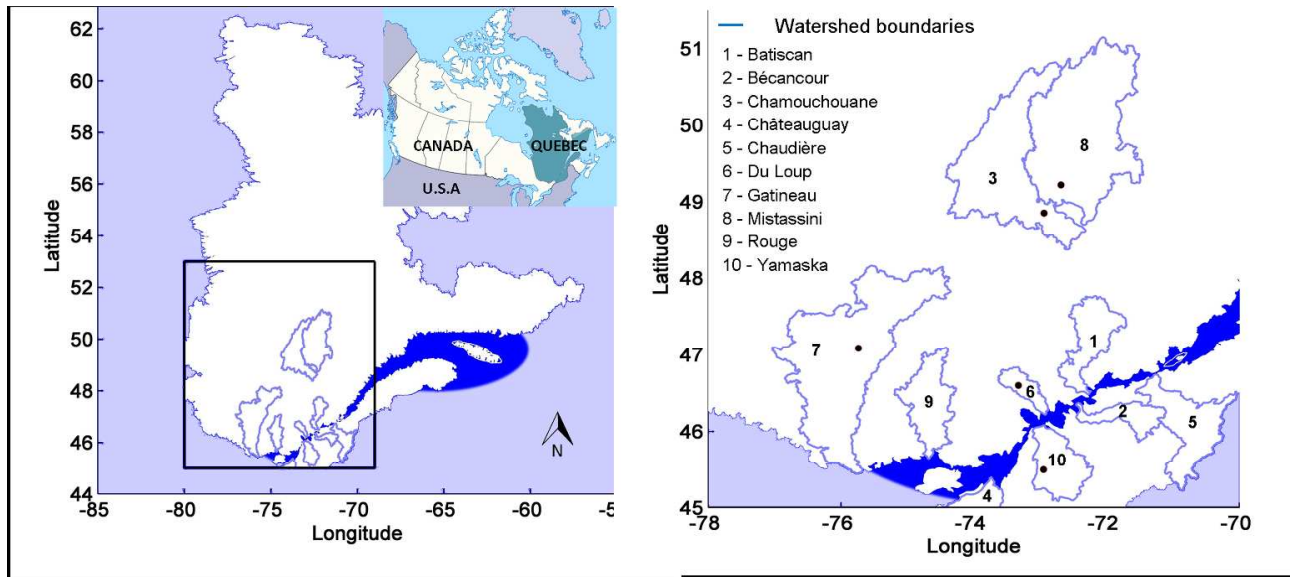

Figure 1: Location of the study watersheds in Québec, Canada, and around the St. Lawrence River $278 \times 122 \mathrm{~mm}(240 \times 240 \mathrm{DPI})$ 


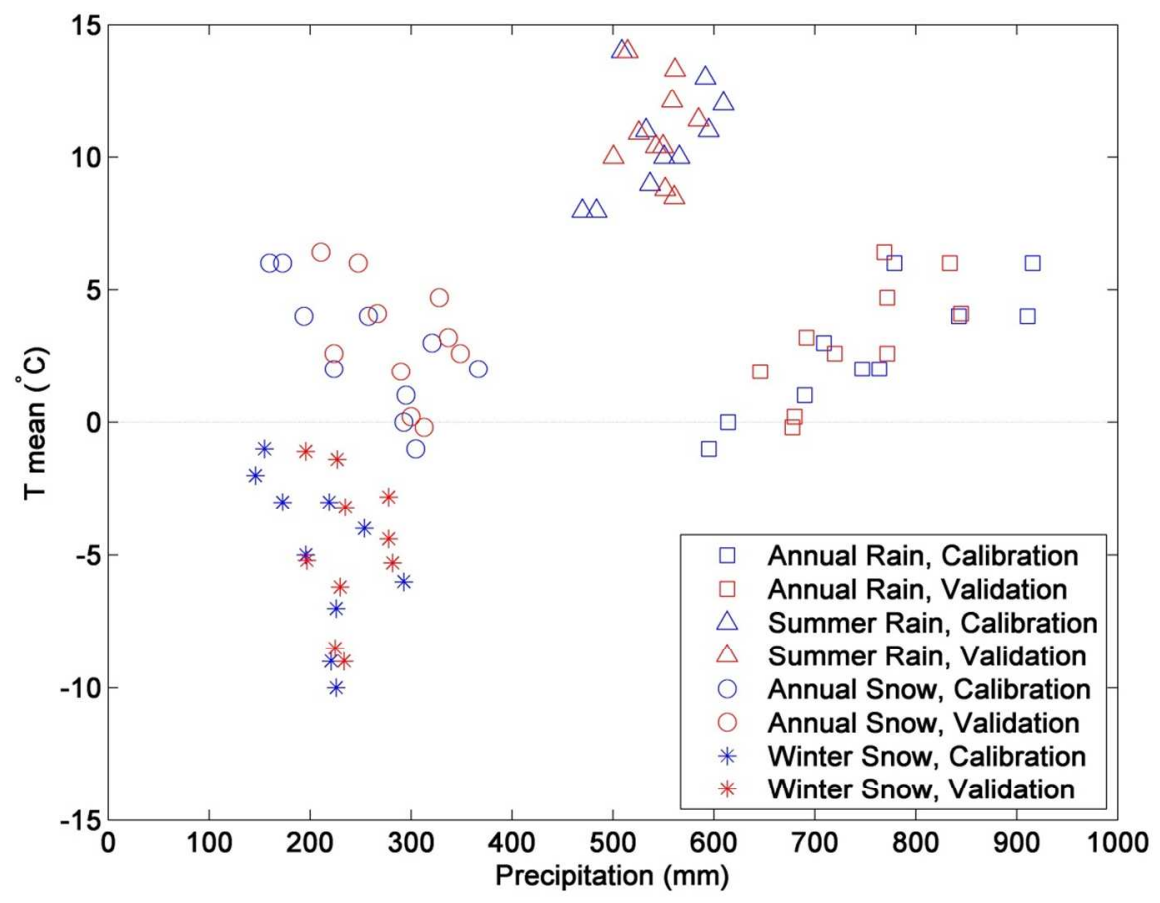

Figure 2: Relationship between mean annual and seasonal temperatures and precipitations for the calibration and validation periods

$160 \times 120 \mathrm{~mm}(220 \times 220 \mathrm{DPI})$ 


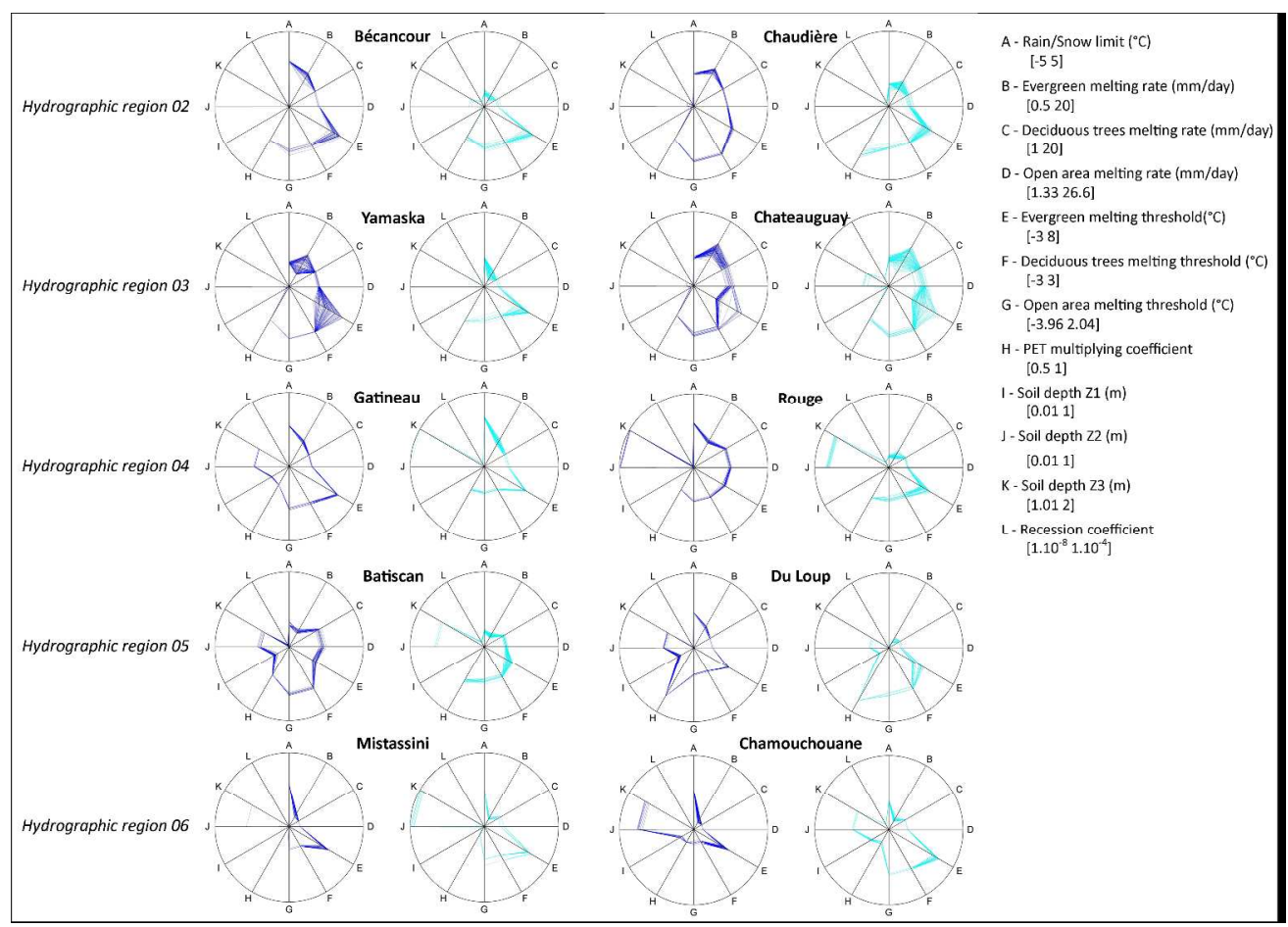

Figure 3: Radar plots of the twelve parameters used in the automatic calibration of HYDROTEL for each study watershed. Parameter $A$ is part of the interpolation coefficients, parameters B through $G$ relate to the snow model, and parameters $F$ through $L$ relate to the soil group of parameters. The dark blue diagrams refer to the KGE OF while the light blue diagrams refer to the Nash-log OF.

$512 \times 364 \mathrm{~mm}(240 \times 240 \mathrm{DPI})$ 
(a)

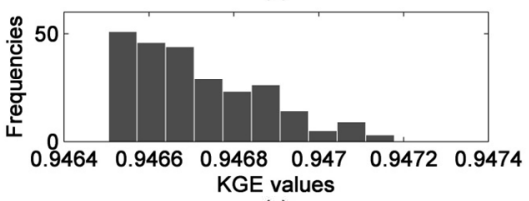

(c)

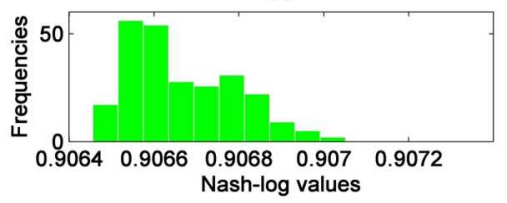

(b)

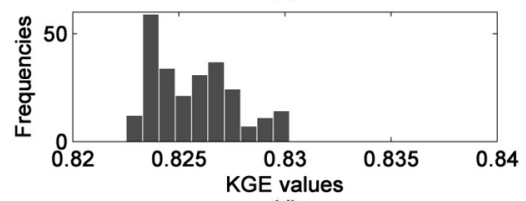

(d)

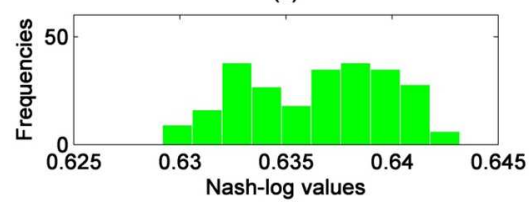

Figure 4: Distribution of the OF values for the Chamouchouane watershed: (a) KGE calibration period; (b) KGE validation period; (c) Nash-log calibration period; (d) Nash-log validation period

$188 \times 67 \mathrm{~mm}(220 \times 220 \mathrm{DPI})$ 
(a)

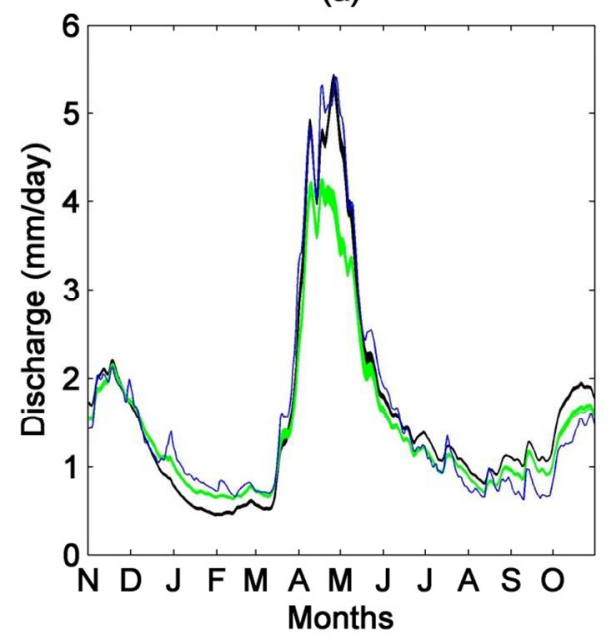

(b)

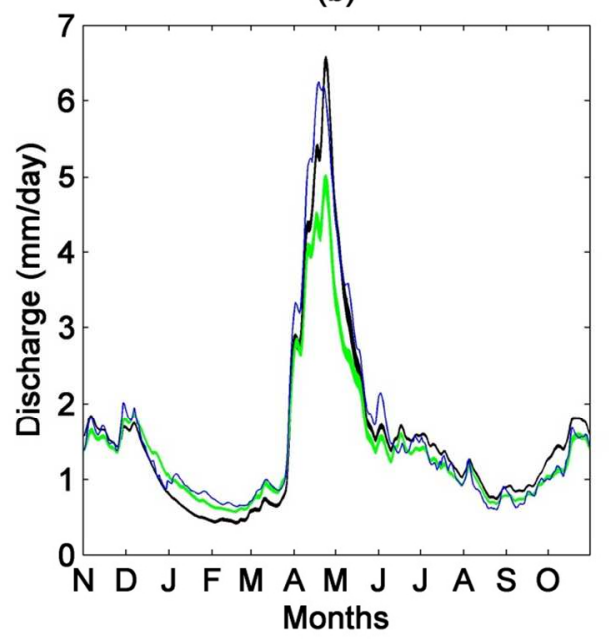

Figure 5: Streamflow uncertainty envelopes for the Rouge watershed: (a) calibration (9-year mean) and (b) validation periods (8-year mean). The black and green envelopes stand for simulated flows under the KGE and Nash-log OFs, respectively while the blue line depicts the observed values.

$161 \times 89 \mathrm{~mm}(220 \times 220 \mathrm{DPI})$ 

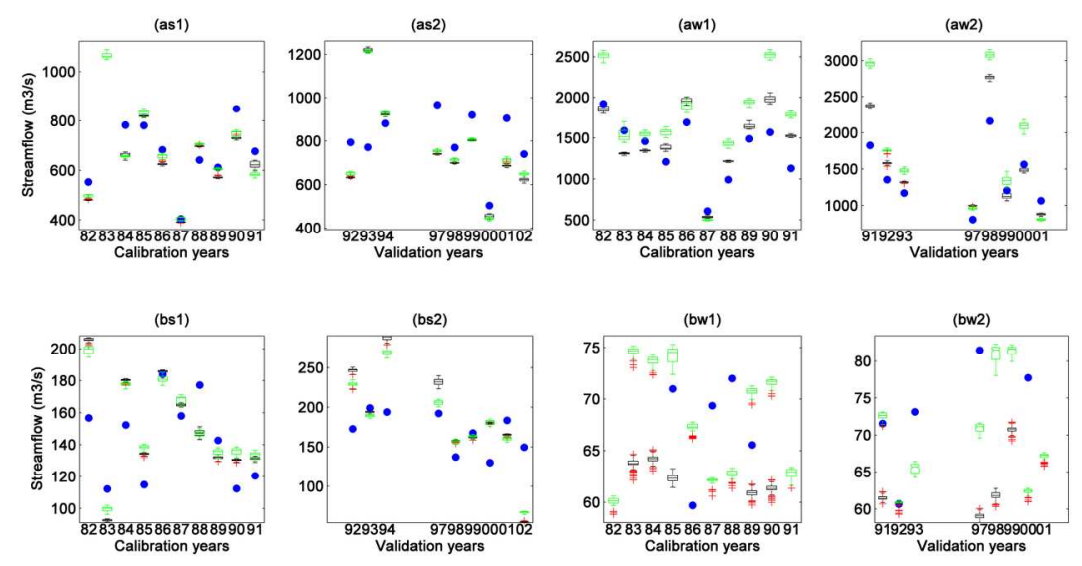

Figure 6: Boxplots of the seasonal hydrological indices for the Chamouchaoune watershed for the calibration (1) and validation (2) periods: (as1) and (as2) display the distribution of the maximum summer peakflows; (aw1) and (aw2) the distribution of maximum winter peakflows; (bs1) and (bs2) the distribution of summer7-day minimum flows; and (bw1) and (bw2) the distribution of winter-7-day minimum flows. The black and green boxplots illustrate the distribution of simulated flows under the KGE and Nash-log OFs, while the blue dots depict the observed values. The superscripts $w$ and $d$ on the $x$-axis indicate the wettest and driest years of each simulation period, respectively.

$177 \times 82 \mathrm{~mm}(300 \times 300 \mathrm{DPI})$ 
(a)

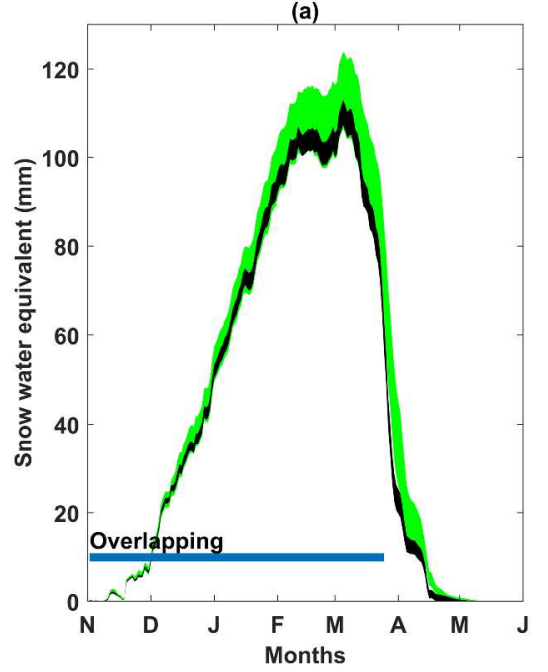

(b)

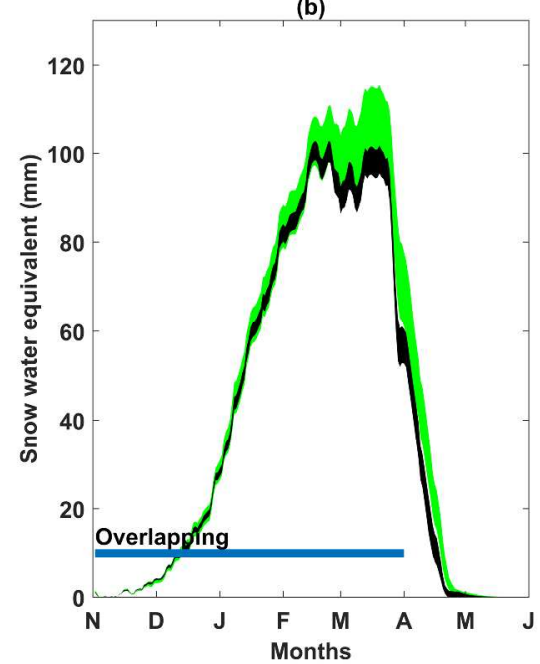

SWE uncertainty envelopes for the Yamaska watershed: (a) calibration (9-year mean) and (b) validation periods (8-year mean). The black and green envelopes illustrate the distribution of simulated flows under the KGE and Nash-log OFs. The line indicates the period of overlapping between the uncertainty envelopes.

$152 \times 83 \mathrm{~mm}(600 \times 600 \mathrm{DPI})$ 
(a)

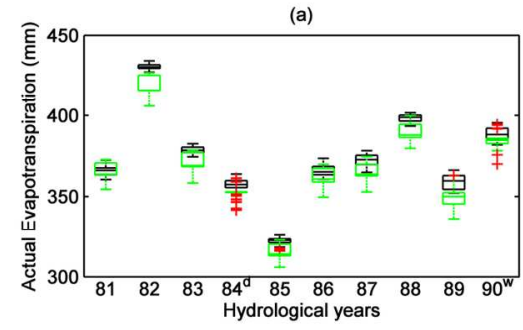

(c)

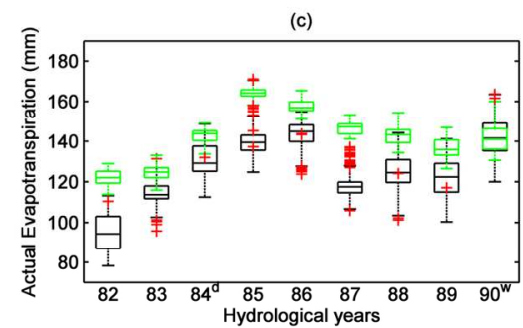

(b)

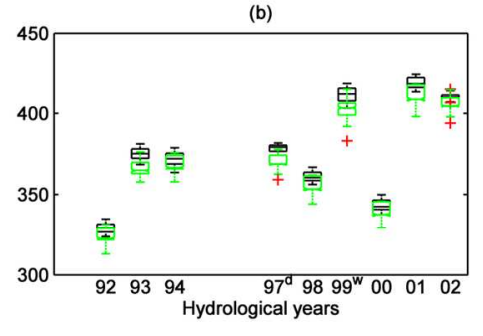

(d)

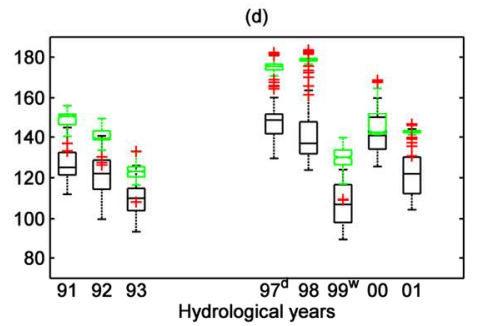

Figure 8: Seasonal actual evapotranspiration for the Bécancour watershed: (a) summer calibration; (b) summer validation; (c) winter calibration and (d) winter validation. The black and green boxplots stand for simulated AET distributions under the KGE and Nash-log OF, respectively. The outliers are represented by red crosses. The superscripts $\mathrm{w}$ and $\mathrm{d}$ on the $\mathrm{x}$-axis stand for the wettest and driest years of each simulation period, respectively.

$152 \times 91 \mathrm{~mm}(300 \times 300 \mathrm{DPI})$ 
(a)

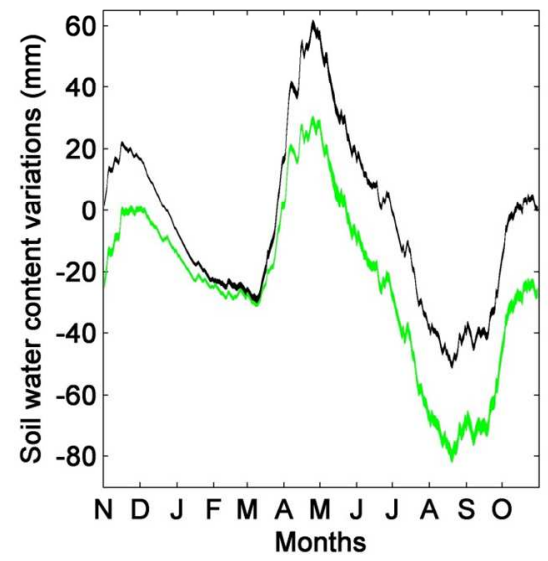

(b)

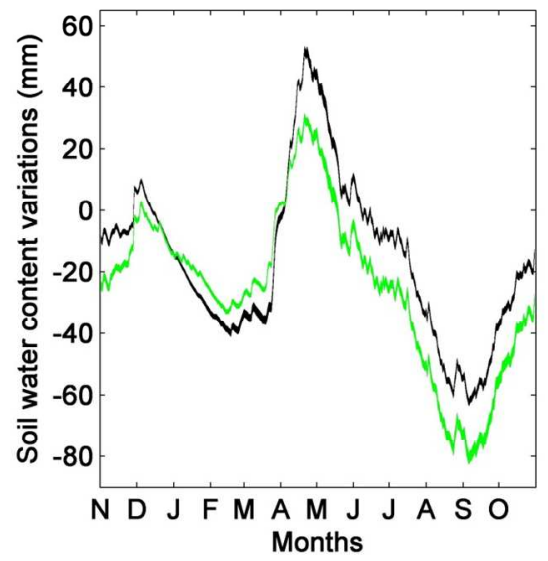

Figure 9: Shallow groundwater content uncertainty envelopes for the Du Loup watershed: (a) calibration (9year mean) and (b) validation periods (8-year mean). The black and green envelopes illustrate the distribution of simulated flows under the KGE and Nash-log OFs, respectively.

$187 \times 85 \mathrm{~mm}(220 \times 220$ DPI $)$ 

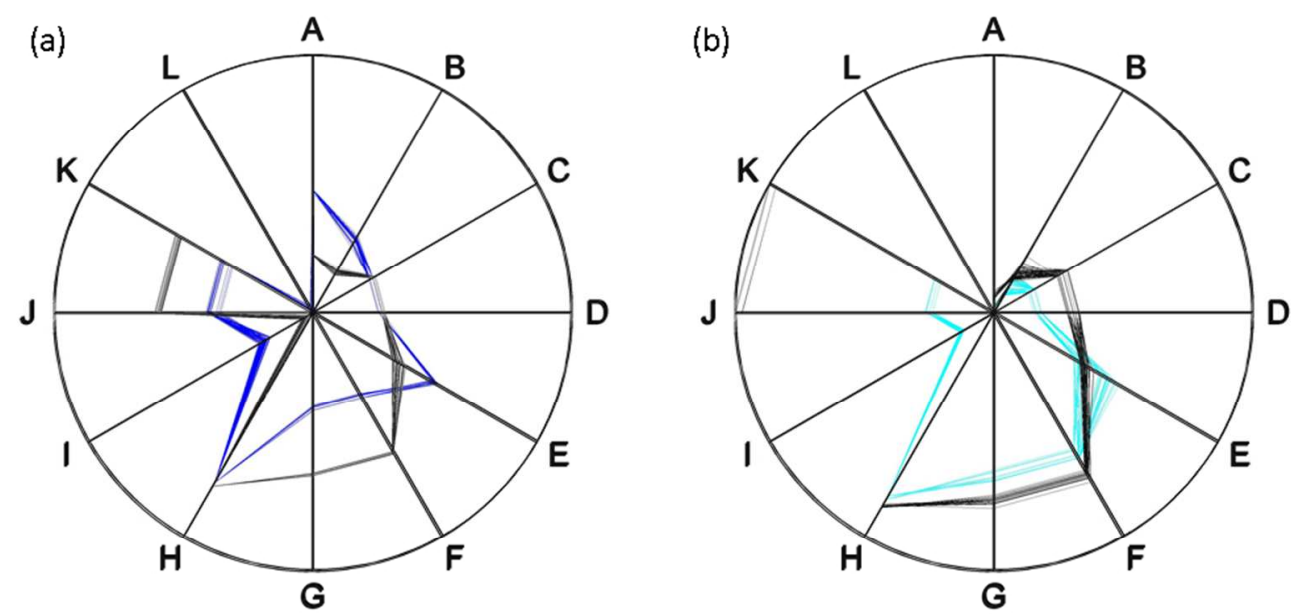
A - Rain/Snow limit $\left({ }^{\circ} \mathrm{C}\right)$ [-5 5]
$B$ - Evergreen melting rate $(\mathrm{mm} /$ day $)$ [0.5 20]
$\mathrm{C}$ - Deciduous trees melting rate ( $\mathrm{mm} / \mathrm{day})$
[1 20]
$D$ - Open area melting rate $(\mathrm{mm} /$ day) [1.33 26.6]

E - Evergreen melting threshold $\left({ }^{\circ} \mathrm{C}\right)$

$$
\text { [-38] }
$$

I- Soil depth Z1 (m) [0.01 1]

$\mathrm{F}$ - Deciduous trees melting threshold ( $\left.{ }^{\circ} \mathrm{C}\right)$

[-3 3]

$\mathrm{G}$ - Open area melting threshold $\left({ }^{\circ} \mathrm{C}\right)$ [-3.962.04]

H- PET multiplying coefficient [0.5 1]

J - Soil depth $Z 2(\mathrm{~m})$ [0.011]

K - Soil depth $Z 3$ (m) [1.01 2]

$\mathrm{L}$ - Recession coefficient $\left[1.10^{-8} 1.10^{-4}\right]$

Figure 10: Radar plots of the twelve parameters used in the automatic calibration of HYDROTEL for each study watershed. Parameter A is part of the interpolation coefficients, parameters B through $G$ relate to the snow model, and parameters $F$ through $L$ relate to the soil group of parameters. Figure (a) refers to the KGE OF; and (b) to the Nash-log OF. The dark and light blue data refer to the first optimization trial of Figure 3, black data to the second optimization trial.

$261 \times 190 \mathrm{~mm}(96 \times 96 \mathrm{DPI})$ 